\title{
Excitatory synaptogenesis in the anterior cingulate cortex is required for effort/reward evaluation
}

Authors: *Francesco Paolo Ulloa Severino ${ }^{1-2-7}$, Oluwadamilola Lawal ${ }^{3}$, Kristina Sakers ${ }^{1}$, Namsoo Kim ${ }^{4}$, Chaichontat Sriworarat ${ }^{1}$, Ryan Hughes ${ }^{2}$, Scott Soderling ${ }^{1-3-6}$, II Hwan Kim ${ }^{5}$, ${ }^{*}$ Henry Yin ${ }^{2-3-6}$, ${ }^{*}$ Cagla Erogluli-3-6-7

\section{Affiliations:}

${ }^{1}$ Department of Cell Biology, Duke University Medical Center, Durham, NC 27710

2Department of Psychology and Neuroscience, Duke University, Durham, NC, 27710

${ }^{3}$ Department of Neurobiology, Duke University Medical Center, Durham, NC 27710

4Howard Hughes Medical Institute, Janelia Research Campus, Ashburn, VA, 20147

${ }^{5}$ Department of Anatomy \& Neurobiology, University of Tennessee Health and Science Center, Memphis, TN 38103

${ }^{6}$ Duke Institute for Brain Sciences (DIBS), Durham, NC 27710

${ }^{7}$ Duke University Regeneration Next Initiative, Durham, NC 27710

*Co-correspondence to: $\quad$ cagla.eroglu@duke.edu

hy43@duke.edu

francesco.ulloa@duke.edu 


\section{Abstract}

Synaptogenesis is essential for circuit development; however, whether it is critical in adulthood for learning and performance of voluntary behaviors is unknown. Here we show that rewardbased training in mice induces excitatory synapse formation onto Anterior Cingulate Cortex (ACC) neurons projecting to the dorsomedial striatum (DMS). We used germline and conditional knockout mice for Gabapentin/Thrombospondin receptor $\alpha 2 \delta-1$, which is required for excitatory synaptogenesis in the cortex, and found that loss of $\alpha 2 \delta-1$ in the adult ACC-DMS circuit is sufficient to abolish training-induced excitatory synaptogenesis. Surprisingly, this manipulation did not affect learning, instead caused a profound increase in effort exertion. Optogenetic activation of ACC-DMS neurons was sufficient to diminish effort exertion in wildtype mice and rescued the effort/reward evaluation deficit of the conditional $\alpha 2 \delta-1$ mutants. These results highlight the importance of synaptogenic signaling in the adult and pinpoint the ACC-DMS neuronal circuit as the controller of effort exertion during voluntary behaviors. 


\section{Introduction}

Proper synaptic wiring during development is essential for healthy brain function throughout life.

Furthermore, experience-dependent remodeling of synapses is thought to underlie cognitive processes such as learning and memory (Chih et al., 2005; Cline, 2005; Robbins et al., 2010; Fernández-García et al., 2020; Sohal and Rubenstein, 2019). A widely accepted cellular mechanism underlying learning is long-term synaptic plasticity (Xiong et al., 2015; Adamsky et al., 2018; Josselyn and Tonegawa, 2020), but whether the formation of new synapses is also required during the acquisition of new behaviors is less studied (Black et al., 1990; Xu et al., 2009). It has been proposed that an increase in the number of synapses underlies learning and memory in mice, and removal of newly formed synapses can erase learned skills (HayashiTakagi et al., 2015; Xu et al., 2019; Bednarek and Caroni, 2011; Robbins et al., 2010). Moreover, loss of synaptic or synaptogenic proteins causes severe sensorimotor and cognitive deficits (Guo et al., 2019; Peixoto et al., 2019; Ribic et al., 2019; Robbins et al., 2010; Connor et al., 2017, 2019), indicating that synaptic rewiring is an important step in learning.

In this study, we investigated whether the formation of excitatory synapses is required to learn new voluntary behaviors using instrumental conditioning in mice. In this behavioral paradigm, a mouse learns to perform a specific action (i.e., press a lever) to earn the desired reward (food pellet). However, the action-outcome relationship may change over time, and the individuals must adapt their behaviors to avoid spending excess or unnecessary effort (Brockett et al., 2020; Coutureau et al., 2012; Klein-Flügge et al., 2016; Schweimer and Hauber, 2006). For instance, the effort/reward relationship can be modified by changing the number of lever presses required to receive the reward (Balleine and Dickinson, 1998; Gremel and Costa, 2013a, 2013b; Parker et al., 2019). Previous research has shown that both learning and performance of instrumental actions require the cortical and basal ganglia circuits (Yin and Knowlton, 2006; Yin et al., 2005). In particular, learning the contingency between action and 
outcome requires the dorsomedial striatum (DMS) (Yin et al., 2005, 2009), which is a hub for a plethora of cortical inputs, including those from the prefrontal cortex (Hart et al., 2018a, 2018b; Brockett et al., 2020). Several studies also implicated roles for the prefrontal cortex in instrumental training, such as learning the action/outcome contingency, evaluation of an outcome's value, and decision-making based on the effort/reward relationship (Hart et al., 2018a, 2018b; Gremel and Costa, 2013b; Parkes et al., 2018; McKee et al., 2010; Schweimer and Hauber, 2005, 2006). However, whether new synapse formation is involved in the establishment of these cognitive processes remains unknown.

Previously, we have shown that the Gabapentin receptor $\alpha 2 \delta-1$ is essential for the proper formation and maturation of intracortical excitatory synapses during development (Risher et al., 2018). The neuronal protein $\alpha 2 \delta-1$, also known as calcium channel subunit $\alpha 2 \delta-1$ (Cacna2d-1), is highly expressed in the developing and adult mouse cortex (Cole et al., 2005). It was first identified as a subunit of voltage-gated calcium channels (Dolphin, 2013) and later was shown to also interact also with several synaptic or synaptogenic proteins (Tong et al., 2017; Risher and Eroglu, 2020), including the astrocyte-secreted Thrombospondins (TSPs) (Eroglu et al., 2009; Risher et al., 2018). The synaptogenic function of $\alpha 2 \delta-1$ is independent of its roles in calcium channel trafficking (Eroglu et al., 2009; Kurshan et al., 2009; Held et al., 2020). Despite its known critical functions in the development and maturation of synapses, whether $\alpha 2 \delta-1$ controls adult synaptogenesis is not known. Moreover, the role of $\alpha 2 \delta-1$ in behavior and cognition remains poorly understood.

Here, we show that instrumental conditioning induces a robust activation of IEGs in the ACC, a sub-region in the prefrontal cortex. This enhancement occurs concurrently with a significant increase in the number of intracortical excitatory synapses in the same region. Training-induced excitatory synaptogenesis can be blocked by deletion of $\alpha 2 \delta-1$ either globally or conditionally only in a specific subset of ACC neurons that project to the DMS (i.e., ACC-DMS neurons). 
Surprisingly, these manipulations did not impair the learning of instrumental actions per se.

However, they strongly increased effort exertion during a demanding task. We also used optogenetics and circuit-specific gene deletion in the ACC and found that activation of the ACCDMS pathway can suppress lever pressing, serving as a negative feedback signal for effort control. Taken together, our findings identify a critical ACC circuitry that is necessary to regulate the evaluation of the effort/gain relationship. These results also indicate that synapse formation in the adult brain plays a critical role in the adaptability of voluntary learned behaviors. 


\section{Results}

\section{Instrumental action training increases immediate-early gene expression in the ACC.}

To model voluntary learned behaviors in mice, we used an instrumental conditioning task, in which mice learn to press a lever for a food reward. In this paradigm, mice first learn the relationship between an action (lever press, LP) and the desired outcome (food reward). Following this initial phase, the animal's performance can increase by increasing the number of LPs required for each reward ("Ratio" Figure 1A).

To identify brain regions responsible for learning and performance of lever pressing, we trained wildtype (WT, C57BL/6J) mice using a fixed ratio (FR) schedule. Prior to training, mice were food-restricted for 3-5 days, where their weights were not less than $85 \%$ free-feeding weights. Subsequently, they were trained on an FR1 schedule (1 lever press/1 reward, days 1-3), moved to an FR5 (5 lever presses/1 reward, days 4-6), and finally were placed on an FR10 schedule (10 lever presses/1 reward, days 7-9) (Figure 1A, see Methods for details). An untrained control group (age- and sex-matched) was also food-restricted and housed in the same instrumental action training chamber for an equivalent number of days and durations as the trained mice. However, the untrained mice were given free access to the same amount of food rewards without the need to press the lever (Figure S1A).

Over the course of training, the mice learned to press the lever efficiently, which is reflected by the significant increase in the numbers of LPs/min between the first day of training (Day 1-FR1) compared to the last day (Day 9-FR10) (Figure 1B). Apart from the increased number of LPs/min (i.e., LP rate), the training served to organize the LPs into action sequences. This can be seen in the raster plots from mice performing FR5 on day 4 compared to FR10 on day 9 (Figure 1C). To quantify the progression in LP performance across the training period, we calculated the mean Inter-Press Interval (IPI, the mean time between two consecutive LPs) on 
day 4 (FR5) and compared it to that on day 9 (FR10). There was a significant reduction in the mean IPI between these two training days (Figure 1D). Taken together, these data showed that at the end of the 9-day training period, the mice learned to press a lever for a food reward and organize their LP behavior into action sequences.

Which brain regions are critical for performance on this task? To answer this question, we first analyzed c-Fos expression as a cellular marker of neuronal activity (Bertaina and Destrade, 1995; Bertaina-Anglade Valérie et al., 2001; Liu et al., 2012) in several brain regions. We processed the brains from trained and untrained mice within 60 minutes after the completion of the last session on day 9 (Figure 1A) to capture the c-Fos protein expression as a measure of neural activity (Bertaina-Anglade Valérie et al., 2001). Coronal brain sections from trained and untrained mice, corresponding to 4 forebrain Bregma coordinates (Figure S1B, anteriorposterior: $-0.3 ;+0.4 ;+1.7 ;+2.2$ ) were stained for c-Fos and DAPI (nuclear DNA marker). The cFos+/DAPI+ cells (hereafter named c-Fos ${ }^{+}$) were imaged from entire coronal brain sections and segmented using a custom U-Net machine-learning algorithm (https://github.com/ErogluLab/CellCounts, see Methods for details). With the Whole Brain Software (Fürth et al., 2018), we mapped the segmented c-Fos ${ }^{+}$cells onto the Allen brain atlas coordinates for the corresponding Bregma coordinates (Figure S1C and 1D). This machinelearning-based analysis revealed a significant increase in the total number of c-Fos ${ }^{+}$cells in trained compared to untrained mice (Figure S1E). When the anatomical distribution of c-Fos ${ }^{+}$ cells in 44 brain regions was analyzed, we found a significant increase in c-Fos only in 4 brain regions: the primary Somatosensory (SSp) cortex, the Primary Motor Cortex (MOp), the Anterior Cingulate Cortex (ACC) and the Basomedial Amygdalar Nucleus (BMA) (Figure S1F). Previous work has implicated the prefrontal cortex in the learning and performance of instrumental actions, decision-making in cost-benefit tasks, and behavioral flexibility (Hart et al., 2018b; Friedman et al., 2015; Schweimer and Hauber, 2005, 2006; Marton et al., 2018). Among the 4 
brain regions with increased c-Fos, only the ACC is located within the prefrontal cortex. The other prefrontal cortical regions did not show any significant increase in the number of c-Fos ${ }^{+}$ cells (Figure S1F). This finding suggests that the ACC is strongly and selectively activated by the instrumental training experience.

To further investigate and confirm the changes in gene expression as a consequence of the training, we micro-dissected the ACC from trained and untrained mice and submitted the samples to RNA sequencing (RNA-seq) (Figure 1E). Of the seventy-five differentially expressed genes (DEGs) identified, thirty-two were significantly upregulated in the ACC of trained mice, and 43 were downregulated (i.e., 1.5-fold change compared to untrained animals, at a nominal $p$-value of $p<0.01$, Figure $1 F)$.

Among the upregulated genes, we found several immediate early genes (IEGs), such as Fos, Jun, Npas4, Arc, Nr4a1, Egr2, and Egr4 (Figure 1G). Moreover, GO term analyses on DEGs showed a significant $(F D R \leq 0.05)$ enrichment ratio $(E R)$ for genes involved in cognitive processes $(E R=12.8)$ and DNA-binding transcription activators $(E R=9.0)$. Taken together, these results reveal increased IEG expression in the ACC of trained mice, providing evidence for heightened neuronal activity in this region. Furthermore, these findings suggest that LPtraining induces long-term circuit remodeling in the ACC.

\section{Training increases the number of c-Fos+ cells and excitatory synapses in the ACC.}

IEGs are involved in the molecular mechanisms underlying long-term structural and functional changes in synaptic circuits during processes like learning and memory (Poirier et al., 2008; Gallo et al., 2018; Lin et al., 2008). Training significantly increased the number of c-Fos ${ }^{+}$cells in layers $2 / 3$ and 5 (L2/3 and L5) of the ventral $A C C$ (vACC, Figure $2 A$ and $2 B$ ). These ACC layers contain neurons that project to the DMS, a striatal region that controls instrumental actions (Figure 2C) (Groenewegen et al., 2016; Hintiryan et al., 2016; Hunnicutt et al., 2016; Yin et al., 
$2005,2009)$. In contrast, there were no significant differences in the numbers of c-Fos ${ }^{+}$cells between trained and untrained mice in the dorsal ACC and the neighboring secondary Motor Cortex (MOs), which also send projections to the DMS (Figure S2A and S2B). This result shows that the increase in the number of $c-F_{0 s}{ }^{+}$cells in the L2/3 and L5 is specific to the vACC.

Based on the c-Fos expression results, we postulated that training promotes a net increase in excitatory inputs onto the neurons in this region. To test this hypothesis, we compared the number of excitatory or inhibitory synaptic structures in the vACC L2/3 and L5 and in the synaptic zone (layer 1, L1) of the vACC from trained and untrained mice. The synaptic zone in L1 harbors the apical dendrites from both L2/3 and L5 neurons, which receive many synapses. In addition, we analyzed also synapse numbers in the DMS, the axonal target for ACC neurons (Figure 2D). To visualize and quantify structural synapses, we used an established protocol (Ippolito and Eroglu, 2010) that marks synapses as the juxta-positioning of pre and postsynaptic markers. This method takes advantage of the fact that pre and postsynaptic proteins are in distinct neuronal compartments (i.e., axons and dendrites, respectively); however, these markers appear to partially co-localize at synapses in images obtained through light microscopy due to their close proximity and resolution of the microscope.

We used the Vesicular Glutamate Transporter 1 and the postsynaptic density protein 95 (VGluT1/PSD95) or the Vesicular GABA Transporter, and gephyrin (VGAT/Gephyrin), to mark the respective pre and postsynaptic compartments of excitatory or inhibitory synapses (Figure 2E and S2D). We found an increase in the VGluT1/PSD95-positive excitatory synapse density in $L 1$ and in $L 2 / 3$ of the ventral $A C C$ of trained mice compared to untrained controls (Figure $2 F$ ). No changes in synapse densities were observed in L5 of the ACC, in the DMS (Figure 2F), or within the adjacent region MOs (Figure S2C). Moreover, training did not alter the numbers of VGAT/Gephyrin-positive inhibitory synapses in any of these regions (Figure S2E). 
Taken together, these data show for the first time that the learning and performance of instrumental actions are accompanied by a significant increase in the numbers of VGIuT1/PSD95-positive excitatory synapses with L1 and L2/3 of the vACC. These findings suggest that LP-training induces excitatory synaptogenesis in the ACC, which can be necessary for the learning and performance of instrumental actions.

\section{Training-induced excitatory synapse formation in the ACC requires the synaptogenic neuronal receptor $\alpha 2 \delta-1$.}

Previous studies have demonstrated that alterations in synaptic connectivity severely impair sensorimotor and cognitive behaviors (Connor et al., 2017; Guo et al., 2019; Ribic et al., 2019; Robbins et al., 2010). Therefore, we hypothesize that inhibition of the training-induced excitatory (VGluT1/PSD95-positive) synaptogenesis would impair the learning or performance of the instrumental task.

Cacna2d1 encodes for the synaptogenic neuronal receptor $\alpha 2 \delta-1$ (Risher et al., 2018), which is required for normal intracortical synaptogenesis. The $\alpha 2 \delta-1 \mathrm{KO}$ mice have a robust $(>50 \%)$ reduction in the numbers of VGIUT1/PSD95-positive synapses in the neocortical areas that include the V1 visual cortex and S1 somatosensory cortex compared to their littermate WT siblings (Risher et al., 2018). To investigate whether training-induced VGluT1/PSD95-positive synapse formation is essential for LP-training, we bred $\alpha 2 \delta-1$ heterozygous mice (Het) and analyzed the numbers of synapses in the vACC of adult trained and untrained $\alpha 2 \delta-1$ WT, Het, and $\mathrm{KO}$ offspring (Figure 3A). We found that both a decrease (Het) and loss (KO) of $\alpha 2 \delta-1$ severely reduce the synapse density in the vACC of the untrained mice (Figure S3A). Generally, the Het mice had $\sim 40 \%$ fewer synapses in both $L 1$ and $L 2 / 3$ and $\sim 60 \%$ fewer in $L 5$ of the VACC. The phenotype of the KO mice phenotype was even more severe with $\sim 60 \%$ decrease in $L 1$ and $L 2 / 3$ and $\sim 75 \%$ reduction in L5 compared to the WT untrained control (Figure S3A). 
Next, we tested if reduced $\alpha 2 \delta-1$ expression affects training-induced synaptogenesis. Here, we compared the numbers of VGIUT1/PSD95-positive synapses among untrained and trained $\alpha 2 \delta$ $1 \mathrm{WT}$, Het, and KO mice. As expected, the trained $\alpha 2 \delta-1 \mathrm{WT}$ mice had a significant increase in the number of VGluT1/PSD95 synapses in L1 and L2/3 of the vACC but no changes in L5 synapses. However, the training-induced increase in synapses in L1 and L2/3 was abolished in both $\alpha 2 \delta-1$ Het and KO mice (Figure 3B-C). In addition, in L5, where we found no differences between untrained and trained WT mice (Figure 2F), we observed a significant increase in VGluT1/PSD95-positive synapses in the trained $\alpha 2 \delta-1$ Het and KOs compared to the untrained mice (Figure S3B). These data suggest that in $\alpha 2 \delta-1$ mutants, the ACC undergoes a differential rewiring as a consequence of LP training. Collectively, our findings show that diminished $\alpha 2 \delta-1$ signaling reduces excitatory synapse numbers in the ACC of adult mice, and it prevents training-induced excitatory synaptogenesis in L1 and L2/3 of the ACC.

\section{Diminished $\alpha 2 \delta$-1-signaling does not impair learning of instrumental actions but causes effort/reward evaluation to become aberrant.}

We examined whether $\alpha 2 \delta-1$ Het and KO mice would exhibit deficits in the LP task (Figure 4A). Surprisingly, there were no differences between genotypes in their ability to learn and perform the LP task across the 9-day training period (Figure 4B). This finding suggests that trainingdependent, $\alpha 2 \delta$-1-mediated excitatory synaptogenesis is not necessary for the establishment of instrumental actions. This result is in agreement with previous work showing that regions other than the ACC are important for initial learning; for example, the prelimbic cortical projections to the DMS play a key role in instrumental learning (Hart et al., 2018b). But what then is the role of the ACC? To further investigate the role of $\alpha 2 \delta-1$-mediated excitatory synapse formation on LP behavior, we tested the performance of WT, Het, and KO mice in a Progressive Ratio (PR) paradigm. This schedule evaluates the effort/reward relationship of instrumental actions (Hodos, 
1961; Killeen et al., 2009; Parker et al., 2019). During PR testing, the numbers of LPs required to receive one food reward progressively are increased by an increment of 5 (i.e., 1 LP for the first reward, 6 LPs for the second, 11 LPs for the third, and etc., Figure 4C). When the task became difficult, there was a clear difference in how WT and $\alpha 2 \delta-1$ Het or KO mice responded to the progressively higher LP demand. Throughout the PR session, the $\alpha 2 \delta-1 \mathrm{KO}$ mouse pressed the lever more frequently compared to the WT control (Figure 4D, bottom). As a result, the KO mice received a higher number of rewards at the end of the PR session (Figure 4D, top). This behavioral difference between genotypes was significant when we quantified the LP rate (Figure 4E) or the cumulative numbers of rewards received across the entire PR session for all three genotypes (Figure 4F). As a result, both $\alpha 2 \delta-1$ Het and $\mathrm{KO}$ mice reached a significantly higher ratio of LPs per reward by the end of the PR session (i.e., breakpoint) than the WT controls (Figure 4G). Consequently, both $\alpha 2 \delta-1$ Het and $\mathrm{KO}$ mice had a significantly lower mean IPI ( 40\% reduction) compared to the $\alpha 2 \delta-1$ WT mice (Figure 4H). However, all three genotypes ( $\alpha 2 \delta-1 \mathrm{WT}$, Het, and $\mathrm{KO}$ ) were able to extinguish their LP behavior at the same rate in the absence of reward (Figure 4I).

To determine if $\alpha 2 \delta-1$ Het and $\mathrm{KO}$ mice have any gross behavioral abnormalities which could produce the phenotype we observed, we tested all three genotypes in an open field arena to quantify their overall motor activities in a novel environment (Figure 4J and S4A). Both WT and Het mice traveled over a similar distance over time; however, the $\alpha 2 \delta-1 \mathrm{KO}$ sere significantly less active (Figure 4J and S4B). This finding demonstrates that none of the genotypes are hyperactive. In fact, $\alpha 2 \delta-1$ WT and Het mice spent $39.8 \%$ and $37.1 \%$ of their time in the center zone $(23.7 \%$, Figure S4C), whereas the $\alpha 2 \delta-1 \mathrm{KO}$ mice spent significantly less time in the center (23.7\% Figure 4K). Taken together, these results reveal that reducing (Het) or eliminating (KO) $\alpha 2 \delta-1$ protein expression blocks training-induced excitatory synapse formation in the mouse ACC, but it does not affect the learning of instrumental actions. Instead, both $\alpha 2 \delta-1$ Het 
and KO mice display a profound persistence of effort exertion when the LP task becomes progressively more demanding. These results suggest that during learning, new excitatory synapses form in the ACC to engage a neural circuit that enables an evaluation of the effort/reward relationship.

\section{Conditional deletion of $\alpha 2 \delta-1$ from ACC neurons that project to the DMS impairs effort/reward evaluation.}

To determine the specific roles of an $\alpha 2 \delta$-1-signaling in the adult ACC, we conditionally deleted $\alpha 2 \delta$ - 1 selectively from the ACC neurons that project to the DMS (ACC-DMS neurons). Here, we used a viral approach that relies upon the combined functions of two adeno-associated viruses (AAVs) (Kim et al., 2020). The first AAV, which is injected bilaterally into the DMS, expresses the Dre-recombinase protein conjugated with Wheat Germ Agglutinin (WGA). WGA is a lectin that is retrogradely transported across synapses in the brain (Schwab et al., 1978). Hence, WGA-conjugated Dre recombinase is transduced in all the neurons that send their axonal projections to the DMS. A second AAV, which is bilaterally injected into the ACC, contains the Cre-recombinase coding sequence; however, Cre expression is interrupted by a Rox-flanked STOP cassette (N-Cre-rox-STOP-rox-C-Cre, Figure 5A). This strategy ensures that only the ACC-DMS neurons receive both of the AAVs. Thus, in these ACC-DMS projection cells, the roxSTOP-rox codon within the Cre recombinase is deleted, and Cre-mediated recombination is enabled (Figure 5A). We verified the efficiency and specificity of this approach to target ACCDMS neurons using a Cre-reporter mouse line, Rosa (STOP)loxP-tdTomato (Figure 5B and $5 C)$. To determine the role of $\alpha 2 \delta-1$, we trained $\alpha 2 \delta-1(+/+)$ or $\alpha 2 \delta-1(\mathrm{f} / \mathrm{f})$ mice carrying the Cre reporter (Rosa (STOP)loxP-tdTomato) using the same behavioral paradigm (Figure 4A). We found that circuit-specific deletion of $\alpha 2 \delta-1$ in adulthood does not affect the learning of lever pressing (FR1 schedule in Figure 5D). During both FR5 and FR10 schedules, we observed a trending, but non-significant, increase in the LP rate for the $\alpha 2 \delta-1(f / f)$ compared to the $\alpha 2 \delta$ - 
$1(+/+)$ mice. However, when we then tested the same mice on the PR schedule, we observed profound differences between $\alpha 2 \delta-1(\mathrm{f} / \mathrm{f})$ and $\alpha 2 \delta-1(+/+)$ mice. The representative LP raster plots from two PR sessions, one from an $\alpha 2 \delta-1(+/+)$ and the other from an $\alpha 2 \delta-1(\mathrm{f} / \mathrm{f})$ mouse, illustrate these differences (Figure 5E). Similar to the $\alpha 2 \delta-1 \mathrm{KO}$ mice, deletion of $\alpha 2 \delta-1$ only in ACC-DMS neurons was sufficient for the $\alpha 2 \delta-1(f / f)$ mice to press the lever more frequently compared to the $\alpha 2 \delta-1(+/+)$ mice (Figure 5E). Quantification of the LP rate and cumulative reward number across the session time $(60 \mathrm{~min})$ revealed that the $\alpha 2 \delta-1(\mathrm{f} / \mathrm{f})$ mice have a higher LP rate and receive a higher number of rewards than the $\alpha 2 \delta-1(+/+)$ controls (Figure $5 F$ and $5 G)$. The $\alpha 2 \delta-1(f / f)$ mice reached a significantly higher max ratio than the $\alpha 2 \delta-1(+/+)$ mice (Figure $5 \mathrm{H})$. Consistent with these results, $\alpha 2 \delta-1(f / f)$ mice had a significantly lower IPI (Figure $5 \mathrm{I})$. These results show that ablating $\alpha 2 \delta$ - 1 specifically in ACC-DMS neurons recapitulates the LP phenotypes that we observed in $\alpha 2 \delta-1 \mathrm{KO}$ mice.

On the other hand, deletion of $\alpha 2 \delta-1$ from ACC-DMS neurons did not affect the ability of $\alpha 2 \delta$ $1(\mathrm{f} / \mathrm{f})$ mice to extinguish LP behavior when the reward is no longer delivered (Figure $5 \mathrm{~J}$ ).

Similarly, $\alpha 2 \delta-1(f / f)$ mice did not show general hyperactivity, as indicated by an open field test: there was no difference in total distance traveled (Figure 5K, S5A and S5B) and time spent in the center of the arena (Figure $5 \mathrm{~L}$ ).

Altogether, these data show that loss of $\alpha 2 \delta-1$ only in the ACC-DMS neurons is sufficient to cause a profound persistence of effort exertion when the task progressively becomes more demanding. These results also suggest that $\alpha 2 \delta-1$ is required in ACC-DMS neurons for new excitatory synapse formation during LP learning to enable the evaluation of the effort/reward relationship.

Conditional deletion of $\alpha 2 \delta-1$ reduces the number and activity of excitatory synapses in the adult ACC-DMS neurons. 
Why does the loss of $\alpha 2 \delta-1$ in the ACC-DMS neurons cause the persistence of effort exertion? We wondered if changes in functional properties of ACC-DMS neurons underlie this behavioral phenotype. To test this possibility, we next performed whole-cell patch-clamp recordings from the Cre-positive (expressing tdTomato) ACC-DMS neurons of $\alpha 2 \delta-1(+/+)$ and $\alpha 2 \delta-1(f / f)$ mice (Figure 6A).

Previously, dorsal-root ganglia neurons lacking $\alpha 2 \delta-1$ were shown to have reduced spiking (Margas Wojciech et al., 2016). Moreover, in the visual cortices of $\alpha 2 \delta-1 \mathrm{KO}$ mice, L2/3 neurons displayed a severe reduction in the frequency of miniature excitatory postsynaptic currents (mEPSCs) compared to littermate WTs (Risher et al., 2018). To determine if these synaptic properties were affected in the ACC-DMS neurons, we performed patch-clamp recordings from L2/3 tdTomato + neurons of $\alpha 2 \delta-1(+/+)$ and $\alpha 2 \delta-1(f / f)$ trained mice (Figure $6 \mathrm{~A})$. There were no differences between the mean AP firing frequencies of tdTomato ${ }^{+}$neurons between the genotypes in any of the step current stimulations used to elicit neuronal APs (Figure 6B-6C). Moreover, we did not observe a difference in the mean resting membrane potentials between $\alpha 2 \delta-1(+/+)$ and $\alpha 2 \delta-1(f / f)$ neurons (Figure 6D). However, we found a significant reduction in the frequency (Figure 6E-F) but not the amplitude (Figure 6G) of the mEPSCs from the ACC-DMS neurons of $\alpha 2 \delta-1(\mathrm{f} / \mathrm{f})$ mice compared to $\alpha 2 \delta-1(+/+)$. These electrophysiological findings indicate that loss of $\alpha 2 \delta-1$ reduces excitatory synaptic inputs onto the ACC-DMS neurons without affecting the excitability or the resting membrane potentials of these cells.

Based on these electrophysiological findings, we next tested whether loss of $\alpha 2 \delta-1$ in ACC-DMS neurons would lead to a reduction in the density of synaptic inputs made onto these cells. To do so, we quantified the number of VGluT1/PSD95-positive synapses made onto the tdTomato ${ }^{+}$ neuronal processes (Figure $6 \mathrm{H}$ ). These analyses were made both in $\mathrm{L} 1$ and $L 2 / 3$ because the L2/3 ACC-DMS pyramidal neurons extend their apical dendrites to L1 and basal dendrites to 
L2/3 (Figure 6H). Training induced a significant increase in the density of VGluT1/PSD95positive synapses made onto $\alpha 2 \delta-1(+/+)$ ACC-DMS neuron processes both in L1 and L2/3 (Figure 6J). Deletion of $\alpha 2 \delta-1$ from the ACC-DMS neurons abolished the training-induced increase in synapse density in L1 (Figure 6J). However, in L2/3, training still induced a significant increase in the density of synapses in both genotypes (Figure 6J). Nevertheless, the synapse density of $\alpha 2 \delta-1(\mathrm{f} / \mathrm{f})$ ACC-DMS neurons was significantly lower than the $\alpha 2 \delta-1(+/+)$ after training (Figure 6J). These results show that $\alpha 2 \delta-1$ is necessary for the training-induced increase in the density of VGluT1/PSD95-positive synapses made onto the adult ACC-DMS neurons in L1.

Taken together, these electrophysiological and neuroanatomical analyses show that circuitspecific conditional deletion of $\alpha 2 \delta-1$ in the adult ACC-DMS neurons reduces the density and the function of excitatory synaptic inputs made onto these neurons without changing intrinsic excitability. These results suggest that training-induced excitatory synaptogenesis is required to properly excite the ACC-DMS neurons, which control the effort/reward relationship. The output from these neurons is required for diminishing the effort exertion when the task becomes more demanding.

\section{Optogenetic-activation of ACC-DMS neurons is sufficient for inhibiting the lever press} behavior and rescue the increased effort exertion observed in circuit-specific $\alpha 2 \delta-1$ conditional knockout mice.

To determine if the excitation of ACC-DMS neurons is sufficient to reduce effort exertion during LP behavior, we expressed a Cre-dependent light-gated cation-selective membrane channel, Channelrhodopsin-2 (flex-ChR2), in these neurons. To do so, WT mice received bi-lateral injections of a retrograde Cre virus in the DMS and the flex-ChR2 virus in the ACC (Figure 7A). Optic fibers were also implanted in the ACC to enable bilateral activation of ACC-DMS neurons 
(Figure 7A). To compare the LP behavior of the same mouse with or without optogenetic stimulation of ACC-DMS neurons, we modified the demanding LP task paradigm. A PR schedule cannot be used for this purpose because the LP/reward ratio changes over time and does not allow comparisons between optogenetic stimulation within the same training session. Therefore, for these experiments, we trained the mice with a very high ratio (FR20) to investigate the effect of the optogenetic manipulation during a demanding task.

Mice were trained for 9 days as described previously. Subsequently, they were trained for an additional two days on an FR20 schedule (Figure 7B). On day 12, we tested these mice over a 30 min session where we alternated 5 minutes of optogenetic stimulation (light-On) with 5 minutes of no stimulation (light-Off) (Figure 7B). For each mouse, the anatomical locations of the optic fiber placement and the efficiency of viral targeting and expression of ChR2 in ACCDMS neurons were confirmed (Figure 7C). In addition, we also included a control group of mice (CTRL), which had only fiber implants to the ACC to control for possible effects of the optogenetic exposure and surgery on behavior (Owen et al., 2019). We observed that CTRL mice behave similarly during periods of light-On and light-Off, showing that optogenetic exposure in the absence of ChR2 expression had no or little effect on their behavior (Figure 7D (left), S6A). In contrast, in mice expressing ChR2, optogenetic excitation of ACC-DMS neurons strongly reduced the number of LPs during the FR20 schedule, compared to the LP of the same mice during light-Off periods (Figure 7D (right) and S6A). To quantify this change, we calculated the modulation index denoting the difference in the number of LP per 15 minutes light-On compared to the 15 minutes of the light-Off period divided by the total number of LPs for the entire 30-minute session. The mice expressing ChR2 in the ACC-DMS neurons displayed a significant reduction in the number of LPs when stimulated (Figure 7E). Moreover, when ACCDMS neurons were optogenetically excited, the IPI significantly increased. By contrast, in CTRL mice, there were no significant changes for LP or IPI between light-On and light-Off intervals 
(Figure S6A and S6B). These results show that optogenetic excitation of ACC-DMS neurons is sufficient to reduce effort exertion during a demanding task (FR20). Because training induces an increase in the number of excitatory synapses made onto these neurons (Figure 6J), our findings also suggest that new synapses formed during LP learning enable increased activation of the ACC-DMS neurons when the task becomes demanding.

To investigate this possibility, we tested whether the persistent effort exertion observed when $\alpha 2 \delta-1$ is deleted in the ACC-DMS neurons could be rescued by optogenetic stimulation. We injected $\alpha 2 \delta-1(+/+)$ and $\alpha 2 \delta-1(\mathrm{f} / \mathrm{f})$ mice with the WGA-Dre virus in the DMS and N-Cre-roxSTOP-rox-C-Cre and flex-ChR2 viruses in the ACC (Figure 7F). This strategy enabled the expression of the ChR2 in the ACC-DMS neurons concurrent with the genetic manipulation of $\alpha 2 \delta-1$ deletion (Figure 7F). We confirmed the correct anatomical targeting of optic fibers, as well as the co-expression of Cre (tdTomato $\left.{ }^{+}\right)$and ChR2 (EYFP $\left.{ }^{+}\right)$in the ACC-DMS neurons (Figure 7G). Mice were trained on the FR20 schedule and tested with 5-minute light-On and 5-minute light-Off intervals over 30 minutes on day 12 as described previously (Figure 7B). As shown by the representative raster plots and histograms, in the absence of optogenetic stimulation, the numbers of LPs are increased in $\alpha 2 \delta-1(f / f)$ compared to $\alpha 2 \delta-1(+/+)$ mice (Figure $7 \mathrm{H})$. However, during the light-On intervals, both $\alpha 2 \delta-1(+/+)$ and $\alpha 2 \delta-1(f / f)$ mice reduce their LP rates (Figure 7H). We quantified the effects of optogenetic stimulation across all the mice by calculating the light modulation index and normalized LP rates across the light-Off and light-On intervals. These analyses revealed that optogenetic stimulation of ACC-DMS neurons reduces LP behaviors in both genotypes (Figure 7I and S6C). Moreover, quantification of the mean IPI for each mouse across the light-Off and light-On intervals revealed that optogenetic stimulation increases the time between presses in both genotypes (Figure $7 \mathrm{~J})$. Importantly, planned t-test analysis showed that under light-On conditions, the normalized LP rate and the mean IPI and of the $\alpha 2 \delta$ $1(f / f)$ mice were comparable with those of the $\alpha 2 \delta-1(+/+)$ mice during light-Off periods (Figure 7 I, 
planned unpaired two-tails t-test [t(17) $=0.25]$, not significant; Figure $7 \mathrm{~J}$, planned unpaired twotails $t$-test [t(17) $=0.25]$, not significant). These results indicate that when $\alpha 2 \delta-1$ is deleted in ACC-DMS neurons, LP behavior can be rescued by optogenetic activation of these neurons. Taken together, we found that optogenetic excitation of ACC-DMS neurons is sufficient to reduce the effort exerted during a demanding task. Furthermore, when considered together with our anatomical analysis (Figure $6 \mathrm{~J}$ ) strongly indicate that $\alpha 2 \delta$-1-mediated synaptogenesis is upstream of the ACC-DMS neuronal activation required for effort/reward evaluation. 


\section{Discussion}

A principal characteristic of voluntary learned behaviors, which is required for survival, is the ability of individuals to modify their actions based on changes in the effort/reward relationship. Although previous work has identified the ACC as a key brain area in monitoring effort exertion (Schweimer and Hauber, 2006; Cowen et al., 2012; Hosokawa et al., 2013; Porter et al., 2019; Hart et al., 2020), the neuronal circuits and the molecular mechanisms underlying effort/reward evaluation are poorly understood. In the LP task we used, the number of lever presses generated can be viewed as the cost, whereas the food pellet reward earned is the benefit. Normally animals regulate the amount of effort exerted relative to a given amount of reward and reduce the effort when the task becomes too demanding (e.g., PR or FR20 schedules). But blocking synaptogenesis by deletion $\alpha 2 \delta-1$ in the ACC results in persistent effort despite a significant increase in cost, revealing a molecular mechanism that underlies effort/reward evaluation.

Our findings suggest the following working model. During the learning and performance phases of instrumental actions, new excitatory synapses are formed onto ACC-DMS neurons. While these new synapses are not necessary for learning the action-outcome relationship, they are required for effort/reward evaluation when the task becomes demanding, thus adjusting the performance gain in an adaptive manner. Indeed, circuit-specific excitation of ACC-DMS neurons is sufficient to reduce the effort exerted during instrumental actions. From a cellular perspective, the Thrombospondin/Gabapentin receptor $\alpha 2 \delta-1$ mediates learning-induced excitatory synapse formation onto the ACC-DMS neurons. Selective deletion of $\alpha 2 \delta-1$ in these neurons is sufficient to generate a maladaptive behavioral phenotype in which mice spend significantly more effort for a given reward. These findings reveal a new brain circuit and a cellular mechanism controlling the effort/reward evaluation. 


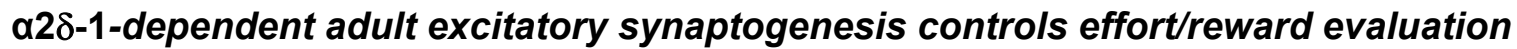

Synaptogenesis is critical for the construction of brain circuits during development (Kurshan et al., 2018; Tong et al., 2017; Connor et al., 2017; Wang et al., 2016; Chih et al., 2005). However, little is known about the role of synaptogenesis in adulthood. Previously, we found that the Thrombospondin/Gabapentin-receptor, $\alpha 2 \delta-1$, is required for the formation of intracortical excitatory synapses (Risher et al., 2018). The synaptogenic function of $\alpha 2 \delta-1$ is distinct from its canonical roles in regulating $\mathrm{Ca}^{2+}$ channel trafficking and activity (Eroglu et al., 2009; Kurshan et al., 2009; Held et al., 2020) and mediated by Rac-1 signaling within the dendrites of cortical neurons (Risher et al., 2018). Here we find that instrumental training induces upregulation of IEG expression concurrent with a significant increase in the numbers of intracortical excitatory synapses in the ACC. Moreover, we show that $\alpha 2 \delta-1$ is required for proper intracortical connectivity in the adult ACC, and the lack of one (Het) or both alleles (KO) of $\alpha 2 \delta-1$ is sufficient to abolish the training-induced excitatory synaptogenesis in this brain region.

Previous studies have identified new synapse formation in the motor cortex as an important step in motor learning and memory (Hayashi-Takagi et al., 2015; Xu et al., 2009). Thus, initially, we expected the $\alpha 2 \delta-1$ mutants would have a deficit in the learning phase of the LP task. Another report using a different $\alpha 2 \delta-1$ mutant mouse line and distinct behavioral paradigms suggested that a constitutive lack of $\alpha 2 \delta-1$ impairs motor and spatial learning (Zhou et al., 2018).

Surprisingly, there were no learning impairments in either $\alpha 2 \delta-1$ Het or KO mice in the LP task despite the fact that these genetic manipulations abolished training-induced synaptogenesis. These findings indicate that training-induced excitatory synapse formation that is mediated by $\alpha 2 \delta-1$ is not required for learning the action-outcome contingency in instrumental conditioning.

What is the physiological role of synapse formation that occurs during instrumental action learning? Relative to WT mice, we found that $\alpha 2 \delta-1$ Het and KO mice continue to exert 
substantial effort during a task that becomes progressively more demanding. These results suggest that the $\alpha 2 \delta$-1-mediated training-induced excitatory synaptogenesis is required for effort/reward evaluation when the task becomes demanding. These findings reveal a previously unknown function for synaptogenic signaling in the adult brain in controlling the adaptability of learned behaviors.

The $\alpha 2 \delta-1$ Het and KO mice have developmental synaptic connectivity deficits, which might have underlined the observed phenotype. However, a circuit-specific deletion of $\alpha 2 \delta-1$ in the adult brain, targeting specifically the ACC-DMS neurons, was sufficient to cause a robust persistence in effort exertion in adult mice. Moreover, physiological and neuroanatomical analyses confirmed that this circuit-specific manipulation of $\alpha 2 \delta-1$ reduced training-induced synaptogenesis and decreased the excitatory synaptic inputs onto the ACC-DMS neurons. These findings show that effort/reward evaluation relies on the formation of excitatory synapses in the adult brain, a fundamental process that is mediated by $\alpha 2 \delta$-1-signaling in ACC-DMS neurons.

During development, astrocytes secrete TSP family proteins to mediate excitatory synaptogenesis through neuronal $\alpha 2 \delta-1$ (Eroglu et al., 2009; Risher et al., 2018). Thus, our findings suggest a potential role for astrocytes in the control of adult synaptogenesis, which is required for behavioral adaptability. Indeed, astrocytes can sense and regulate neuronal activity (Martín et al., 2015; Ma et al., 2016; Stobart et al., 2018; Corkrum et al., 2020). Moreover, manipulating astrocytic activity is sufficient to impact animal behavior and control learning and memory (Suzuki et al., 2011; Adamsky et al., 2018; Kol et al., 2020). It has also been reported that astrocytes in the striatum and in the medial prefrontal cortex can control locomotor behaviors and goal-directed actions by mediating changes in synaptic and neuronal activity (Nagai et al., 2019; Mederos et al., 2020; Corkrum et al., 2020). In zebrafish larvae, radial glia function is required to suppress futile behaviors by increasing the activity of GABAergic neurons 
(Mu et al., 2019). The increased effort exertion phenotype observed in $\alpha 2 \delta$-1-depleted mice is not caused by hyperactivity, as indicated by their normal open field performance. Nor is their phenotype due to inability to suppress actions, as they showed normal extinction behavior when the reward is no longer delivered. Therefore, our findings emphasize a role for the astrocyteinduced excitatory synaptogenesis in the adult ACC in effort regulation. Future studies investigating the roles of astrocyte-neuron crosstalk on higher-cognitive functions, such as behavioral adaptability, are necessary to test this possibility.

\section{Excitation of ACC-DMS circuit reduces effort exertion.}

To date, the functional roles of the ACC remain controversial. Previous lesion and drug infusion studies have suggested that ACC function is required for the efficiency of action performance and decision-making (McKee et al., 2010; Aly-Mahmoud et al., 2017; Brockett et al., 2020; Schweimer and Hauber, 2005, 2006). These observations indicate that the ACC controls the execution of learned behaviors. However, the ACC is also active during the initial phase of instrumental action learning under continuous reinforcement, as shown by the upregulation of IEG c-fos (Bertaina-Anglade Valérie et al., 2001).

Here we show that the acquisition of instrumental actions induces upregulation of IEG expression in the ACC, which occurs concurrently with an increase in excitatory synapse numbers. Furthermore, in WT mice, optogenetic excitation of ACC-DMS neurons can reduce the LP behavior. This observation reveals that ACC-DMS projections form part of a circuit responsible for controlling instrumental action performance. Moreover, we find that disruption of training-induced excitatory synaptogenesis does not impair learning, but it strongly impacts the ability of mice to evaluate the effort/reward relationship and modify their behavior. Thus, our results indicate that during learning, new excitatory synapses are formed onto the ACC neurons. When the task becomes demanding, these synapses enable excitation of ACC neurons, which can potentially command downstream regions (e.g., DMS) to reduce action performance. There 
may be a threshold of excitatory synaptic inputs necessary for ACC neurons to become active.

This model is supported by our findings showing that when training-induced excitatory

synaptogenesis becomes diminished, it results in an increased effort exertion.

The mechanism that we have identified could be relevant to previously proposed functions of the ACC in rodents (Friedman et al., 2015; Hart et al., 2020; Hillman and Bilkey, 2010; Porter et al., 2019, 2020; Rudebeck et al., 2006) and primates (Botvinick et al., 2009; Klein-Flügge et al., 2016; Fouragnan et al., 2019; Kennerley et al., 2006). In mice and non-human primates, it has been found that ACC activity is necessary during behavioral tasks in which past or current action-reward events guide future behavioral decisions (Kennerley et al., 2006; Fouragnan et al., 2019; Akam et al., 2020). This result is consistent with the temporal requirement reported for our observed training-induced synaptogenesis that occurs on a long timescale (days) of behavioral training (Xu et al., 2009). Nonetheless, the time scale of synaptogenesis is unlikely to be a mechanism for online adjustment of performance. Instead, it might be an anticipatory mechanism. In other words, the formation of new excitatory synapses in the ACC allows signals representing the effort to activate a mechanism for behavioral suppression. Indeed, TSP- $\alpha 2 \delta-1$ signaling stimulates the formation of silent, structural synapses (e.g., NMDA receptors), whereby astrocytes can then activate them by recruiting AMPA receptors to the synapse (Baldwin and Eroglu, 2017).

ACC is known to receive VGluT1 inputs from the Claustrum (CLA) and Hippocampus (Chia et al., 2020; Kol et al., 2020; Qadir et al., 2018; White et al., 2018). Moreover, it also receives a plethora of neuromodulatory inputs from the Ventral Tegmental Area (VTA) and the Raphe nuclei (Sun et al., 2019; Elston et al., 2019). In the future, investigation of the ACC-DMS neurons and their functional connectivity will expand our knowledge of this critical circuit required for effort/reward evaluation and adaptability of instrumental actions.

\section{A potential relationship between impaired synaptogenesis and repetitive behaviors}


Mutations in genes controlling synapse formation and maturation are strongly linked to many neuropsychiatric disorders, including Autism Spectrum Disorder (ASD), Schizophrenia, Obsessive-Compulsive Disorder (OCD), and Alzheimer's Disease (AD) (Nelson and Valakh, 2015; Sekar et al., 2016; Sohal and Rubenstein, 2019; Ullrich et al., 2018; Calafate et al., 2015). A common hallmark of these disorders is the presence of repetitive and ineffective behaviors (Cath et al., 2001; Luchins et al., 1992). Here we show that inhibition of molecular mechanisms that regulate synapse formation impairs the evaluation of the effort/reward relationship during the execution of voluntary learned behaviors. These findings provide a direct link between adult synaptogenesis and a fundamental cognitive process, behavioral adaptability.

Our data support previous studies showing a lack of synaptic or synaptogenic proteins (e.g., Shank3, Neuroligins, and SynCAM1) can alter the formation of excitatory or inhibitory synapses, causing hyperactivity, social dysfunction, and impaired learning (Chih et al., 2005; Cline, 2005; Guo et al., 2019; Robbins et al., 2010). Our results indicate that the synaptogenic function of $\alpha 2 \delta-1$ is necessary to increase the amount of excitatory input onto the ACC-DMS neurons to avoid the repetition of exhaustive behaviors. The impaired function of the ACC has been linked to both ASD and OCD symptoms which require proper cortico-striatal connectivity (Graybiel, 1998; Guo et al., 2019). Thus, our findings may be extended to these neuropsychiatric disorders providing a possible mechanism producing the dysfunctional and maladaptive behaviors and, thereby, providing an insight into the etiology of such conditions. 


\section{Acknowledgments}

This work was supported by grants from the National Institutes of Health (NS096352 and AG059409 to CE and MH112883 and DA040701 to HHY). FPUS was supported by postdoctoral fellowships from the Regeneration Next Initiative. Illustrations were created with BioRender.com. We would like to thank: Alexander Friedman, for his help with preparing the behavioral setup and troubleshoot some of the analysis scripts; Donna Porter, for helping with mouse colony maintenance; William Wetsel, Dolores Irala, Shiyi Wang, Dhanesh Sivadasan Bindu, Alessandro De Simone and Sehwon Koh for their critical feedback on the manuscript.

\section{Author Contributions}

Conceptualization, FPUS, HY, and CE; Methodology, FPUS, OL, KS, NK, RH, HY, and CE; Investigation, FPUS, OL, KS, NK; and RH Formal analysis, FPUS, OL, KS, NK, and CS; Resources, IHK; and SS Writing - original draft, FPUS, HY, and CE; Writing - Review \& Editing, FPUS, OL, KS, HY, and CE Funding Acquisition, FPUS, HY, and CE.

\section{Declaration of Interests}

The authors declare no competing financial interests. 


\section{Material and Methods}

\section{Animals, housing, and genotyping}

All mice were used in accordance with the Institutional Animal Care and Use Committee (IACUC) and the Duke Division of Laboratory Animal Resources (DLAR) oversight (IACUC Protocol Numbers A173-14-07, A147-17-06, and A263-16-12). All mice were housed under typical day/night conditions of 12-hours cycles. Wild type C57BL/6J (Stock \#000664) and

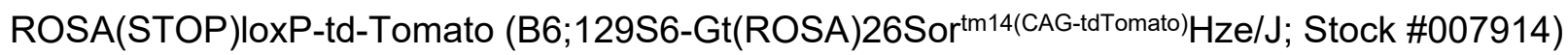
line were obtained through Jackson. The constitutive $\alpha 2 \delta-1$ Het and $\mathrm{KO}$ mice, as well as the conditional $\alpha 2 \delta-1(\mathrm{f} / \mathrm{f})$ mouse lines, were generated from our laboratory (Risher et al., 2018). All male and female mice (3-5 months old) used in this study were handled for 5-10 min a day for a week to allow them to get used to the operator. After this time, animals were food-restricted for 3-5 days until they rich $85-90 \%$ of their normal body weight. The target weight was maintained stable by daily feeding them, with $1.5 / 2 \mathrm{~g}$ of home chow, after training.

\section{Instrumental training}

Lever pressing training was performed in operant chambers (St Albans, VT, USA) set within light resistant and sound attenuating walls. Each chamber was equipped with a food magazine, where an infrared beam recorded the head entries into the magazine, that received pellets from a dispenser. The delivered reward was a Bio-Serv 14mg Dustless Precision Pellets (Bio-Serv, NJ, USA). Each chamber also had two retractable levers on either side of the magazine and a 3-W 24-V house light mounted to the opposite side of the levers. A computer with the Med-PCIV program was able to control the equipment and record the behavior according to the desired schedule. Timestamps for each lever press and head entries were recorded with a $10 \mathrm{~ms}$ resolution and then analyzed using custom-written programs (available upon request). Lever pressing training was performed using only the left lever. 


\section{Fixed Ratio schedule}

To test the capability of learning new behaviors, we used a continuous reinforcement schedule, here named Fixed Ratio 1 (FR1). The first day of FR1 began with 3 food pellets left in the food magazine, allowing the mice to learn about the possibility to receive food and the location of food delivery, the left lever inserted and the house light illuminated. The initial schedule consisted of 3 days of FR1, during which the animals received a pellet for each lever press. The session ended when one of the two restrictions was reached, 120 min or 50 rewards, with the retraction of the lever and the light turned off.

At the end of the 3 days of FR1, mice were moved to 3 different testing schedules.

Three days of FR5 schedule, during which the animals received a pellet for every 5 lever presses, were followed by the other three days of FR10 increasing the number of lever presses up to 10 for one reward. Session ended when one of the two restrictions was reached, 60 min or 50 rewards, with the retraction of the lever and the light turned off.

At the end of these 9 days, the mice were either sacrificed within 1 hour for histological analysis and RNA purification (WT C57BI/6J mice) or shifted to the next step of the behavioral test.

\section{Progressive Ratio, Extinction tests}

On day 10, a Progressive Ratio (PR) schedule was used to evaluate the motivation of the mice.

The PR schedule consists of an increasing number of lever presses every time a reward is received. In our case, we decided to use 5 as increased progression. The session ended after 60 minutes with the retraction of the lever and the light turned off.

During days 11 and 12 we used an Extinction schedule, during which mice could press the lever but there was no food delivered as a reward. The session ended after 30 minutes with the retraction of the lever and the light turned off. 


\section{Open field test}

After the operant task under food deprivation was completed, mice were normally housed with food and water provided ad libitum for 2-3 days, until their normal body weight was reestablished. Mice were then tested in an open field chamber equipped with a blackfly camera (Flyr System, BFS-U3-04S2M-CS) to record the animal movement. The Bonsai software (https://bonsai-rx.org/) was used to automatically detect and record the $\mathrm{x}$ and $\mathrm{y}$ coordinates for the center of mass of the mouse. The session began, after the mice were acclimated for 30min to the new room. The mouse was positioned to the center of the arena at the start of the recording which then finished after $30 \mathrm{~min}$. The chamber was carefully cleaned and the bedding was changed between different groups of littermates to avoid distraction due to other animals` odor stimuli.

\section{c-Fos staining and analysis}

Both trained WT mice $(n=6)$ and untrained WT mice $(n=6)$ were anesthetized with $200 \mathrm{mg} / \mathrm{kg}$ tribromoethanol (avertin) and then terminated by perfusing with a solution made of TBS with heparin (0.1128g Heparin ammonium salt from porcine intestinal mucosa [Sigma; H6279]) and then with 4\% Paraformaldehyde (PFA) within $1 \mathrm{~h}$ after the last day of FR10 schedule to observe changes in the activity-dependent expression of the immediate-early gene c-Fos. Mouse brains were then kept in $4 \%$ PFA o.n. at $4^{\circ} \mathrm{C}$. The day after brains were rinsed 3 times with TBS, immersed in $30 \%$ Sucrose in TBS and stored at $4^{\circ} \mathrm{C}$ until they were not floating anymore in the solution. At this time brains were included in a mixture of $30 \%$ Sucrose in TBS, and Tissue Tek O.C.T. compound (frozen tissue matrix) at a $1: 2$ ratio and stored at $-80^{\circ} \mathrm{C}$.

Using a cryostat, the brains were cut into $25-30 \mu \mathrm{m}$ coronal sections and stored floating in $50 \%$ Glycerol in TBS in a 24 multiwell plate, 5 sections per well, to have a $100 \mu \mathrm{m}$ spatial 
representation in the rostrocaudal direction. 4 sections for each mouse were selected at these approximate $( \pm 0.2)$ coordinates relative to Bregma: $+2.2,+1.7,+0.4$ and -0.3 .

The sections were rinsed 3 times $(1 \times 2 \mathrm{~min}, 1 \times 20 \mathrm{~min}$, and $1 \times 30 \mathrm{~min})$ in TBS, then they were moved for $1 \mathrm{~h}$ in a blocking solution containing 5\% Normal Donkey Serum (NDS) in TBS+0.3\% v/v of Triton. Primary antibody, Rabbit anti-cFos (Calbiochem, PC05), was diluted 1:50 in the blocking solution $+0.1 \% \mathrm{v} / \mathrm{v}$ of Sodium azide. The sections were incubated in this solution for $48-72 \mathrm{~h}$ at $4^{\circ} \mathrm{C}$ with gentle shaking. After this time, they were transferred to a secondary antibody solution after 3 washing steps in TBST (Triton 0.3\%) (1x10min, 1x30min, 1x40min). Donkey anti-rabbit conjugated to Alexa fluor-594 was used as secondary Ab in blocking solution to incubate the sections $2 \mathrm{~h}$ at RT. DAPI (1:50000) was added $15 \mathrm{~min}$ before the end of this step and then sections were rinsed again 3 times as before mounting them on a Superfrost Plus slides using a Refractive Index solution (RI solution: $20 \mathrm{mM}$ Tris ( $\mathrm{pH} 8.0$ ), 0.5\% N-propylgallate, 90\% Glycerol).

Tile scan images were then acquired using an Olympus Fluoview confocal microscope using 20X lens in resonant scanner mode, allowing the fast acquisition of entire coronal sections with an optical section step of $1 \mathrm{um}$ and the necessary number of images/stacks to acquire the entire depth of the section. Images were then processed using a combination of software. First, the images were restored using Content-aware image restoration (CARE) (Weigert et al., 2018), this neural network allowed us to use images (minimum of 30 images used to train the code) acquired in galvo scanner mode for the restoration of the tile scan acquired in resonant scanner mode. The only requirement is that for both the scanner modes the same parameters have to be used for the acquisition (i.e. type of objective and zoom). Then flat field correction and stitching were performed with a custom code (https://github.com/ErogluLab/CellCounts) and finally, segmentation for $\mathrm{DAPI}^{+}$and c-Fos ${ }^{+}$(from now called c-Fos ${ }^{+}$) cells was performed using the UNet software (https://arxiv.org/abs/1505.04597, and adapted by Chaichontat (Richard) 
Sriworarat). In this case, images that were manually segmented by the user to indicate the $\mathrm{DAPI}^{+}$and $\mathrm{c}-\mathrm{Fos}^{+}$cells, as well as ROls that were not positive for either marker, were used to train the UNet neural network. The training process was reiterated until the segmentation was able to recognize the positive cells correctly on a small set of data and then applied to analyze the entire batch of images. The segmentation step produced 16-bit images with the mask of the segmented c-Fos ${ }^{+}$cells in which the intensity is indicative of the degree of confidence of the segmentation. The mask was then used to select, based on the intensity, and count the c-Fos ${ }^{+}$ cells using the WholeBrain software (Fürth et al., 2018). All the brain regions represented by less than 3 mice were not considered in the analysis.

\section{RNA sequencing preparation and analysis}

RNA-sequencing libraries were made from $\geq 500$ ng of purified mouse $A C C$ ( $n=6$ mice per condition; $n=3$ mice per sex; 1 untrained male mouse was removed from the final analysis for having a low number of reads) RNA using the Kapa Stranded mRNA-seq kit. For each replicate 40-72 million, 2x51 reads were obtained from a NovaSeq 6000 . Raw reads were adapter trimmed using Trimmomatic (Bolger et al., 2014) (v0.38), aligned to the reference mouse genome (mm10) using Bowtie2 (Langmead and Salzberg, 2012) (v2.3.5.1), and counted using Subread (Liao et al., 2013) (featureCounts (Liao et al., 2014), v1.6.3). Differential gene expression was conducted using edgeR (Robinson et al., 2010) (v3.30.3). RNA-sequencing data have been deposited in the Gene Expression Omnibus (GEO) repository with accession number: GSE169392.

\section{Immunohistochemistry}

Brain sections were washed three times then permeabilized in TBS with $0.2 \%$ Triton-X 100 (TBST; Roche, Switzerland) at room temperature. Sections were blocked in $5 \%$ Normal Goat Serum (NGS) in TBST for $1 \mathrm{~h}$ at room temperature. Primary antibodies (guinea pig anti-VGlut1 
1:2000 [AB5905, Millipore, MA], rabbit anti-PSD95 1:300 [51-6900, Invitrogen, CA], guinea pig anti-VGAT 1:1000 [Synaptic Systems 131 004], rabbit anti-Gephyrin 1:500 [Synaptic Systems 147 002], were diluted in 5\% NGS containing TBST. Sections were incubated overnight at $4^{\circ} \mathrm{C}$ with primary antibodies. Secondary Alexa-fluorophore $(488,594$, and 647$)$ conjugated antibodies (Invitrogen) were added (1:200 in TBST with 5\% NGS) for $2 \mathrm{~h}$ at room temperature. Slides were mounted in Vectashield with DAPI (Vector Laboratories, CA) and images were acquired on an Olympus Fluoview confocal microscopy using a 60X oil lens at 1.64X Zoom.

\section{Quantification of Synapses}

3-4 animals per genotype of a2d1 WT, Heterozygous, KO, $\alpha 2 \delta-1(f / f)$, and $\alpha 2 \delta-1(+/+)$ were used for synapse analysis. Three independent brain sections per group were used for immunohistochemistry. $5 \mu \mathrm{m}$ thick confocal z-stacks (optical section depth $0.33 \mu \mathrm{m}, 15$ sections/z-stack) of the ACC (layer 1,2/3,5), DMS were imaged at $60 \times$ magnification on an Olympus Fluoview confocal laser-scanning microscope. Maximum projections of three consecutive optical sections (corresponding to $1 \mu \mathrm{m}$ total depth) were generated from the original z-stack. Analyses were performed blindly as to genotype. The Puncta Analyzer plugin (written by Barry Wark, modified by Chaichontat (Richard) Sriworarat, and available upon request from Cagla Eroglu at c.eroglu@cellbio.duke.edu for either ImageJ $(\mathrm{NIH}$; http://imagej.nih.gov/ij/) or FIJI (https://imagej.net/Fiji/Download) was used to count the number of co-localized puncta. This quantification method is based on the fact that pre- and postsynaptic proteins (such as VGluT1 and PSD95) are not within the same cellular compartments of neurons (axons versus dendrites, respectively) and would only appear to partially co-localized at synaptic junctions due to their proximity. This quantification method yields an accurate estimation of the number of synapses both in vitro and in vivo because it measures colocalization as opposed to staining of a single pre- or postsynaptic protein that often accumulates in extrasynaptic regions during the course of their life cycle. In agreement, 
numerous previous studies by ourselves and others have shown that synaptic changes observed by this quantification method are verified by techniques such as electron microscopy and electrophysiology (Christopherson et al., 2005; Eroglu et al., 2009; Kucukdereli et al., 2011; Allen et al., 2012; Risher et al., 2014; Singh et al., 2016; Koh et al., 2019). Details of the quantification method have been described previously (Ippolito and Eroglu, 2010). Briefly, $1 \mu \mathrm{m}$ thick maximum projections are separated into red and green channels, backgrounds are subtracted (rolling ball radius $=50$ ), and thresholds are determined to detect discrete puncta without introducing noise. The minimum pixel size of puncta was set as 4 to remove any background noise. The Puncta Analyzer plugin then uses an algorithm to detect the number of puncta that are in close proximity across the two channels, yielding quantified co-localized puncta. In order to calculate the percentage of WT co-localization, co-localized puncta values for WT were averaged, then all image values (WT, Heterozygous, KO, and flox mouse line) were normalized to the ratio of the calculated WT average.

\section{Adeno-Associated Virus (AAV) Production}

AAV-EF1 $\alpha-W G A-D r e$ and AAV-EF1 $\alpha-(N) C r e-R o x-S t o p-R o x-(C) C r e$, were produced and purified as described before (Kim et al., 2020). More in detail, AAVs were produced by co-transfecting each AAV vector $(15 \mu \mathrm{g})$ to the HEK cells with a helper (pAD-delta F6, $30 \mu \mathrm{g})$ and the capsid plasmids $(15 \mu \mathrm{g})$. A total of five $15 \mathrm{~cm}$ tissue culture dishes $\left(12 \times 10^{6} \mathrm{HEK}\right.$ cells per dish) were used to produce one type of virus. Three days post-transfection, HEK cells were lysed using the cell lysis buffer (Cell lysis buffer: Add $3 \mathrm{ml}$ of $5 \mathrm{M} \mathrm{NaCl}$ and $5 \mathrm{ml}$ of $1 \mathrm{M} \mathrm{Tris-HCl}(\mathrm{pH} 8.5)$ to 80 $\mathrm{ml}$ of $\mathrm{dH} 2 \mathrm{O}$. Adjust the $\mathrm{pH}$ to 8.5 with $\mathrm{NaOH}$ and adjust the volume to $100 \mathrm{ml}$ with $\mathrm{dH}_{2} \mathrm{O}$. Sterilize by passing through a $0.22-\mu \mathrm{m}$ filter and store at $4^{\circ} \mathrm{C}$ ). Then the AAV particles were released from the cells by three cycles of freeze/thaw between dry ice-ethanol and $37^{\circ} \mathrm{C}$ water bath and then treated with Benzonase (Novagen, 70664 ) at $37^{\circ} \mathrm{C}$ for 30 minutes. Then AAVs were purified using lodixanol Gradient Ultracentrifugation as described by Addgene 
(https://www.addgene.org/protocols/aav-purification-iodixanol-gradient-ultracentrifugation/).

Briefly, the cell lysates were loaded to the gradients of iodixanol (Sigma D1556, 15\%, 25\%, $40 \%$, and $60 \%$ ) in the OptiSeal tubes (Beckman Coulter, Indianapolis, IN). Then the lysates were spin down at $67,000 \mathrm{rpm}$ for 1 hour at $18^{\circ} \mathrm{C}$ with the ultracentrifuge (Beckman). The AAV particles were collected by collecting the interface between 40 and $60 \%$ iodixanol with a syringe. The collected AAV-containing solution was mixed with ice-cold DPBS and concentrated using the Vivaspin column (100 MWCO) at $4^{\circ} \mathrm{C}$. Collected virus particles were aliquoted and stored at $-80^{\circ} \mathrm{C}$ until use.

\section{Surgery procedure}

Mice were anesthetized with 2.0 to $3.0 \%$ isoflurane mixed with $0.60 \mathrm{~L} / \mathrm{min}$ of oxygen for surgical procedures and placed into a stereotactic frame (David Kopf Instruments, Tujunga, CA). Meloxicam (2 $\mathrm{mg} / \mathrm{kg}$ ) and topical bupivacaine $(0.20 \mathrm{~mL})$ were administered prior to incision. $\alpha 2 \delta-1(\mathrm{f} / \mathrm{f})$ and $\alpha 2 \delta-1(+/+)$ mice were used for the behavioral and electrophysiological test as well as for anatomical and synaptic count studies. For these purposes, $50 \mathrm{~nL}$ of AAV-EF1a-WGADre were injected bilaterally in the dorsomedial striatum (AP: +0.5 relative to bregma, ML: 1.4 relative to bregma, DV: 2.0 relative to brain surface) and $100 \mathrm{~nL}$ of AAV-EF1a-(N)Cre-Rox-StopRox-(C)Cre were injected bilaterally in the frontal and caudal part of the Anterior Cingulate Cortex (AP: +1.5 relative to bregma, ML: 0.12 relative to bregma, DV: 1.5 relative to brain surface; $\mathrm{AP}:-0.2$ relative to bregma, $\mathrm{ML}: 0.12$ relative to bregma, $\mathrm{DV}: 1.0$ relative to brain surface) using a microinjector (Nanoject 3000, Drummond Scientific) at a rate of $1 \mathrm{~nL} / \mathrm{s}$.

For optogenetic stimulation experiments, $200 \mathrm{~nL}$ of AAV-EF1a-DIO-hChR2(E123T/T15 9C)eYFP (UNC viral vector core) were bilaterally injected into the ACC (AP: +0.9 relative to bregma, ML: 0.12 relative to bregma, DV: 1.1 relative to brain surface) and $200 \mathrm{~nL}$ of AAV(RETRO2)-EF1a-Cre (Duke viral vector core) were bilaterally injected into the DMS (AP: 
+0.5 relative to bregma, ML: 1.4 relative to bregma, DV: 2.0 relative to brain surface) of $\mathrm{WT}$, $\alpha 2 \delta-1(\mathrm{f} / \mathrm{f})$ and $\alpha 2 \delta-1(+/+)$ mice. Custom-made optic fibers $(2-3 \mathrm{~mm}$ length below ferrule, $>80 \%$ transmittance, $105 \mu \mathrm{m}$ core diameter) were then implanted directly above the ACC at an angle (AP: +0.5 with respect to bregma, ML: 1.1 with respect to bregma, DV: 1.3 from the brain surface; $25^{\circ}$ ). Fibers were secured in place with dental acrylic adhered to skull screws. Mice were allowed to recover for three weeks after surgery before experimentation.

\section{Optogenetic Stimulation}

For optogenetic stimulations, WT, $\alpha 2 \delta-1(f / f)$, and $\alpha 2 \delta-1(+/+)$ mice expressing ChR2 and implanted with optic fibers were trained for the LP task as described above. After the 3days FR1, mice were trained with the optic fibers attached to the laser source to allow habituation. The training was conducted as described above for the 9 days and in addition, we performed 2 more days with an FR20 schedule. On day 12 the laser was turned on at a frequency of $20 \mathrm{~Hz}$ and a power of $7 \mathrm{~mW}$ to allow light stimulation for $5 \mathrm{~min}$ soon after $5 \mathrm{~min}$ without light stimulation. This cycle was repeated 3 times for a total of $30 \mathrm{~min}$.

\section{Circuit tracing and fiber implant control}

The circuit tracing and surgery check were conducted as follow. After the behavioral tests were concluded, mice were anesthetized with $200 \mathrm{mg} / \mathrm{kg}$ tribromoethanol (avertin) and terminated by perfusing with a solution made of TBS with heparin $(0.1128 \mathrm{~g}$ Heparin ammonium salt from porcine intestinal mucosa [Sigma; H6279]) and then with 4\% Paraformaldehyde (PFA). Mouse brains were then kept in $4 \%$ PFA o.n. at $4^{\circ} \mathrm{C}$. The day after brains were rinsed 3 times with TBS, immersed in $30 \%$ Sucrose in TBS, and stored at $4^{\circ} \mathrm{C}$ until they were not floating anymore in the solution. At this time brains were included in a mixture of $30 \%$ Sucrose in TBS and Tissue Tek O.C.T. compound (frozen tissue matrix) at a $1: 2$ ratio and stored at $-80^{\circ} \mathrm{C}$. Brains were cut into 20 or 50 um coronal sections and stored in a 1:1 mixture of TBS/glycerol at-20 C. Sections were 
washed in 1x TBS containing $0.2 \%$ Triton-X100 (TBST) and blocked in 10\%NGS diluted in TBST. For the mice expressing ChR2 and their control with only fiber implants, sections were incubated o.n. with a primary antibody against GFP (1:1000; Millipore, AB16901). In addition, brain sections from $\alpha 2 \delta-1(\mathrm{f} / \mathrm{f})$ and $\alpha 2 \delta-1(+/+)$ mice, were also incubated with a primary antibody against RFP (1:2000; Rockland, 600-401-379). Secondary Alexa-fluorophore $(488,594)$ conjugated antibodies (Invitrogen) were added (1:200 in TBST with 5\% NGS) for $2 \mathrm{~h}$ at room temperature. Slides were mounted in Vectashield with DAPI (Vector Laboratories, CA) and images were acquired on an Olympus Fluoview confocal microscope using 20X objective at 1.3X Zoom. Mice were excluded if fiber placement was not located in the target site.

\section{Whole-cell patch-clamp recording}

For whole-cell patch-clamp recordings, 8 animals were used to measure excitability and 7 animals were used to measure miniature excitatory postsynaptic current (mEPSC). Viral injection to label ACC neurons projecting to the DMS was performed as described previously and the animals were sacrificed 6 weeks after the injection. The brain was removed quickly and placed in ice-cold solution bubbled with 95\% O2-5\% CO2 containing the following (in mM): 194 sucrose, $30 \mathrm{NaCl}, 2.5 \mathrm{KCl}, 1 \mathrm{MgCl} 2,26 \mathrm{NaHCO}$, $1.2 \mathrm{NaH} 2 \mathrm{PO} 4$, and 10 D-glucose. After 5 minutes, $250 \mu \mathrm{m}$ coronal slices were cut with a vibratome (PELCO) and then placed in $35.5^{\circ} \mathrm{C}$ oxygenated artificial cerebrospinal fluid (aCSF) solution containing the following (in $\mathrm{mM}$ ): 124 $\mathrm{NaCl}, 2.5 \mathrm{KCl}, 2 \mathrm{CaCl}, 1 \mathrm{MgCl}$, $26 \mathrm{NaHCO}$, $1.2 \mathrm{NaH} 2 \mathrm{PO} 4$, and $10 \mathrm{D}$-glucose, $\mathrm{pH}$ adjusted to 7.4 with $\mathrm{HCl}$ and osmolality set to $\sim 310$ mosM. After 30 minutes, the slices were maintained in aCSF at $\sim 22-23^{\circ} \mathrm{C}$ for at least $30 \mathrm{~min}$ before recording. Following recovery, all recordings were conducted under continuous perfusion of aCSF at $29-30^{\circ} \mathrm{C}$, and the pipette`s impedances were between 3.5 and $5 \mathrm{M} \Omega$. All recordings were performed with MultiClamp 700B amplifier (Molecular Device) and filtered at $10 \mathrm{kHz}$ and digitized at $20 \mathrm{kHz}$ with a Digidata 1440A digitizer (Molecular Devices). To measure the excitability, the internal solution contained (in mM) 150 
potassium gluconate, $2 \mathrm{MgCl}$, $1.1 \mathrm{EGTA}, 10 \mathrm{HEPES}, 3$ sodium ATP, and 0.2 sodium GTP, with $\mathrm{pH}$ adjusted to 7.2 with $\mathrm{KOH}$ and osmolarity set to $\sim 300$ mosM. Pipettes impedances were between 3.5 and $5 \mathrm{M} \Omega$. The excitability was measured in current-clamp mode by injection of current between -300 and 400 pA. Each step was 100 pA with a duration of $1 \mathrm{~s}$. The number of spikes for each depolarizing step was counted by peak detection software in pCLAMP10 (Molecular Devices). To measure miniature excitatory postsynaptic current (mEPSC), the internal solution contained the following (in $\mathrm{mM}$ ): 120 cesium methanesulfonate, $5 \mathrm{NaCl}, 10$ tetraethylammonium chloride, 10 HEPES, 4 lidocaine N-ethyl bromide, 1.1 EGTA, 4 magnesium ATP, and 0.3 sodium GTP, pH adjusted to 7.2 with $\mathrm{CsOH}$ and osmolality set to $\sim 300$ mosM. mEPSCs were measured in the aCSF bath solution containing $1 \mu \mathrm{M}$ tetrodotoxin and $50 \mu \mathrm{M}$ Picrotoxin at $-70 \mathrm{mV}$ in voltage-clamp mode. The amplitudes of mEPSCs over $-10 \mathrm{pA}$ by the peak detection software in PCLAMP10 were counted.

\section{Quantification and statistical analysis}

All statistical analyses were performed in GraphPAD Prism 8 with the exception of nested ANOVA analysis which was performed in TIBCO Statistica Software (Version 13.3) and JMP. Sample size and specific statistical tests for each experiment are indicated in the figure legend for each experiment. Exact $p$-values are listed in the figures for each experiment. The significance for all the quantifications is $p<0.05$. A Geisser-Greenhouse correction was used for Two-way ANOVA analyses. Sample sizes were determined based on previous experience for each experiment to yield high power to detect specific effects. No statistical methods were used to predetermine sample size. 
Figure legends

\section{Figure 1. Action sequence engages the Anterior Cingulate Cortex during instrumental actions}

(A) Left. Representation of the Skinner box used for training and testing mice. Right. The training protocol.

(B) Lever press (LP) rate for trained C57BL/6J mice ( $\mathrm{n}=17$ mice, 8 males, and 9 females) across the 9 days of training (Day $1=3 \pm 0.4 \mathrm{LP} / \mathrm{min}$, Day $9=22 \pm 1.9 \mathrm{LP} / \mathrm{min}$; One-way ANOVA for repeated measures, main effects of Days $[F(8,128)=74.86, p<0.0001]$ and Subject $[F(2.13$, $17.04)=10.30, p=0.001]$.

(C) Representative raster plots for FR5 day 4 and FR10 day 9 of LP performance.

(D) Mean IPI for a day of FR5 (7.22 \pm 0.71$)$ and FR10 (3.05 \pm 0.23$)$. Unpaired t-test ( $n=17$ mice; $t(32)=5.5)$. Data shown as mean \pm s.e.m.

(E) Schematic representation of the ACC microdissection and RNA-seq of trained and untrained mice.

(F) Heat map of the top 20 differentially expressed genes (DEG) in the Trained and Untrained groups that are ranked based on the z-score of the $\log _{2} \mathrm{CPM}$. Bolded genes are the IEGs overexpressed in Trained mice.

(G) Volcano plot for DEG is organized based on their logarithmic fold change (logFC) and pvalue $\left(-\log _{10} p\right.$ value). Arrows signify genes of interest.

Figure 2. High ratio schedule induces excitatory synaptogenesis in the Anterior Cingulate Cortex

(A) Example images of the layer-specific organization of the ACC.

(B) Layer specific count of the c-Fos ${ }^{+}$cells in the dorsal and ventral ACC in trained and untrained C57BL/6J mice ( $n=6$ mice per condition ( 3 males and 3 females); 4 sections per mouse). Samples from respective untrained and trained mice (ACCd-L6b: $6.83 \pm 2.6,20.5 \pm$ 5.12 [U= 4]; ACCv-L2/3: 106.2 \pm 19.71, $230 \pm 26.78$ [U= 1]; ACCv-L5: $119.7 \pm 26.40,208.8 \pm$ $20.78[U=4] ; A C C v-L 6 b: 4.8 \pm 1.9,14.0 \pm 3.4[U=4.5])$. Unpaired two-tailed Mann-Whitney test.

(C) Schematic representation of the anatomical location of the ACC relative to other brain regions in a coronal brain section. In green are highlighted the two layers with neurons that project their axons to the DMS.

(D) Representation of the specific regions in which synaptic analysis was performed for VGlut1 and VGAT synapses. L1, cortical layer 1; L2/3, cortical layers 2/3' L5, cortical layer 5; DMS, dorsomedial striatum. 
(E) Representative images from Untrained and Trained mice that were stained with VGluT1 and PSD95 antibodies. The arrows in the merged channel indicate co-localized puncta. Scale bar 2 $\mu m$.

(F) Quantification of VGluT1/PSD95 co-localized puncta, normalized using the means of the Untrained values in the ACC and DMS. $n=4$ mice per condition, 3 images per mouse. Trained L1: $110 \pm 5.56 \%$ [t(34) = 2.17, $p=0.037]$; Trained L2/3: $132 \pm 9.7 \%$ [t(28) = 2.69, $p=0.012]$;

Trained L5: $113 \pm 5.5 \%$ [t(34) $=1.86]$; Trained DMS: $110 \pm 4.04 \%$ [t(34) $=1.64]$. Unpaired Twotailed t-test.

For all graphs: Data shown as mean \pm s.e.m.

Figure 3. VGlut1-PSD95 synapse formation in the Anterior Cingulate Cortex is regulated by the Thrombospondin receptor $\alpha 2 \delta-1$

(A) Breeding scheme for the generation of $\alpha 2 \delta-1 \mathrm{WT}$, Het, and KO mice.

(B) Representative images of VGluT1/PSD95 staining in the ACC of $\alpha 2 \delta-1$ WT, Het, and KO mice. The arrows in the merged channel indicate co-localized puncta. Scale bar $2 \mu \mathrm{m}$.

(C) Comparison between untrained and trained groups of VGluT1/PSD95 co-localized puncta in the L1 and L2/3 of the ACC for $\alpha 2 \delta-1$ WT (Trained L1: $110 \pm 3.3 \%$ [t(34) = 2.17, $p=0.037$; L2/3: $131.8 \pm 9.7 \%[t(28)=2.70, p=0.012]$ ), Het (Untrained-Trained: L1: $57.6 \pm 5.9 \% ; 69.3 \pm$ $6.1 \%[t(22)=1.36] ; L 2 / 3: 60.9 \pm 6.3 \% ; 76.2 \pm 6.7 \%[t(22)=1.66])$ and KO mice (UntrainedTrained L1: $38.7 \pm 3.3 \% ; 47.9 \pm 5.3 \%[t(22)=1.47] ; L 2 / 3: 42.2 \pm 3.3 \% ; 52.7 \pm 5.9 \%[t(22)=$ 1.54]). $n=4-6$ mice per condition and genotype ( $n=3$ images per mouse). Data were normalized on the average of the Untrained $\alpha 2 \delta-1 \mathrm{WT}$.

For all graphs: Planned unpaired Two-tailed t-test. Data shown as mean \pm s.e.m.

Figure 4. Constitutive lack of $\alpha 2 \delta-1$ causes persist responses without affecting the learning of instrumental actions

(A) Schematic representation of the training schedule used for the $\alpha 2 \delta-1 \mathrm{WT}$, Het, and KO mice.

(B) Lever press (LP) rate for the 9 days on the FR schedule for $\alpha 2 \delta-1 \mathrm{WT}$ ( $n=27$ mice; 14 male and 13 female), Het ( $n=35$ mice; 19 male and 16 female) and $K O(n=20$ mice; 10 male and 10 female). Two-way ANOVA for repeated measures. Main effects of Days $[F(2.571,203.1)=$ 324.1, $p<0.0001]$.

(C) Schematic representation of the Progressive Ratio (PR) schedule. The value $(n)$ of the ratio

$(R)$ increment of 5 for every received reward (i), starting with $R=1$.

(D) Representative peri-reward raster histograms of LP for an $\alpha 2 \delta-1 \mathrm{WT}$ and $\alpha 2 \delta-1 \mathrm{KO}$ mouse. 
(E) LP rate as function of time during the PR test for $\alpha 2 \delta-1$ WT $(n=22 ; 147.9 \pm 13$ LP), Het $(n=$ 29; $231.3 \pm 14.6 \mathrm{LP})$ and $\mathrm{KO}(\mathrm{n}=19 ; 226.6 \pm 11.4 \mathrm{LP})$ animals. Two-way ANOVA for repeated measures. Main effects of Time $[F(7.358,493.0)=26.14, p<0.0001]$ and Genotype $[F(2,67)=$ 11.33, $p<0.0001]$.

(F) Cumulative reward count over the PR session (bin=5 $\mathrm{min}$ ) for $\alpha 2 \delta-1 \mathrm{WT}(\mathrm{n}=22 ; 17.2 \pm 0.8$ rewards), Het ( $\mathrm{n}=29 ; 21.1 \pm 0.7$ rewards $)$ and $\mathrm{KO}(\mathrm{n}=19 ; 20.2 \pm 0.6$ rewards $)$ animals. Twoway ANOVA for repeated measures. Main effects of Time $[F(1.630,109.2)=1096, p<0.0001]$, Genotype $[F(2,67)=6.528, p<0.0001]$ and Time by Genotype interaction $[F(24,804)=7.232$, $p<0.0001]$.

(G) Break point for $\alpha 2 \delta-1 \mathrm{WT}(\mathrm{n}=22$; Max Ratio = 79.1 \pm 3.8$)$, Het $(\mathrm{n}=29$; Max Ratio $=100.8 \pm$ $3.5)$ and $\mathrm{KO}(\mathrm{n}=19 ;$ Max Ratio = $99.9 \pm 2.6)$ animals. One-way ANOVA $[F(2,67)=11.97, p<$ $0.0001]$.

$(\mathrm{H})$ Mean IPI for $\alpha 2 \delta-1$ WT $(\mathrm{n}=22 ; 5.64 \pm 0.55 \mathrm{~s})$, Het $(\mathrm{n}=29 ; 3.56 \pm 0.32 \mathrm{~s})$ and $\mathrm{KO}(\mathrm{n}=19$; $3.28 \pm 0.15 \mathrm{~s})$ animals. One-way ANOVA $[\mathrm{F}(2,67)=10.58, p=0.0001]$.

(I) left: Schematic representation of the Extinction schedule in which mice do not receive any rewards upon lever press. right: LP number in a $3 \mathrm{~min}$ bin, normalized to the mean LP from the first bin for $\alpha 2 \delta-1$ WT ( $n=22 ; 0.31 \pm 0.03 \mathrm{LP} / 3 \mathrm{~min}$ ), Het $(\mathrm{n}=29 ; 0.30 \pm 0.02 \mathrm{LP} / 3 \mathrm{~min}$ ) and KO $(\mathrm{n}=19 ; 0.39 \pm 0.03 \mathrm{LP} / 3 \mathrm{~min}$ ) animals. Two-way ANOVA for repeated measures. Main effects of Time $[F(8.689,582.2)=57.15, p<0.0001]$ and Genotype $[F(2,67)=3.854, p=0.026]$.

(J) Bar graph of the total distance travelled in pixels for $\alpha 2 \delta-1$ WT $\left(n=25 ; 9.3^{*} 10^{4} \pm 4.0^{*} 10^{3}\right.$ pixels), Het $\left(n=31 ; 8.9 * 10^{4} \pm 3.4^{*} 10^{3}\right.$ pixels $)$ and $\mathrm{KO}\left(\mathrm{n}=16 ; 7.4^{*} 10^{4} \pm 3.8^{*} 10^{3}\right.$ pixels $)$ mice during the open field test. One-way ANOVA $[F(2,69)=5.489, p=0.006]$.

(K) Percent time spent in the center of the arena by $\alpha 2 \delta-1$ WT $(n=25 ; 40 \pm 1.7 \%)$, Het $(n=31$; $37 \pm 1.4 \%)$ and $\mathrm{KO}(\mathrm{n}=16 ; 24 \pm 2.1 \%)$ mice. One-way $\operatorname{ANOVA}[F(2,69)=20, p<0.0001]$

For all graphs: Data shown as mean \pm s.e.m.

Figure 5. Conditional deletion of $\alpha 2 \delta-1$ from ACC-DMS neurons increases effort exertion without affecting the learning of instrumental actions.

(A) Schematic representation of the injections for both EF1a-WGA-Dre and EF1a-N-Cre-roxSTOP-rox-C-Cre viruses

(B) Tile scan image of a coronal brain section from an $\alpha 2 \delta-1(f / f)_{-}$tdTomato ${ }^{+}$mouse, showing labeled ACC neurons.

(C) Magnification of the ACC (top) and DMS (bottom) of a mouse injected with the WGA-Dre and the Rox-Cre viruses. 
(D) Lever press rate for the 9 days on the FR schedule for $\alpha 2 \delta-1(+/+)(n=12 ; 6$ male and 6 female) and $\alpha 2 \delta-1(\mathrm{f} / \mathrm{f})(\mathrm{n}=12 ; 6$ male and 6 female) mice. Two-way ANOVA for repeated measures. Main effect of Days $[F(1.795,39.50)=55.72, p<0.0001]$.

(E) Representative peri-reward raster histograms of LP for an $\alpha 2 \delta-1(+/+)$ and $\alpha 2 \delta-1(\mathrm{f} / \mathrm{f})$ mouse.

(F) LP number, in a 5 min bin, as function of time during the PR test for $\alpha 2 \delta-1(+/+)(n=12 ; 15.1$ $\pm 1.8 \mathrm{LP})$ and $\alpha 2 \delta-1(\mathrm{f} / \mathrm{f})(\mathrm{n}=12 ; 29.5 \pm 4.0 \mathrm{LP})$ animals. Two-way ANOVA for repeated measures. Main effects of Genotype $[F(1,22)=10.84, p=0.003]$ and Time by Genotype interaction $[F(11,242)=1.932, p=0.03]$.

(G) Cumulative reward count over the PR session (bin=5min) for $\alpha 2 \delta-1(+/+)(\mathrm{n}=12 ; 18.5 \pm 1.2$ rewards) and $\alpha 2 \delta-1(\mathrm{f} / \mathrm{f})$ animals ( $\mathrm{n}=12 ; 25.8 \pm 1.8$ rewards). Two-way ANOVA for repeated measures. Main effects of Genotype $[F(1,22)=8.832, p=0.007]$ and Time $[F(12,264)=298.4$, $p<0.0001]$ and Time by Genotype interaction $[F(12,264)=10.62, p<0.0001]$.

(H) Break point for $\alpha 2 \delta-1(+/+)(n=12$; Max Ratio = 88.5 \pm 6.1$)$ and $\alpha 2 \delta-1(f / f)(n=12$; Max Ratio $=125.2 \pm 9.0)$ animals. Unpaired t-test $[t(22)=3.366, p=0.003]$.

(I) Mean IPI for $\alpha 2 \delta-1(+/+)(n=12 ; 4.8 \pm 0.79 \mathrm{~s})$ and $\alpha 2 \delta-1(\mathrm{f} / \mathrm{f})(\mathrm{n}=12 ; 2.4 \pm 0.28 \mathrm{~s})$ mice. Unpaired t-test $[t(22)=2.8, p=0.010]$.

(J) left: Schematic representation of the Extinction schedule in which mice do not receive any rewards upon lever press. right: Lever press number in a 3 min bins, normalized over the mean LP for the first bin for $\alpha 2 \delta-1(+/+)(\mathrm{n}=12 ; 0.40 \pm 0.06 \mathrm{LP} / 3 \mathrm{~min})$ and $\alpha 2 \delta-1(\mathrm{f} / \mathrm{f})(\mathrm{n}=12 ; 0.37 \pm$ $0.05 \mathrm{LP} / 3 \mathrm{~min})$ animals. Two-way ANOVA for repeated measures. Main effects of Time [F(5.433, 119.5) $=13.14, p<0.0001]$.

(K) Bar graph of the total distance traveled in pixels fory $\alpha 2 \delta-1(+/+)\left(n=12 ; 8.0^{*} 10^{4} \pm 5.8^{*} 10^{3}\right.$ pixels) and $\alpha 2 \delta-1(f / f)\left(n=12 ; 8.7^{*} 10^{4} \pm 8.2^{*} 10^{3}\right.$ pixels $)$ mice during the open field test. Unpaired t-test, not significant.

(L) Percent time spent in the center of the arena by $\alpha 2 \delta-1(+/+)(n=12 ; 31 \pm 3.3 \%)$ and $\alpha 2 \delta$ $1(\mathrm{f} / \mathrm{f})(\mathrm{n}=12 ; 33 \pm 2.6 \%)$ mice. Unpaired t-test, not significant.

For all graphs: Data shown as mean \pm s.e.m.

Figure 6. Circuit-specific conditional deletion of $\alpha 2 \delta-1$ reduces the excitatory synapses number onto the ACC-DMS neurons

(A) Schematic representation of the electrophysiological recordings from tdTomato ${ }^{+}$neurons in both $\alpha 2 \delta-1(+/+)$ and $\alpha 2 \delta-1(\mathrm{f} / \mathrm{f})$ mice.

(B) Example traces of the excitability of $\alpha 2 \delta-1(+/+)$ and $\alpha 2 \delta-1(f / f)$ tdTomato ${ }^{+}$neurons. 
(C) Action potential (AP) frequency as function of the injected current for both $\alpha 2 \delta-1(+/+)(n=4$ mice, 19 cells) and $\alpha 2 \delta-1(\mathrm{f} / \mathrm{f})(\mathrm{n}=4$ mice, 16 cells) animals. Two-way ANOVA for repeated measures. Main effect of Current $[F(2.3,75.91)=221.6, p<0.0001$.

(D) Resting membrane potentials of tdTomato ${ }^{+}$neurons in both $\alpha 2 \delta-1(+/+)(n=4$ mice, 19 cells $)$ and $\alpha 2 \delta-1(\mathrm{f} / \mathrm{f})(\mathrm{n}=4$ mice, 16 cells) animals. Unpaired t-test, not significant.

(E) Example traces from mEPSC recordings from $\alpha 2 \delta-1(+/+)$ and $\alpha 2 \delta-1(f / f)$ mice.

(F) left: cumulative distribution of the Inter-event interval of mEPSC in $\alpha 2 \delta-1(+/+)(n=4$ mice; 20 cells) and $\alpha 2 \delta-1(\mathrm{f} / \mathrm{f})(\mathrm{n}=3$ mice; 18 cells) mice. Kolmogorov-Smirnov test $(p<0.0001)$. right:

Average frequency of mEPSC in $\alpha 2 \delta-1(+/+)(n=4$ mice, 20 cells; $0.64 \pm 0.08 \mathrm{~Hz})$ and $\alpha 2 \delta-1(f / f)$ ( $n=3$ mice, 18 cells; $0.41 \pm 0.06 \mathrm{~Hz}$ ) mice. Unpaired t-test.

(G) left: cumulative distribution of amplitude of mEPSC in pA for both $\alpha 2 \delta-1(+/+)(n=4$ mice; 20 cells) and $\alpha 2 \delta-1(f / f)(n=3$ mice; 18 cells) mice. Kolmogorov-Smirnov test, not significant. right: Average amplitude of mEPSC in $\alpha 2 \delta-1(+/+)(n=4$ mice, 20 cells; $14 \pm 0.38$ pA) and $\alpha 2 \delta-1(f / f)(n$ $=3$ mice, 18 cells; $13 \pm 0.34 \mathrm{pA})$ mice. Unpaired t-test, not significant.

(H) Schematic representation of the methodology used to quantify the VGluT1-PSD95 colocalized puncta.

(I) Representative images of the tdTomato positive neurons labeled for both VGluT1 and PSD95. The merged channel only shows the puncta within the tdTomato mask (white arrows).

(J) Comparison between untrained and trained mice showing the VGluT1/PSD95-positive synaptic density in $L 1$ and $L 2 / 3$ of the ACC for $\alpha 2 \delta-1(+/+)$ (Trained $L 1: 149.5 \pm 44.1 \%$ [t(16) $=$ 3.20, $p=0.005]$; L2/3: $211.4 \pm 18.7 \%[t(16)=5.84, p<0.0001]$ ) and $\alpha 2 \delta-1(f / f)$ mice (UntrainedTrained: $L 1: 69.2 \pm 24.3 \% ; 87.3 \pm 35.7 \%$ [t(16) = 1.25]; L2/3: $55.4 \pm 5.5 \% ; 106.5 \pm 12.9$ [t(16) = 3.63, $p=0.002]$ ). Planned comparison across genotype for trained conditions for L1 [t(16) $=3.3$, $p=0.005]$ and $L 2 / 3$ [t(16) $=4.6, p<0.001]$. Planned unpaired Two-tailed t-test. $\mathrm{n}=3$ mice per condition and genotype ( $n=3$ images per mouse). Data were normalized by the mean of the untrained $\alpha 2 \delta-1(+/+)$ mice.

For all graphs: Data shown as mean \pm s.e.m.

\section{Figure 7. Optogenetic excitation of ACC-DMS neurons inhibits the lever press behavior}

(A) Schematic representation of the viral injections and fiber implants for the optogenetic excitation of ACC-DMS projecting neurons.

(B) Schematic representation of the FR20 schedule used for the optogenetic experiments.

(C) Anatomical localization of the viral expression and fiber tracts in the WT-CTRL and WTChR2 mice in the ACC neurons projecting to the DMS.

(D) Representative peri-reward raster histograms with and without light stimulation of the ACCDMS projections in WT-CTRL and WT-ChR2 ${ }^{+}$mice. 
(E) Modulation index for WT-CTRL $(\mathrm{n}=6$ mice; $0.011 \pm 0.02)$ and WT-ChR2 mice $(\mathrm{n}=10$ mice; $-0.19 \pm 0.03)$. Unpaired $t$-test $[t(14)=4.1, p=0.001]$.

(F) Schematic representation of the viral injections and fiber implants for the optogenetic rescue experiments in the ACC-DMS projecting neurons of $\alpha 2 \delta-1(+/+)$ and $\alpha 2 \delta-1(\mathrm{f} / \mathrm{f})$ mice.

(G) Anatomical confirmation of viral expression and fiber placement in a representative example of an $\alpha 2 \delta-1(f / f)$ mouse expressing the Rox-Cre and the Cre-dependent ChR2 in ACC-DMS neurons.

(H) Representative peri-reward raster histograms of an $\alpha 2 \delta-1(+/+)$ and an $\alpha 2 \delta-1(\mathrm{f} / \mathrm{f})$ mouse during the light-Off and light-On periods.

(I) LP rate for the $\alpha 2 \delta-1(+/+)$ mice $(n=8$; light-Off: $1.0 \pm 0.11$, light-On: $0.72 \pm 0.10$ ) and $\alpha 2 \delta$ 1 (f/f) mice ( $n=11$; light-Off: $1.5 \pm 0.13$, light-On: $1.0 \pm 0.12)$. Paired Two-tailed t-test for $\alpha 2 \delta$ $1(+/+)[t(7)=6.9, p<0.001]$ and for $\alpha 2 \delta-1(f / f)[t(10)=6.7, p<0.0001]$.

(J) Mean IPI for $\alpha 2 \delta-1(+/+)$ mice during light-Off (2.24 $\pm 0.2 \mathrm{~s})$ and light-On $(3.07 \pm 0.39)$ and for $\alpha 2 \delta-1(f / f)$ mice during light-Off (1.54 $\pm 0.13 \mathrm{~s})$ and light-On (2.16 \pm 0.19$)$. Paired Two-tailed t-test for $\alpha 2 \delta-1(+/+)[t(7)=4.1, p=0.004]$ and for $\alpha 2 \delta-1(f / f)[t(10)=5.3, p<0.001]$.

For all graphs: Data showed as mean \pm s.e.m.

\section{Supplementary Figure legends}

\section{Figure Supplementary 1.}

(A) Representation of an Untrained mouse within a Skinner box with the lever retracted and free access to food rewards.

(B) Stereotaxic coordinates of the brain sections used for the c-Fos analysis.

(C-D) Image processing flow chart with examples for a trained and an untrained animal.

(E) Total numbers of c-Fos ${ }^{+}$cells in Untrained $\left(35.1 \pm 3.2{ }^{*} 10^{3} \mathrm{c}\right.$-Fos + cells) and Trained mice $\left(53.2 \pm 5.1 * 10^{3} \mathrm{c}\right.$-Fos + cells). $\mathrm{n}=6$ mice per condition; mean of 4 sections per mouse [U $\left.=3\right], p$ $=0.015$.

(F) Bar plot of c-Fos ${ }^{+}$cells for all the analyzed brain regions. The significant regions are primary Somato Sensory cortex (SSp, $n=5$ Untrained mice, $2381 \pm 438$ c-Fos ${ }^{+}$cells; $n=4$ Trained mice, $5100 \pm 822$ c-Fos $^{+}$cells; $[U=1], p=0.032$ ), primary Motor cortex (MOp, $\mathrm{n}=6$ Untrained

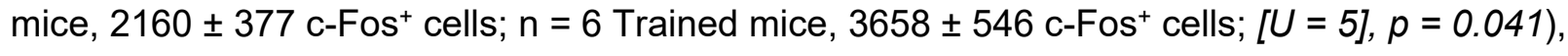
Anterior Cingulate Cortex (ACC, $n=6$ Untrained mice, $822 \pm 136$ c-Fos $^{+}$cells; $n=6$ Trained

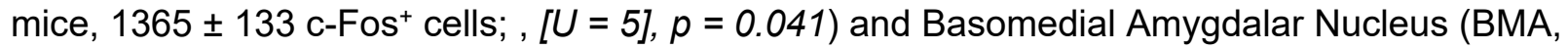

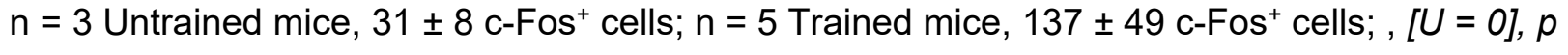
$=0.036)$. 
For all graphs: Unpaired two-tailed Mann-Whitney test. Data shown as mean \pm s.e.m.

\section{Figure Supplementary 2.}

(A) Schematic representation of $L 2 / 3$ neurons projecting from the MOs to the DMS.

(B) Layer-specific count of c-Fos ${ }^{+}$cells in the MOs. Unpaired two-tailed Mann-Whitney tests, none were significant.

(C) Quantification of VGlut1/PSD95 co-localized puncta in layer 2/3 of MOs ( $n=4$ mice per condition, 3 images per mouse). Unpaired Two-tailed t-test [t(22) $=0.168]$.

(D) Representative images for Untrained and Trained mice of Gephyrin and VGAT staining. The arrows in the merged channel indicate co-localized puncta. Scale bar $20 \mu \mathrm{m}$.

(E) Quantification of Gephyrin/VGAT co-localized puncta in ACC (L1, L2/3 and L5) and DMS (n $=4$ mice per condition, 3 images per mouse). Unpaired Two-tailed t-test. ACC L1 [t(22) =0.98], $A C C$ L2/3 [t(22) $=0.0003], A C C$ L5 [t(22) $=0.66]$, DMS [t(22) $=1.28]$.

For all graphs: Data were normalized on the average percentage of the Untrained values. Data shown as mean \pm s.e.m.

\section{Figure Supplementary 3.}

(A) Quantification of VGlut1/PSD95 co-localized puncta in the L1, L2/3, and L5 of Untrained $\alpha 2 \delta-1 \mathrm{WT}$, Het, and KO mice. $n=4-6$ mice per genotype ( $n=3$ images per mouse). Data normalized on the average percentage of $\alpha 2 \delta-1$ WT mice. One-Way ANOVA, for L1 [F $(2,39)=$ 59.98, $p<0.0001]$; $L 2 / 3[F(2,36)=26.94, p<0.0001]$; and $L 5[F(2,39)=88.38, p<0.0001]$. Tukey`s post-hoc test for multiple comparison.

(B) Quantification of VGlut1/PSD95 co-localized puncta in the L5 of the ACC for Untrained and Trained $\alpha 2 \delta-1$ WT (Trained L5: $113.3 \pm 5.5 \%$ [t(34) = 1.86]), Het (Untrained L5: $41.8 \pm 5.3 \%$;

Trained L5: $60.6 \pm 5.4 \%[t(22)=2.45, p=0.022]$ ) and KO mice (Untrained L5: $24.9 \pm 1.8 \%$; Trained L5: $48.9 \pm 7.7 \%[t(22)=3.01, p=0.006]) . n=4-6$ mice per condition and genotype $(n=$ 3 images per mouse). Data were normalized on the average of the Untrained $\alpha 2 \delta-1 \mathrm{WT}$.

Planned Unpaired Two-tailed T-test.

For all graphs: Data shown as mean \pm s.e.m.

\section{Figure Supplementary 4.}

(A) Examples of open field patterns of locomotion by $\alpha 2 \delta-1 \mathrm{WT}$, Het, and KO mice.

(B) Distance travelled/min during a 30 min session by $\alpha 2 \delta-1$ WT $(n=25)$, Het $(n=31)$ and KO $(n=16)$ mice. 
For all the graphs: Data shown as mean \pm s.e.m.

\section{Figure Supplementary 5.}

(A) Examples of open field patterns of locomotion by $\alpha 2 \delta-1$ WT and $\alpha 2 \delta-1(f / f)$.

(B) Distance travelled/min during a 30 min session by $\alpha 2 \delta-1$ WT $(n=12)$ and $\alpha 2 \delta-1(f / f)(n=12)$ mice.

For all the graphs: Data shown as mean \pm s.e.m.

Figure Supplementary 6.

(A) Normalized numbers of LPs by the WT-CTRL group ( $n=7$; Off state: $1.0 \pm 0.17$ LP, On state: $1.0 \pm 0.15$ LP. Paired t-test, not significant) and WT-ChR2 group $(n=7$; Off state: $1.0 \pm$ 0.09 LP, On state: $0.66 \pm 0.08$ LP. Paired t-test [t $(6)=5.1, p=0.002]$.

(B) Mean IPI for WT-CTRL mice during the light-Off (4.3 $\pm 1.3 \mathrm{~s})$ and light-On (3.6 \pm 0.6$)$ sessions. Paired t-test, not significant). Same for WT-ChR2 mice during light-Off (3.5 $\pm 0.53 \mathrm{~s})$ and light-On (5.5 $\pm 0.91 \mathrm{~s})$. Paired t-test [t(6) =3.3, $p=0.017]$.

(C) Modulation index for $\alpha 2 \delta-1(+/+)(n=8$ mice; $-0.17 \pm 0.03)$ and $\alpha 2 \delta-1(\mathrm{f} / \mathrm{f})$ mice $(\mathrm{n}=11 ;-0.18$ $\pm 0.03)$. Unpaired t-test [t(17) $=0.077]$, not significant.

For all graphs: Data shown as mean \pm s.e.m. 


\section{References}

Adamsky, A., Kol, A., Kreisel, T., Doron, A., Ozeri-Engelhard, N., Melcer, T., Refaeli, R., Horn, H., Regev, L., Groysman, M., et al. (2018). Astrocytic Activation Generates De Novo Neuronal Potentiation and Memory Enhancement. Cell 0 .

Akam, T., Rodrigues-Vaz, I., Marcelo, I., Zhang, X., Pereira, M., Oliveira, R.F., Dayan, P., and Costa, R.M. (2020). The Anterior Cingulate Cortex Predicts Future States to Mediate Model-Based Action Selection. Neuron 0.

Allen, N.J., Bennett, M.L., Foo, L.C., Wang, G.X., Chakraborty, C., Smith, S.J., and Barres, B.A. (2012). Astrocyte glypicans 4 and 6 promote formation of excitatory synapses via GluA1 AMPA receptors. Nature 486, 410-414.

Aly-Mahmoud, M., Carlier, P., Salam, S.A., Houari Selmani, M., Moftah, M.Z., Esclapez, M., and Boussaoud, D. (2017). Role of Anterior Cingulate Cortex in Instrumental Learning: Blockade of Dopamine D1 Receptors Suppresses Overt but Not Covert Learning. Front. Behav. Neurosci. 11.

Baldwin, K.T., and Eroglu, C. (2017). Molecular mechanisms of astrocyte-induced synaptogenesis. Curr. Opin. Neurobiol. 45, 113-120.

Balleine, B.W., and Dickinson, A. (1998). Goal-directed instrumental action: contingency and incentive learning and their cortical substrates. Neuropharmacology 37, 407-419.

Bednarek, E., and Caroni, P. (2011). $\beta$-Adducin Is Required for Stable Assembly of New Synapses and Improved Memory upon Environmental Enrichment. Neuron 69, 1132-1146.

Bertaina, V., and Destrade, C. (1995). Differential time courses of c-fos mRNA expression in hippocampal subfields following acquisition and recall testing in mice. Cogn. Brain Res. 2, 269-275.

Bertaina-Anglade Valérie, Tramu Gérard, and Destrade Claude (2001). Differential learning-stage dependent patterns of c-Fos protein expression in brain regions during the acquisition and memory consolidation of an operant task in mice. Eur. J. Neurosci. 12, 3803-3812.

Black, J.E., Isaacs, K.R., Anderson, B.J., Alcantara, A.A., and Greenough, W.T. (1990). Learning causes synaptogenesis, whereas motor activity causes angiogenesis, in cerebellar cortex of adult rats. Proc. Natl. Acad. Sci. U. S. A. 87, 5568-5572.

Bolger, A.M., Lohse, M., and Usadel, B. (2014). Trimmomatic: a flexible trimmer for Illumina sequence data. Bioinformatics 30, 2114-2120.

Botvinick, M.M., Huffstetler, S., and McGuire, J.T. (2009). Effort discounting in human nucleus accumbens. Cogn. Affect. Behav. Neurosci. 9, 16-27.

Brockett, A.T., Tennyson, S.S., deBettencourt, C.A., Gaye, F., and Roesch, M.R. (2020). Anterior cingulate cortex is necessary for adaptation of action plans. Proc. Natl. Acad. Sci. 
Calafate, S., Buist, A., Miskiewicz, K., Vijayan, V., Daneels, G., de Strooper, B., de Wit, J., Verstreken, P., and Moechars, D. (2015). Synaptic Contacts Enhance Cell-to-Cell Tau Pathology Propagation. Cell Rep. $11,1176-1183$.

Cath, D.C., Spinhoven, P., Hoogduin, C.A.L., Landman, A.D., van Woerkom, T.C.A.M., van de Wetering, B.J.M., Roos, R.A.C., and Rooijmans, H.G.M. (2001). Repetitive behaviors in Tourette's syndrome and OCD with and without tics: what are the differences? Psychiatry Res. 101, 171-185.

Chia, Z., Augustine, G.J., and Silberberg, G. (2020). Synaptic Connectivity between the Cortex and Claustrum Is Organized into Functional Modules. Curr. Biol. 0.

Chih, B., Engelman, H., and Scheiffele, P. (2005). Control of Excitatory and Inhibitory Synapse Formation by Neuroligins. Science 307, 1324-1328.

Christopherson, K.S., Ullian, E.M., Stokes, C.C.A., Mullowney, C.E., Hell, J.W., Agah, A., Lawler, J., Mosher, D.F., Bornstein, P., and Barres, B.A. (2005). Thrombospondins Are Astrocyte-Secreted Proteins that Promote CNS Synaptogenesis. Cell 120, 421-433.

Cline, H. (2005). Synaptogenesis: A Balancing Act between Excitation and Inhibition. Curr. Biol. 15, R203R205.

Cole, R.L., Lechner, S.M., Williams, M.E., Prodanovich, P., Bleicher, L., Varney, M.A., and Gu, G. (2005). Differential distribution of voltage-gated calcium channel alpha- 2 delta $(\alpha 2 \delta)$ subunit mRNA-containing cells in the rat central nervous system and the dorsal root ganglia. J. Comp. Neurol. 491, 246-269.

Connor, S.A., Ammendrup-Johnsen, I., Kishimoto, Y., Karimi Tari, P., Cvetkovska, V., Harada, T., Ojima, D., Yamamoto, T., Wang, Y.T., and Craig, A.M. (2017). Loss of Synapse Repressor MDGA1 Enhances Perisomatic Inhibition, Confers Resistance to Network Excitation, and Impairs Cognitive Function. Cell Rep. 21, 3637-3645.

Connor, S.A., Elegheert, J., Xie, Y., and Craig, A.M. (2019). Pumping the brakes: suppression of synapse development by MDGA-neuroligin interactions. Curr. Opin. Neurobiol. 57, 71-80.

Corkrum, M., Covelo, A., Lines, J., Bellocchio, L., Pisansky, M., Loke, K., Quintana, R., Rothwell, P.E., Lujan, R., Marsicano, G., et al. (2020). Dopamine-Evoked Synaptic Regulation in the Nucleus Accumbens Requires Astrocyte Activity. Neuron 105, 1036-1047.e5.

Coutureau, E., Esclassan, F., Di Scala, G., and Marchand, A.R. (2012). The Role of the Rat Medial Prefrontal Cortex in Adapting to Changes in Instrumental Contingency. PLoS ONE 7.

Cowen, S.L., Davis, G.A., and Nitz, D.A. (2012). Anterior cingulate neurons in the rat map anticipated effort and reward to their associated action sequences. J. Neurophysiol. 107, 2393-2407.

Dolphin, A.C. (2013). The $\alpha 2 \delta$ subunits of voltage-gated calcium channels. Biochim. Biophys. Acta BBA Biomembr. 1828, 1541-1549.

Elston, T.W., Croy, E., and Bilkey, D.K. (2019). Communication between the Anterior Cingulate Cortex and Ventral Tegmental Area during a Cost-Benefit Reversal Task. Cell Rep. 26, 2353-2361.e3. 
Eroglu, Ç., Allen, N.J., Susman, M.W., O’Rourke, N.A., Park, C.Y., Özkan, E., Chakraborty, C., Mulinyawe, S.B., Annis, D.S., Huberman, A.D., et al. (2009). Gabapentin Receptor $\alpha 2 \delta-1$ Is a Neuronal Thrombospondin Receptor Responsible for Excitatory CNS Synaptogenesis. Cell 139, 380-392.

Fernández-García, S., Conde-Berriozabal, S., García-García, E., Gort-Paniello, C., Bernal-Casas, D., GarcíaDíaz Barriga, G., López-Gil, J., Muñoz-Moreno, E., Soria, G., Campa, L., et al. (2020). M2 cortexdorsolateral striatum stimulation reverses motor symptoms and synaptic deficits in Huntington's disease. ELife 9, e57017.

Fouragnan, E.F., Chau, B.K.H., Folloni, D., Kolling, N., Verhagen, L., Klein-Flügge, M., Tankelevitch, L., Papageorgiou, G.K., Aubry, J.-F., Sallet, J., et al. (2019). The macaque anterior cingulate cortex translates counterfactual choice value into actual behavioral change. Nat. Neurosci. 22, 797-808.

Friedman, A., Homma, D., Gibb, L.G., Amemori, K., Rubin, S.J., Hood, A.S., Riad, M.H., and Graybiel, A.M. (2015). A Corticostriatal Path Targeting Striosomes Controls Decision-Making under Conflict. Cell 161, 1320-1333.

Fürth, D., Vaissière, T., Tzortzi, O., Xuan, Y., Märtin, A., Lazaridis, I., Spigolon, G., Fisone, G., Tomer, R., Deisseroth, K., et al. (2018). An interactive framework for whole-brain maps at cellular resolution. Nat. Neurosci. 21, 139.

Graybiel, A.M. (1998). The Basal Ganglia and Chunking of Action Repertoires. Neurobiol. Learn. Mem. 70, 119-136.

Gremel, C., and Costa, R. (2013a). Premotor cortex is critical for goal-directed actions. Front. Comput. Neurosci. 7.

Gremel, C.M., and Costa, R.M. (2013b). Orbitofrontal and striatal circuits dynamically encode the shift between goal-directed and habitual actions. Nat. Commun. 4, 2264.

Groenewegen, H.J., Wouterlood, F.G., and Uylings, H.B.M. (2016). Chapter 21 - Organization of Prefrontal-Striatal Connections. In Handbook of Behavioral Neuroscience, H. Steiner, and K.Y. Tseng, eds. (Elsevier), pp. 423-438.

Guo, B., Chen, J., Chen, Q., Ren, K., Feng, D., Mao, H., Yao, H., Yang, J., Liu, H., Liu, Y., et al. (2019). Anterior cingulate cortex dysfunction underlies social deficits in Shank3 mutant mice. Nat. Neurosci. 22, 1223.

Hart, E.E., Blair, G.J., O’Dell, T.J., Blair, H.T., and Izquierdo, A. (2020). Chemogenetic modulation and single-photon calcium imaging in anterior cingulate cortex reveal a mechanism for effort-based decisions. J. Neurosci.

Hart, G., Bradfield, L.A., and Balleine, B.W. (2018a). Prefrontal Corticostriatal Disconnection Blocks the Acquisition of Goal-Directed Action. J. Neurosci. 38, 1311-1322.

Hart, G., Bradfield, L.A., Fok, S.Y., Chieng, B., and Balleine, B.W. (2018b). The Bilateral Prefronto-striatal Pathway Is Necessary for Learning New Goal-Directed Actions. Curr. Biol. 28, 2218-2229.e7. 
Hayashi-Takagi, A., Yagishita, S., Nakamura, M., Shirai, F., Wu, Y.I., Loshbaugh, A.L., Kuhlman, B., Hahn, K.M., and Kasai, H. (2015). Labelling and optical erasure of synaptic memory traces in the motor cortex. Nature 525, 333-338.

Held, R.G., Liu, C., Ma, K., Ramsey, A.M., Tarr, T.B., De Nola, G., Wang, S.S.H., Wang, J., van den Maagdenberg, A.M.J.M., Schneider, T., et al. (2020). Synapse and Active Zone Assembly in the Absence of Presynaptic Ca2+ Channels and Ca2+ Entry. Neuron.

Hillman, K.L., and Bilkey, D.K. (2010). Neurons in the Rat Anterior Cingulate Cortex Dynamically Encode Cost-Benefit in a Spatial Decision-Making Task. J. Neurosci. 30, 7705-7713.

Hintiryan, H., Foster, N.N., Bowman, I., Bay, M., Song, M.Y., Gou, L., Yamashita, S., Bienkowski, M.S., Zingg, B., Zhu, M., et al. (2016). The mouse cortico-striatal projectome. Nat. Neurosci. 19, 1100-1114.

Hodos, W. (1961). Progressive Ratio as a Measure of Reward Strength. Science 134, 943-944.

Hosokawa, T., Kennerley, S.W., Sloan, J., and Wallis, J.D. (2013). Single-Neuron Mechanisms Underlying Cost-Benefit Analysis in Frontal Cortex. J. Neurosci. 33, 17385-17397.

Hunnicutt, B.J., Jongbloets, B.C., Birdsong, W.T., Gertz, K.J., Zhong, H., and Mao, T. (2016). A comprehensive excitatory input map of the striatum reveals novel functional organization. ELife 5.

Ippolito, D.M., and Eroglu, C. (2010). Quantifying Synapses: an Immunocytochemistry-based Assay to Quantify Synapse Number. J. Vis. Exp. JoVE.

Josselyn, S.A., and Tonegawa, S. (2020). Memory engrams: Recalling the past and imagining the future. Science 367.

Kennerley, S.W., Walton, M.E., Behrens, T.E.J., Buckley, M.J., and Rushworth, M.F.S. (2006). Optimal decision making and the anterior cingulate cortex. Nat. Neurosci. 9, 940-947.

Killeen, P.R., Posadas-Sanchez, D., Johansen, E.B., and Thrailkill, E.A. (2009). Progressive Ratio Schedules of Reinforcement. J. Exp. Psychol. Anim. Behav. Process. 35, 35-50.

Kim, I.H., Kim, N., Kim, S., Toda, K., Catavero, C.M., Courtland, J.L., Yin, H.H., and Soderling, S.H. (2020). Dysregulation of the Synaptic Cytoskeleton in the PFC Drives Neural Circuit Pathology, Leading to Social Dysfunction. Cell Rep. 32.

Klein-Flügge, M.C., Kennerley, S.W., Friston, K., and Bestmann, S. (2016). Neural Signatures of Value Comparison in Human Cingulate Cortex during Decisions Requiring an Effort-Reward Trade-off. J.

Neurosci. 36, 10002-10015.

Koh, S., Roy, S., Eroglu, O., Strader, S., Chen, W.J., Kay, J.N., Field, G.D., and Eroglu, C. (2019). Thrombospondin-1 Promotes Circuit-Specific Synapse Formation Via $\beta 1$-Integrin (Rochester, NY: Social Science Research Network).

Kol, A., Adamsky, A., Groysman, M., Kreisel, T., London, M., and Goshen, I. (2020). Astrocytes contribute to remote memory formation by modulating hippocampal-cortical communication during learning. Nat. Neurosci. 1-11. 
Kucukdereli, H., Allen, N.J., Lee, A.T., Feng, A., Ozlu, M.I., Conatser, L.M., Chakraborty, C., Workman, G., Weaver, M., Sage, E.H., et al. (2011). Control of excitatory CNS synaptogenesis by astrocyte-secreted proteins Hevin and SPARC. Proc. Natl. Acad. Sci. U. S. A. 108, E440-E449.

Kurshan, P.T., Oztan, A., and Schwarz, T.L. (2009). Presynaptic $\alpha 2 \delta-3$ is required for synaptic morphogenesis independent of its Ca 2+-channel functions. Nat. Neurosci. 12, 1415-1423.

Kurshan, P.T., Merrill, S.A., Dong, Y., Ding, C., Hammarlund, M., Bai, J., Jorgensen, E.M., and Shen, K. (2018). - -Neurexin and Frizzled Mediate Parallel Synapse Assembly Pathways Antagonized by Receptor Endocytosis. Neuron 100, 150-166.e4.

Langmead, B., and Salzberg, S.L. (2012). Fast gapped-read alignment with Bowtie 2. Nat. Methods 9, 357-359.

Liao, Y., Smyth, G.K., and Shi, W. (2013). The Subread aligner: fast, accurate and scalable read mapping by seed-and-vote. Nucleic Acids Res. 41, e108.

Liao, Y., Smyth, G.K., and Shi, W. (2014). featureCounts: an efficient general purpose program for assigning sequence reads to genomic features. Bioinformatics 30, 923-930.

Liu, X., Ramirez, S., Pang, P.T., Puryear, C.B., Govindarajan, A., Deisseroth, K., and Tonegawa, S. (2012). Optogenetic stimulation of a hippocampal engram activates fear memory recall. Nature 484, 381-385.

Luchins, D.J., Goldman, M.B., Lieb, M., and Hanrahan, P. (1992). Repetitive behaviors in chronically institutionalized schizophrenic patients. Schizophr. Res. 8, 119-123.

Ma, Z., Stork, T., Bergles, D.E., and Freeman, M.R. (2016). Neuromodulators signal through astrocytes to alter neural circuit activity and behavior. Nature 539, 428-432.

Margas Wojciech, Ferron Laurent, Nieto-Rostro Manuela, Schwartz Arnold, and Dolphin Annette C. (2016). Effect of knockout of $\alpha 2 \delta-1$ on action potentials in mouse sensory neurons. Philos. Trans. R. Soc. B Biol. Sci. 371, 20150430.

Martín, R., Bajo-Grañeras, R., Moratalla, R., Perea, G., and Araque, A. (2015). Circuit-specific signaling in astrocyte-neuron networks in basal ganglia pathways. Science 349, 730-734.

Marton, T.F., Seifikar, H., Luongo, F.J., Lee, A.T., and Sohal, V.S. (2018). Roles of Prefrontal Cortex and Mediodorsal Thalamus in Task Engagement and Behavioral Flexibility. J. Neurosci. 38, 2569-2578.

McKee, B.L., Kelley, A.E., Moser, H.R., and Andrzejewski, M.E. (2010). Operant learning requires NMDAreceptor activation in the anterior cingulate cortex and dorsomedial striatum, but not in the orbitofrontal cortex. Behav. Neurosci. 124, 500-509.

Mederos, S., Sánchez-Puelles, C., Esparza, J., Valero, M., Ponomarenko, A., and Perea, G. (2020). GABAergic signaling to astrocytes in the prefrontal cortex sustains goal-directed behaviors. Nat. Neurosci. 1-11. 
Mu, Y., Bennett, D.V., Rubinov, M., Narayan, S., Yang, C.-T., Tanimoto, M., Mensh, B.D., Looger, L.L., and Ahrens, M.B. (2019). Glia Accumulate Evidence that Actions Are Futile and Suppress Unsuccessful Behavior. Cell 178, 27-43.e19.

Nagai, J., Rajbhandari, A.K., Gangwani, M.R., Hachisuka, A., Coppola, G., Masmanidis, S.C., Fanselow, M.S., and Khakh, B.S. (2019). Hyperactivity with Disrupted Attention by Activation of an Astrocyte Synaptogenic Cue. Cell.

Nelson, S.B., and Valakh, V. (2015). Excitatory/Inhibitory Balance and Circuit Homeostasis in Autism Spectrum Disorders. Neuron 87, 684-698.

Owen, S.F., Liu, M.H., and Kreitzer, A.C. (2019). Thermal constraints on in vivo optogenetic manipulations. Nat. Neurosci. 22, 1061-1065.

Parker, K.E., Pedersen, C.E., Gomez, A.M., Spangler, S.M., Walicki, M.C., Feng, S.Y., Stewart, S.L., Otis, J.M., Al-Hasani, R., McCall, J.G., et al. (2019). A Paranigral VTA Nociceptin Circuit that Constrains Motivation for Reward. Cell 178, 653-671.e19.

Parkes, S.L., Ravassard, P.M., Cerpa, J.-C., Wolff, M., Ferreira, G., and Coutureau, E. (2018). Insular and Ventrolateral Orbitofrontal Cortices Differentially Contribute to Goal-Directed Behavior in Rodents. Cereb. Cortex 28, 2313-2325.

Peixoto, R.T., Chantranupong, L., Hakim, R., Levasseur, J., Wang, W., Merchant, T., Gorman, K., Budnik, B., and Sabatini, B.L. (2019). Abnormal Striatal Development Underlies the Early Onset of Behavioral Deficits in Shank3B-/- Mice. Cell Rep. 29, 2016-2027.e4.

Porter, B.S., Hillman, K.L., and Bilkey, D.K. (2019). Anterior cingulate cortex encoding of effortful behavior. J. Neurophysiol. 121, 701-714.

Porter, B.S., Li, K., and Hillman, K.L. (2020). Regional Activity in the Rat Anterior Cingulate Cortex and Insula during Persistence and Quitting in a Physical-Effort Task. ENeuro 7.

Qadir, H., Krimmel, S.R., Mu, C., Poulopoulos, A., Seminowicz, D.A., and Mathur, B.N. (2018). Structural Connectivity of the Anterior Cingulate Cortex, Claustrum, and the Anterior Insula of the Mouse. Front. Neuroanat. 12.

Ribic, A., Crair, M.C., and Biederer, T. (2019). Synapse-Selective Control of Cortical Maturation and Plasticity by Parvalbumin-Autonomous Action of SynCAM 1. Cell Rep. 26, 381-393.e6.

Risher, W.C., and Eroglu, C. (2020). Emerging roles for $\alpha 2 \delta$ subunits in calcium channel function and synaptic connectivity. Curr. Opin. Neurobiol. 63, 162-169.

Risher, W.C., Patel, S., Kim, I.H., Uezu, A., Bhagat, S., Wilton, D.K., Pilaz, L.-J., Singh Alvarado, J., Calhan, O.Y., Silver, D.L., et al. (2014). Astrocytes refine cortical connectivity at dendritic spines. ELife 3, e04047.

Risher, W.C., Kim, N., Koh, S., Choi, J.-E., Mitev, P., Spence, E.F., Pilaz, L.-J., Wang, D., Feng, G., Silver, D.L., et al. (2018). Thrombospondin receptor $\alpha 2 \delta-1$ promotes synaptogenesis and spinogenesis via postsynaptic Rac1. J Cell Biol jcb.201802057. 
Robbins, E.M., Krupp, A.J., Arce, K.P. de, Ghosh, A.K., Fogel, A.I., Boucard, A., Südhof, T.C., Stein, V., and Biederer, T. (2010). SynCAM 1 Adhesion Dynamically Regulates Synapse Number and Impacts Plasticity and Learning. Neuron 68, 894-906.

Robinson, M.D., McCarthy, D.J., and Smyth, G.K. (2010). edgeR: a Bioconductor package for differential expression analysis of digital gene expression data. Bioinformatics 26, 139-140.

Rudebeck, P.H., Walton, M.E., Smyth, A.N., Bannerman, D.M., and Rushworth, M.F.S. (2006). Separate neural pathways process different decision costs. Nat. Neurosci. 9, 1161-1168.

Schwab, M.E., Javoy-Agid, F., and Agid, Y. (1978). Labeled wheat germ agglutinin (WGA) as a new, highly sensitive retrograde tracer in the rat brain hippocampal system. Brain Res. 152, 145-150.

Schweimer, J., and Hauber, W. (2005). Involvement of the rat anterior cingulate cortex in control of instrumental responses guided by reward expectancy. Learn. Mem. 12, 334-342.

Schweimer, J., and Hauber, W. (2006). Dopamine D1 receptors in the anterior cingulate cortex regulate effort-based decision making. Learn. Mem. 13, 777-782.

Sekar, A., Bialas, A.R., de Rivera, H., Davis, A., Hammond, T.R., Kamitaki, N., Tooley, K., Presumey, J., Baum, M., Van Doren, V., et al. (2016). Schizophrenia risk from complex variation of complement component 4. Nature 530, 177-183.

Singh, S.K., Stogsdill, J.A., Pulimood, N.S., Dingsdale, H., Kim, Y.H., Pilaz, L.-J., Kim, I.H., Manhaes, A.C., Rodrigues, W.S., Pamukcu, A., et al. (2016). Astrocytes Assemble Thalamocortical Synapses by Bridging NRX1 $\alpha$ and NL1 via Hevin. Cell 164, 183-196.

Sohal, V.S., and Rubenstein, J.L.R. (2019). Excitation-inhibition balance as a framework for investigating mechanisms in neuropsychiatric disorders. Mol. Psychiatry 24, 1248-1257.

Stobart, J.L., Ferrari, K.D., Barrett, M.J.P., Glück, C., Stobart, M.J., Zuend, M., and Weber, B. (2018). Cortical Circuit Activity Evokes Rapid Astrocyte Calcium Signals on a Similar Timescale to Neurons. Neuron 0 .

Sun, Q., Li, X., Ren, M., Zhao, M., Zhong, Q., Ren, Y., Luo, P., Ni, H., Zhang, X., Zhang, C., et al. (2019). A whole-brain map of long-range inputs to GABAergic interneurons in the mouse medial prefrontal cortex. Nat. Neurosci. 1.

Suzuki, A., Stern, S.A., Bozdagi, O., Huntley, G.W., Walker, R.H., Magistretti, P.J., and Alberini, C.M. (2011). Astrocyte-Neuron Lactate Transport Is Required for Long-Term Memory Formation. Cell 144, 810-823.

Tong, X.-J., López-Soto, E.J., Li, L., Liu, H., Nedelcu, D., Lipscombe, D., Hu, Z., and Kaplan, J.M. (2017). Retrograde Synaptic Inhibition Is Mediated by $\alpha$-Neurexin Binding to the $\alpha 2 \delta$ Subunits of N-Type Calcium Channels. Neuron 95, 326-340.e5.

Ullrich, M., Weber, M., Post, A.M., Popp, S., Grein, J., Zechner, M., Guerrero González, H., Kreis, A., Schmitt, A.G., Üçeyler, N., et al. (2018). OCD-like behavior is caused by dysfunction of thalamo-amygdala 
circuits and upregulated TrkB/ERK-MAPK signaling as a result of SPRED2 deficiency. Mol. Psychiatry 23, 444-458.

Wang, T., Jones, R.T., Whippen, J.M., and Davis, G.W. (2016). $\alpha 2 \delta-3$ Is Required for Rapid Transsynaptic Homeostatic Signaling. Cell Rep. 16, 2875-2888.

Weigert, M., Schmidt, U., Boothe, T., Müller, A., Dibrov, A., Jain, A., Wilhelm, B., Schmidt, D., Broaddus, C., Culley, S., et al. (2018). Content-aware image restoration: pushing the limits of fluorescence microscopy. Nat. Methods 15, 1090-1097.

White, M.G., Panicker, M., Mu, C., Carter, A.M., Roberts, B.M., Dharmasri, P.A., and Mathur, B.N. (2018). Anterior Cingulate Cortex Input to the Claustrum Is Required for Top-Down Action Control. Cell Rep. 22, 84-95.

Xiong, Q., Znamenskiy, P., and Zador, A.M. (2015). Selective corticostriatal plasticity during acquisition of an auditory discrimination task. Nature $521,348-351$.

Xu, T., Yu, X., Perlik, A.J., Tobin, W.F., Zweig, J.A., Tennant, K., Jones, T., and Zuo, Y. (2009). Rapid formation and selective stabilization of synapses for enduring motor memories. Nature 462, 915-919.

Xu, Z., Adler, A., Li, H., Pérez-Cuesta, L.M., Lai, B., Li, W., and Gan, W.-B. (2019). Fear conditioning and extinction induce opposing changes in dendritic spine remodeling and somatic activity of layer 5 pyramidal neurons in the mouse motor cortex. Sci. Rep. 9, 4619.

Yin, H.H., and Knowlton, B.J. (2006). The role of the basal ganglia in habit formation. Nat. Rev. Neurosci. 7, 464-476.

Yin, H.H., Ostlund, S.B., Knowlton, B.J., and Balleine, B.W. (2005). The role of the dorsomedial striatum in instrumental conditioning. Eur. J. Neurosci. 22, 513-523.

Yin, H.H., Mulcare, S.P., Hilário, M.R.F., Clouse, E., Holloway, T., Davis, M.I., Hansson, A.C., Lovinger, D.M., and Costa, R.M. (2009). Dynamic reorganization of striatal circuits during the acquisition and consolidation of a skill. Nat. Neurosci. 12, 333-341.

Zhou, J.-J., Li, D.-P., Chen, S.-R., Luo, Y., and Pan, H.-L. (2018). The $\alpha 2 \delta-1-N M D A$ receptor coupling is essential for corticostriatal long-term potentiation and is involved in learning and memory. J. Biol. Chem. 293, 19354-19364. 
bioRxiv preprint doi: https://doi.org/10.1101/2021.04.20.440613; this version posted April 21, 2021. The copyright holder for this preprint (which was not certified by peer review) is the author/funder, who has granted bioRxiv a license to display the preprint in perpetuity. It is made available.under aÇC-BYilinc-ND 4.0 International license.

A

\section{Ratio $=\mathrm{n}$ Lever Press $/ 1$ Reward}
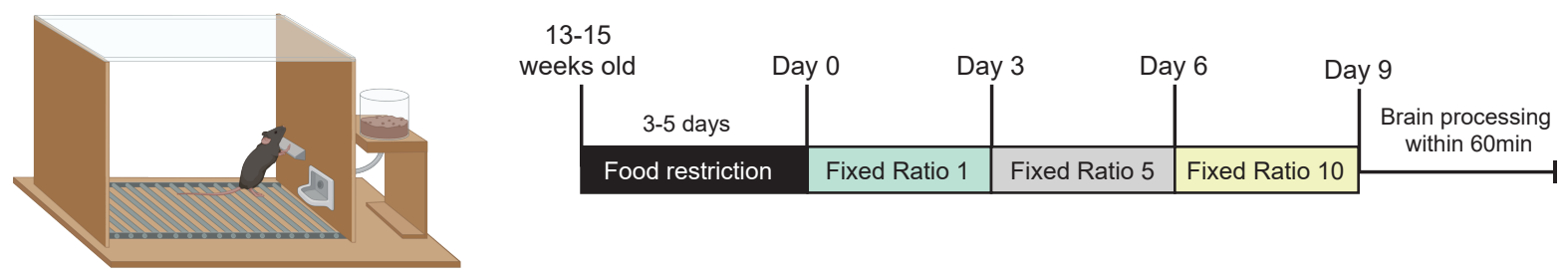

B
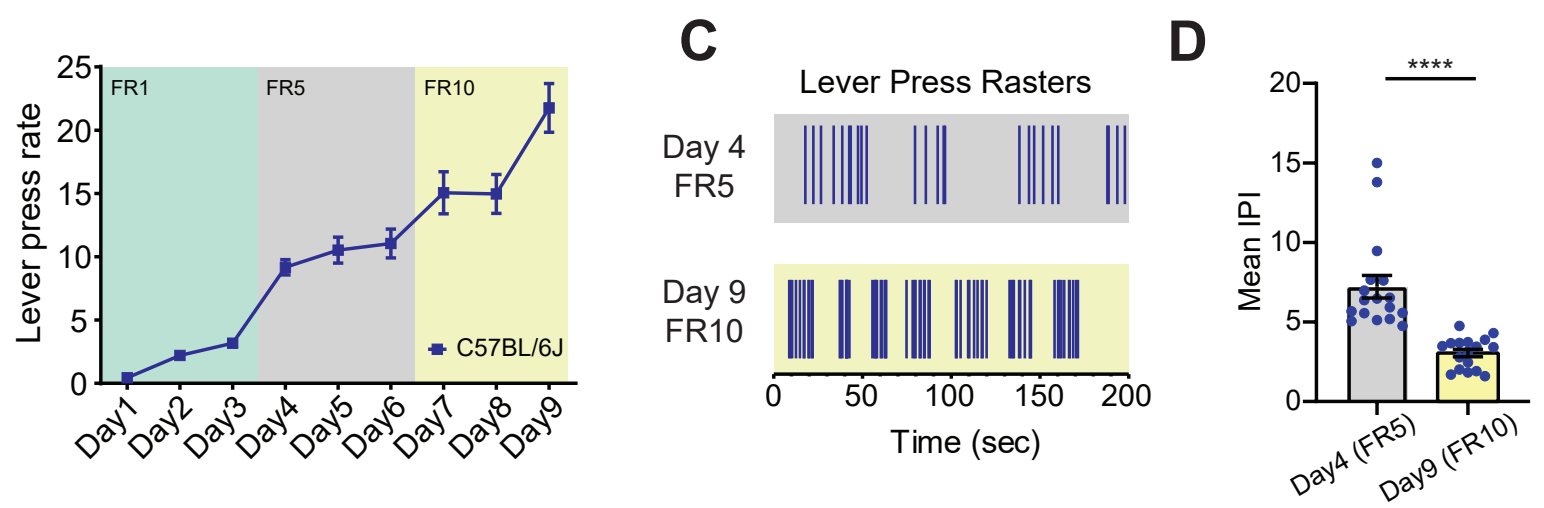

$\mathbf{E}$

\section{F}

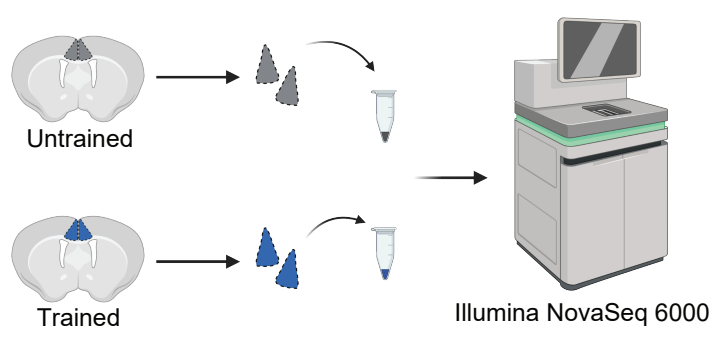

G
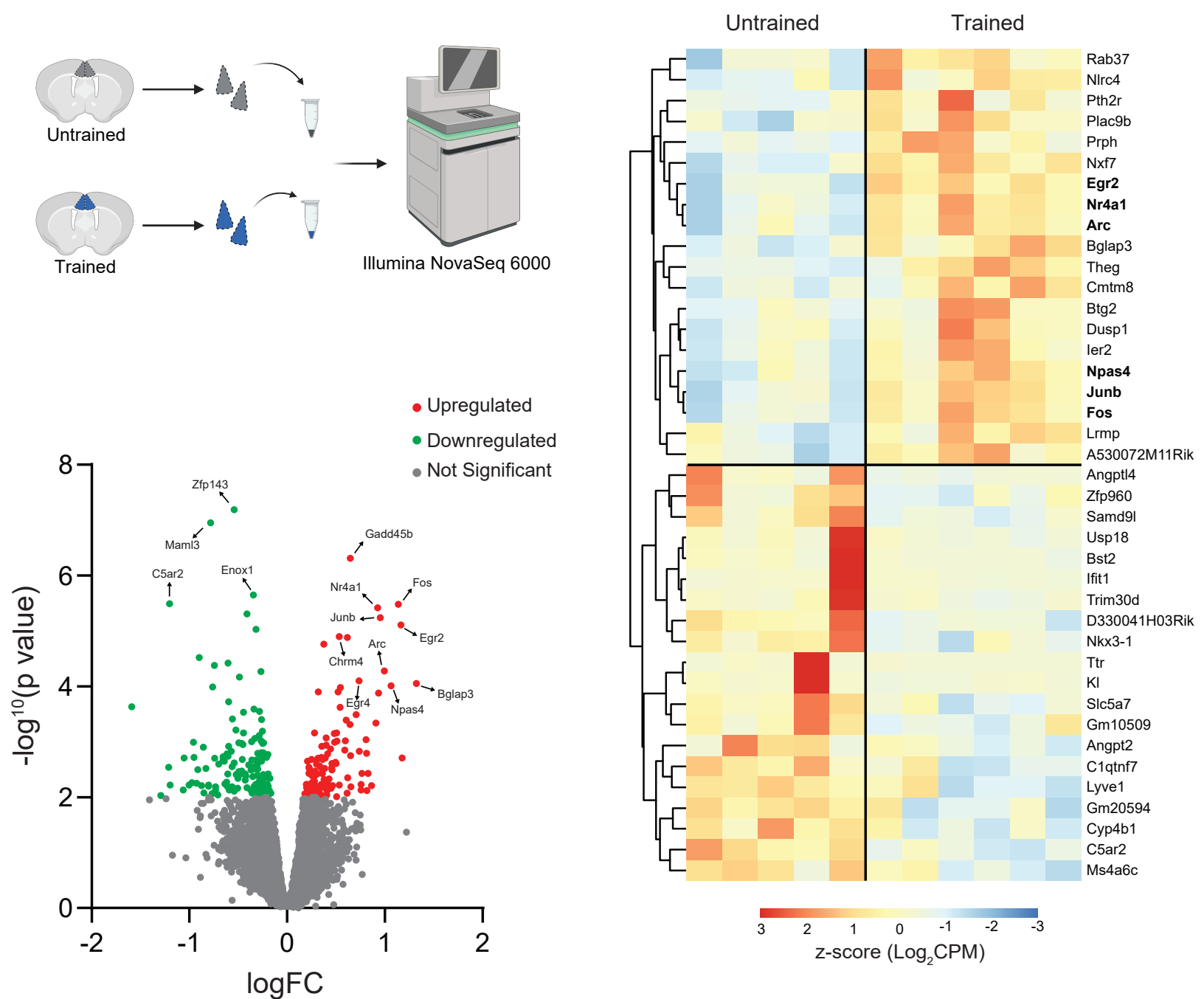
bioRxiv preprint doi: https://doi.org/10.1101/2021.04.20.440613; this version posted April 21, 2021. The copyright holder for this preprint (which was not certified by peer review) is the author/funder, who has granted bioRxiv a license to display the preprint in perpetuity. It is made available under aCC-BY-NC-ND 4.0 International license.

Figure 2, Ulloa Severino et al.

A

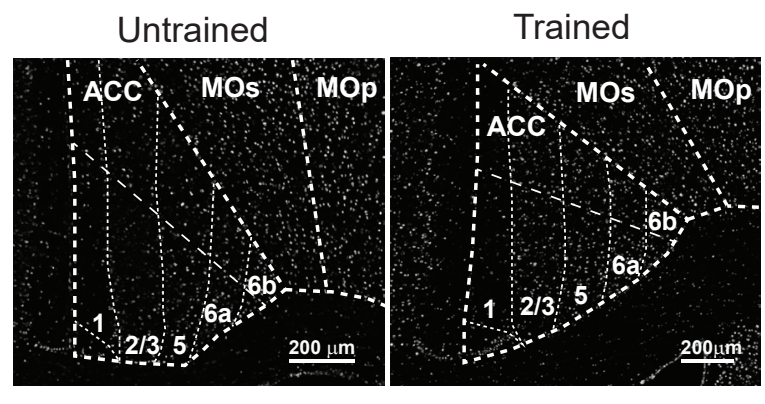

C

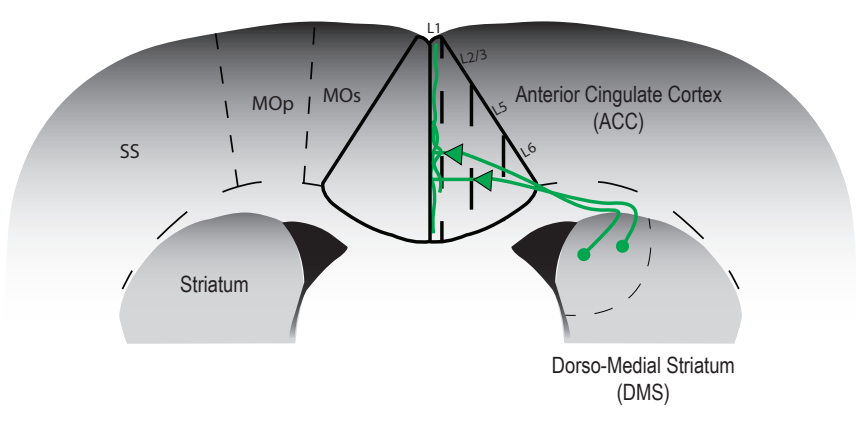

E

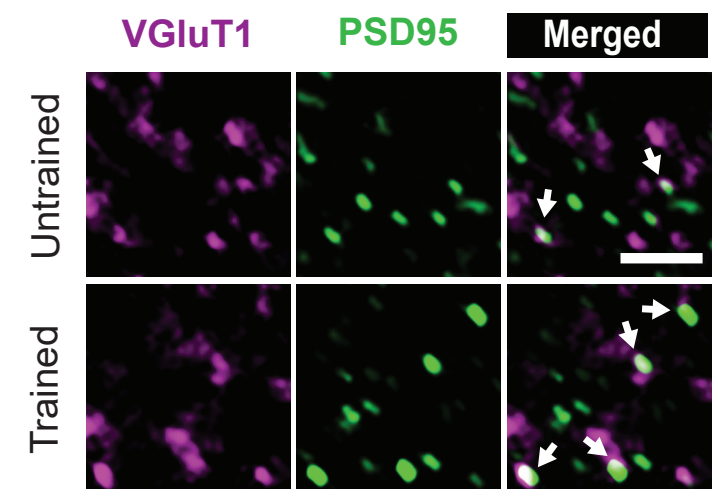

B
Anterior Cingulate Cortex (ACC)

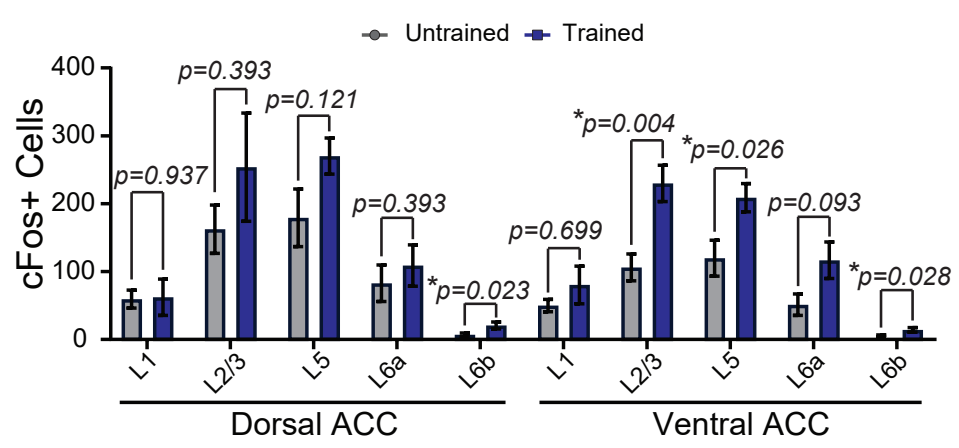

D

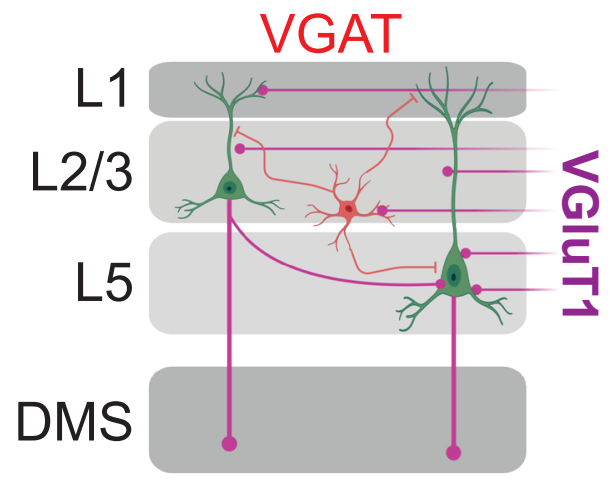

$\mathbf{F}$

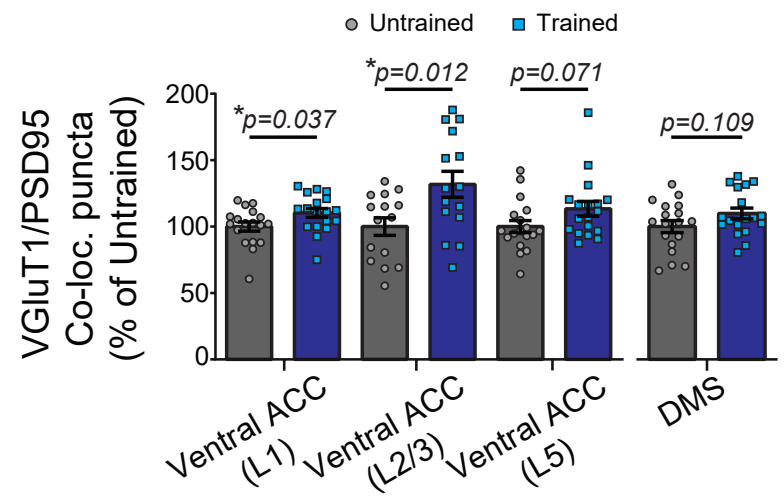


bioRxiv preprint doi: https://doi.org/10.1101/2021.04.20.440613; this version posted April 21, 2021. The copyright holder for this preprint (which was not certified by peer review) is the author/funder, who has granted bioRxiv a license to display the preprint in perpetuity. It is made available under aCC-BY-NC-ND 4.0 International license.

A

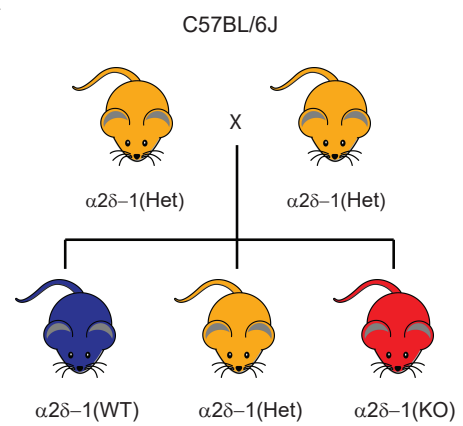

B

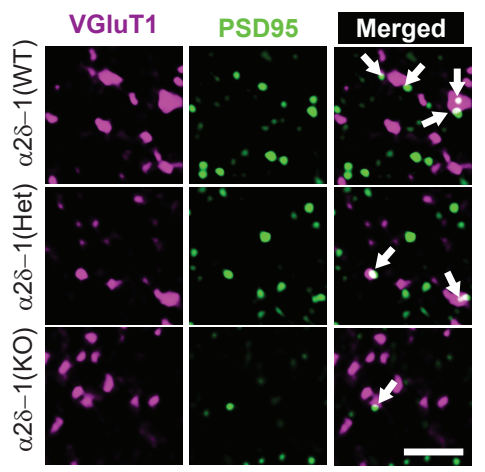

C

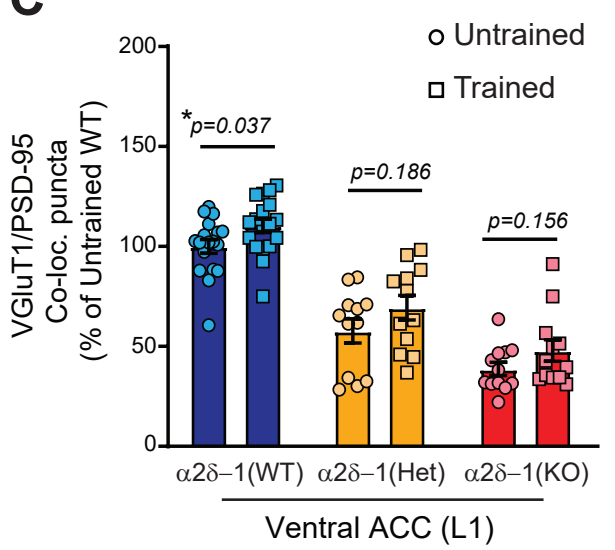

Figure 3, Ulloa Severino et al.

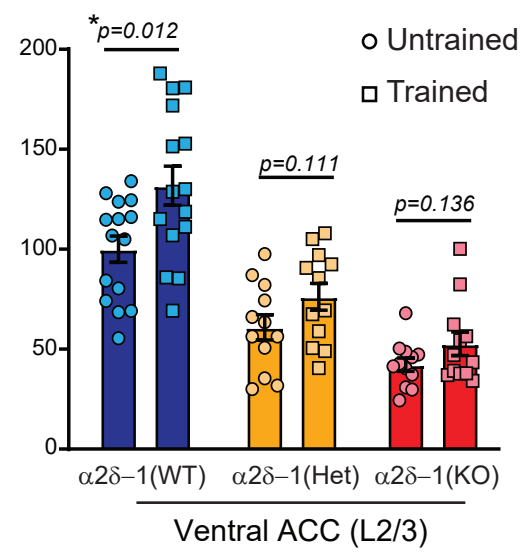



available under aCC-BY-NC-ND 4.0 International license.

\section{Figure 4, Ulloa Severino et al.}

A

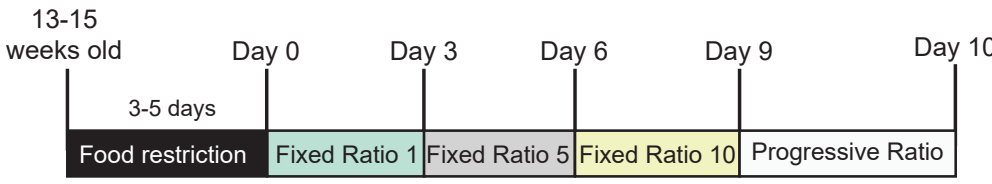

C

Progressive Ratio (PR) schedule

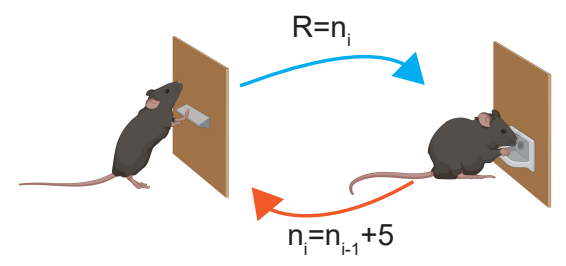

D

$$
\alpha 2 \delta-1 \text { (WT) }
$$
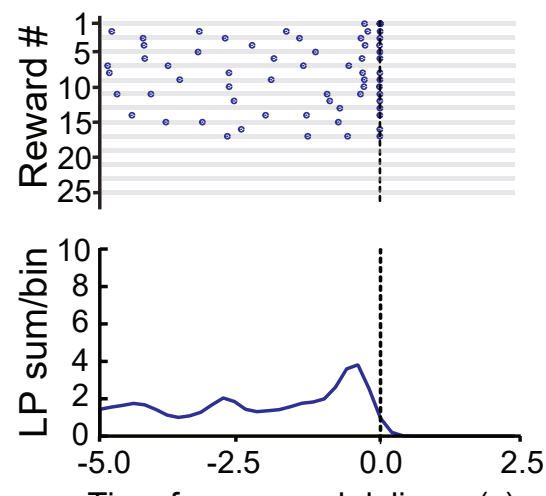

Time from reward delivery (s)
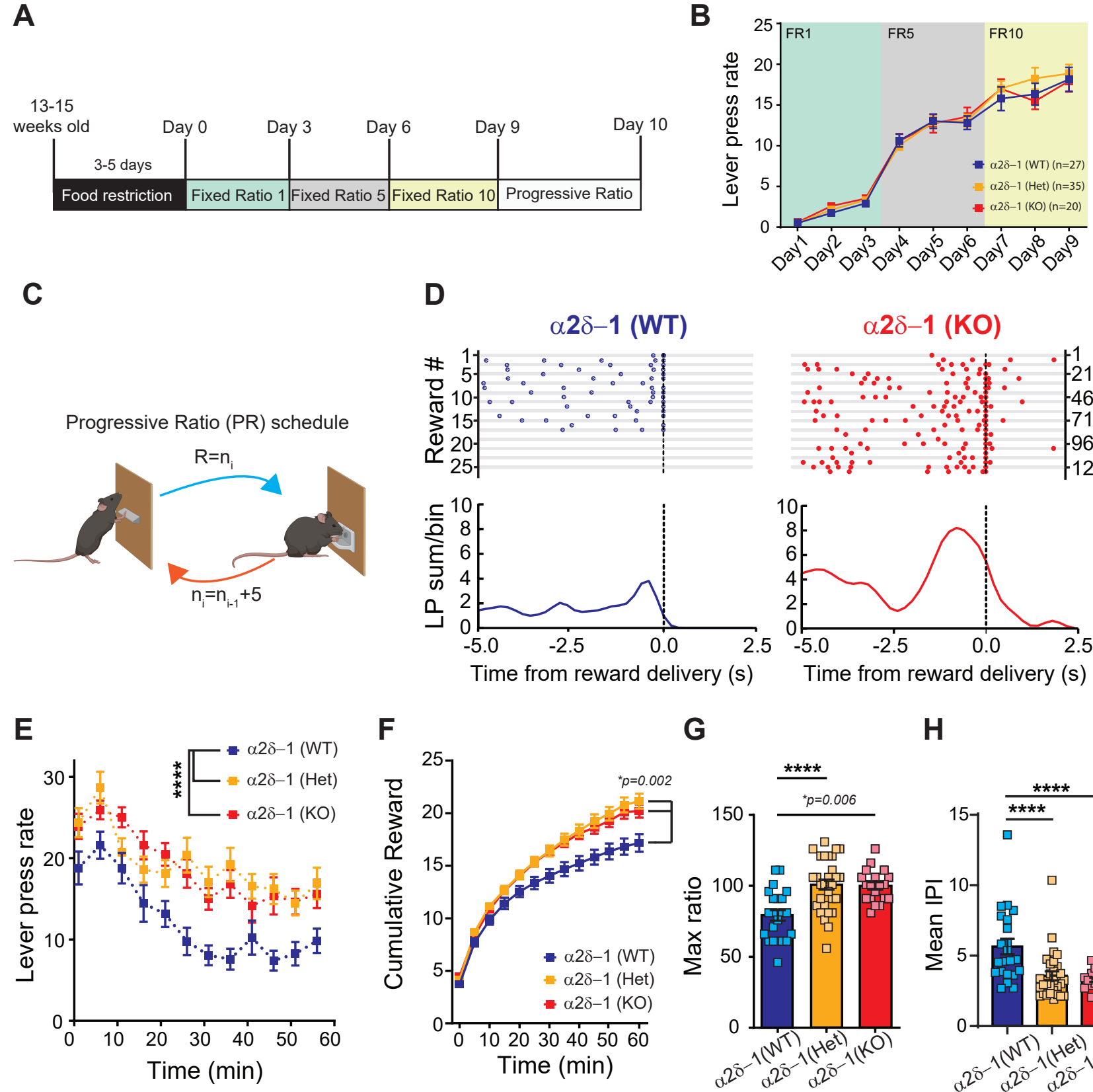

G
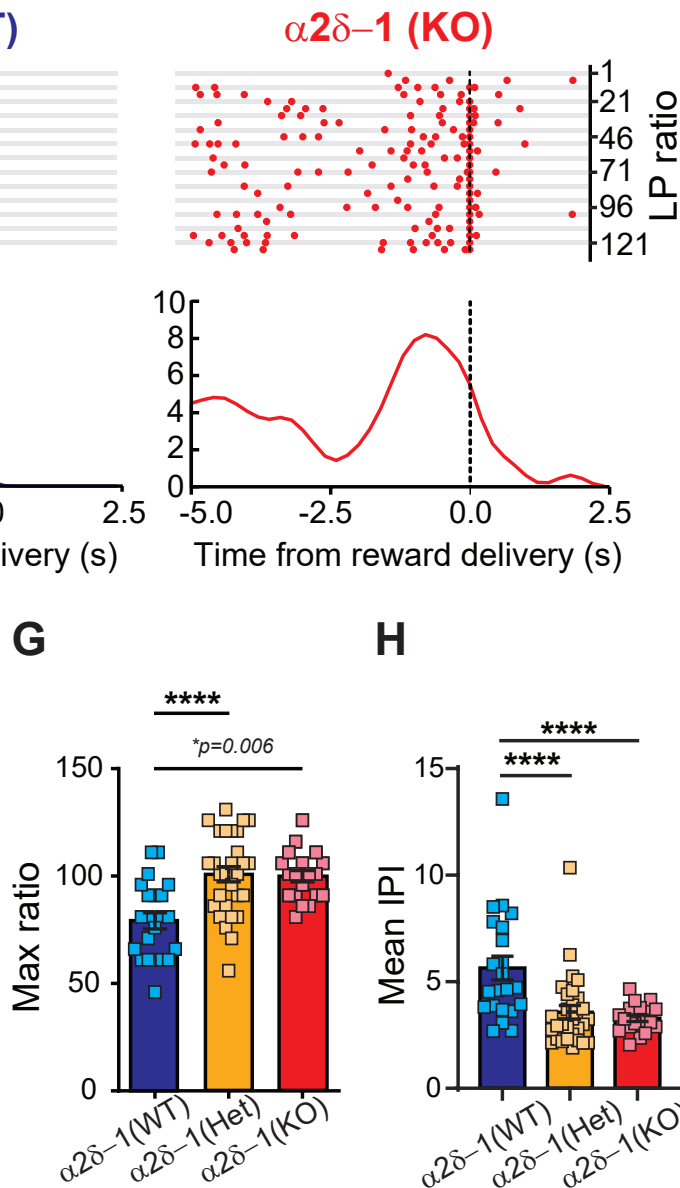

H
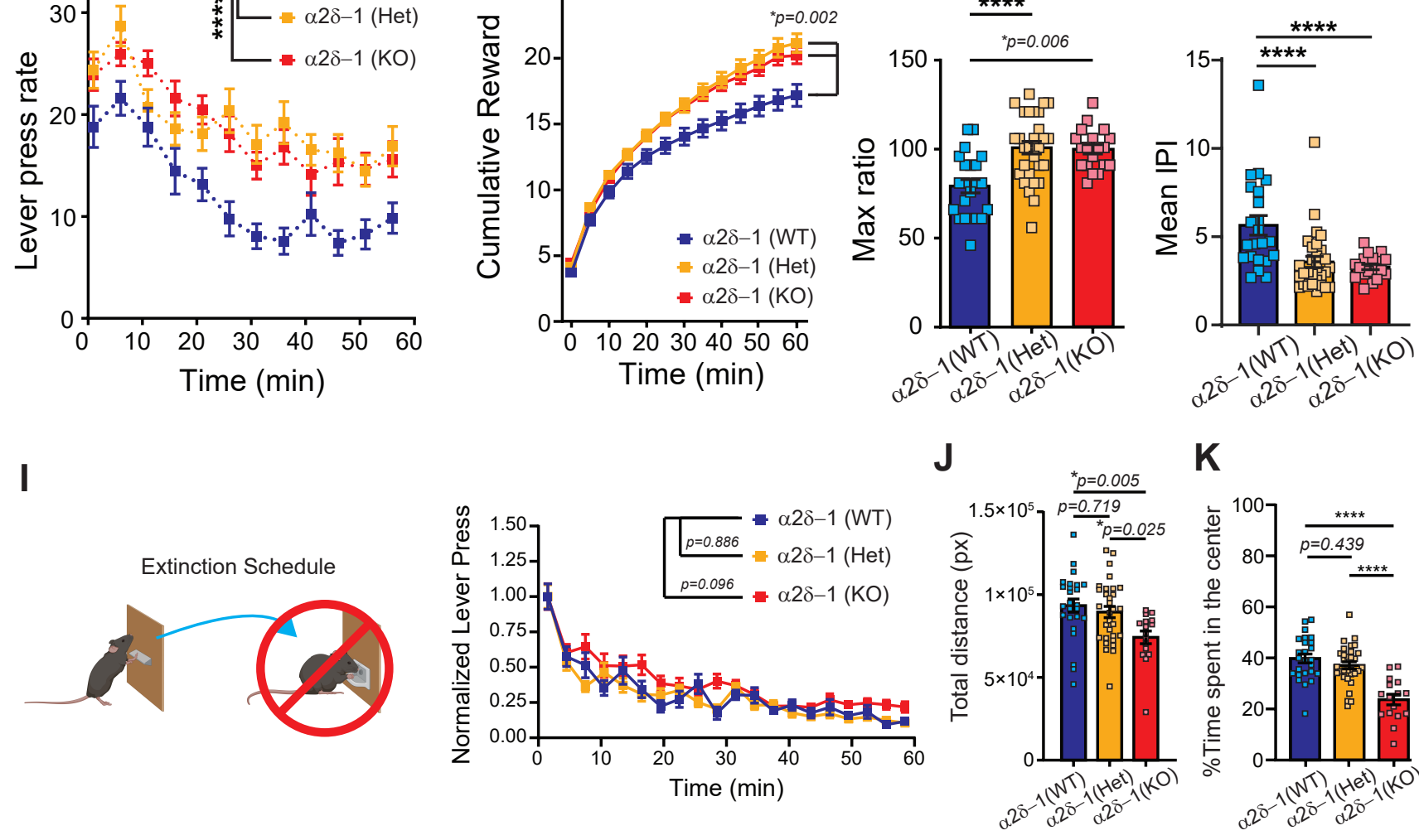

$\mathrm{K}$

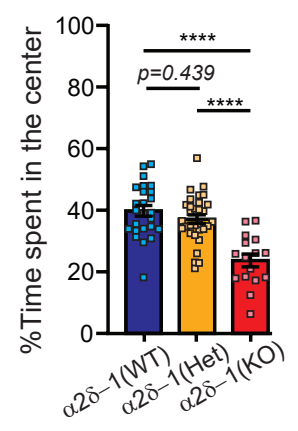


Figure 5 Ulloa Severino et al.

A

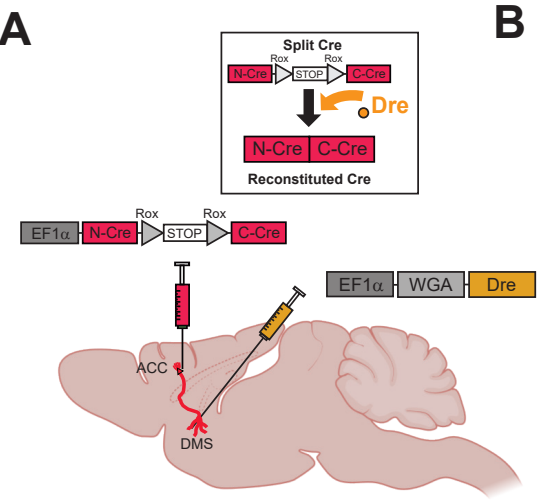

$\alpha 2 \delta-1(+/+)::$ Rosa(STOP)loxP-tdTomato

$\alpha 2 \delta-1(\mathrm{f} / \mathrm{f})::$ Rosa(STOP)loxP-tdTomato

D

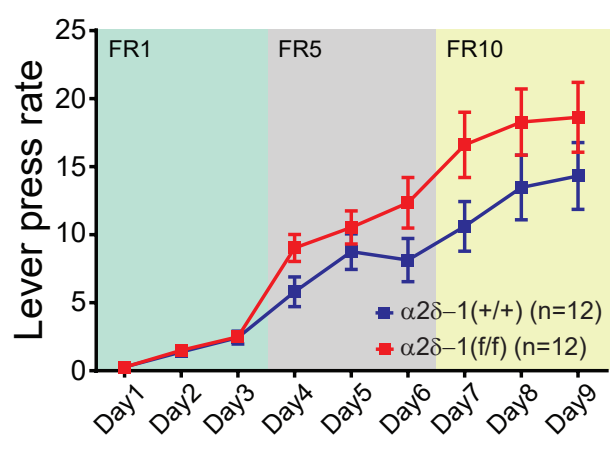

B

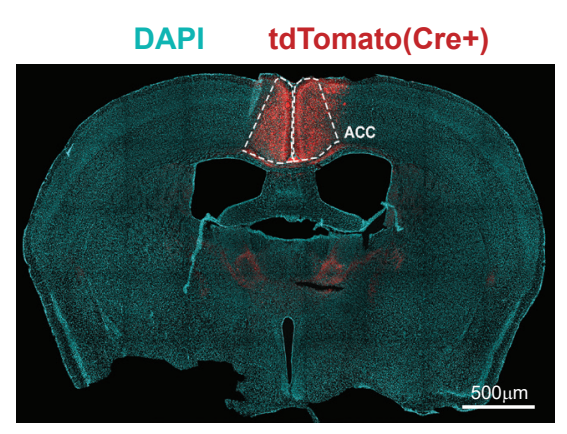

E

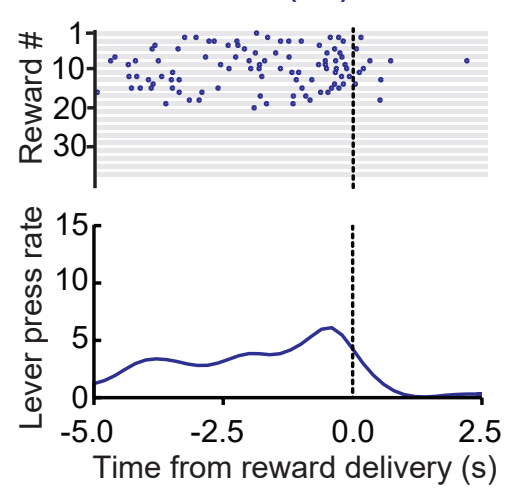

C
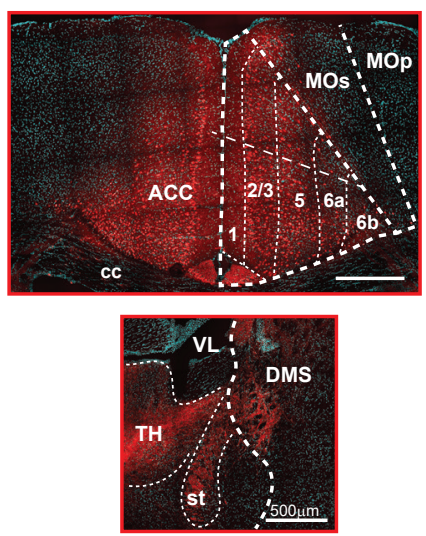

$\alpha 2 \delta-1(f / f)$
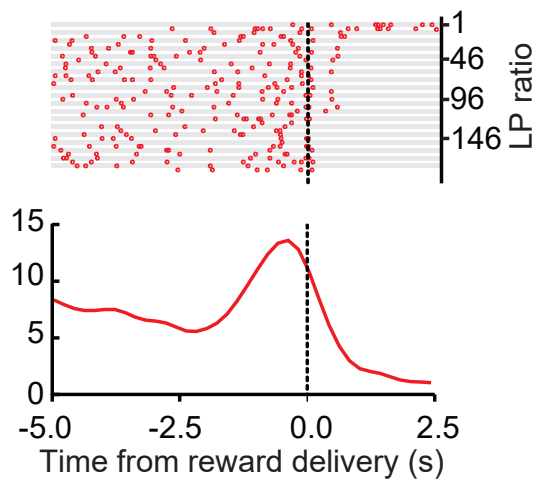

F

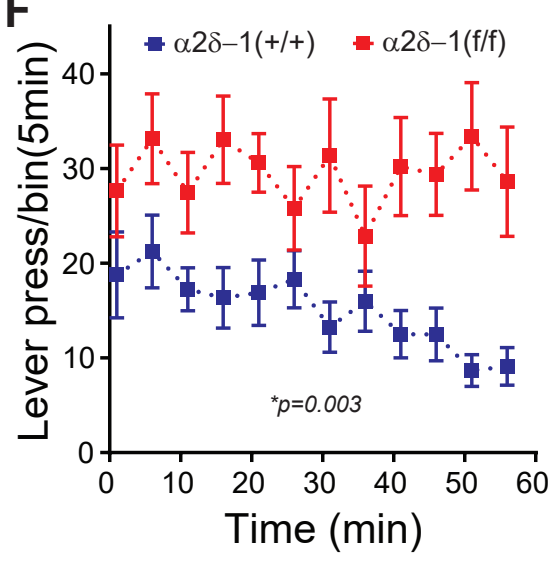

G

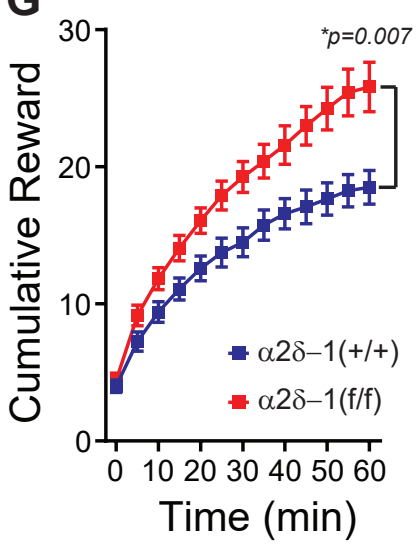

H
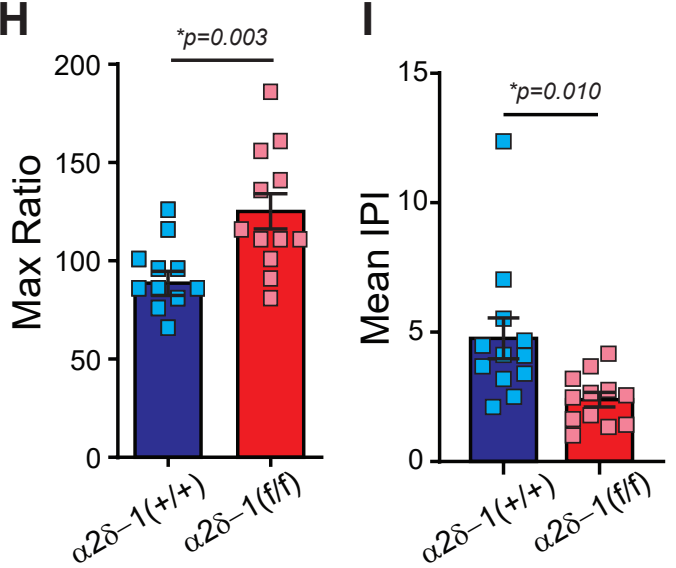

J

$\mathrm{K}$

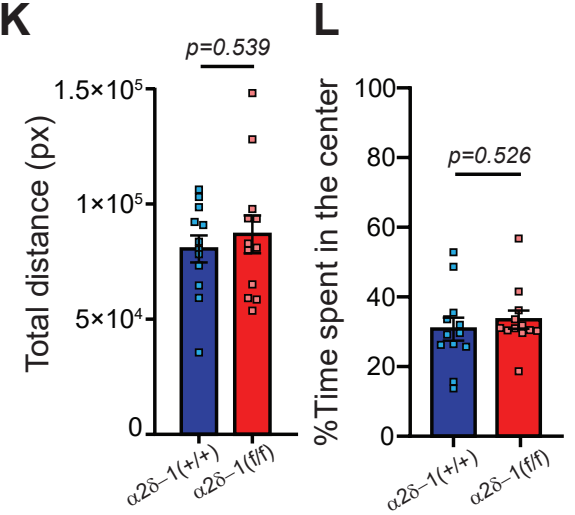


bioRxiv preprint doi: https://doi.org/10.1101/2021.04.20.440613; this version posted April 21, 2021. The copyright holder for this preprint (which was not certified by peer review) is the author/funder, who has granted bioRxiv a license to display the preprint in perpetuity. It is made available under aCC-BY-NC-ND 4.0 International license.

Figure 6, Ulloa Severino et al.

A

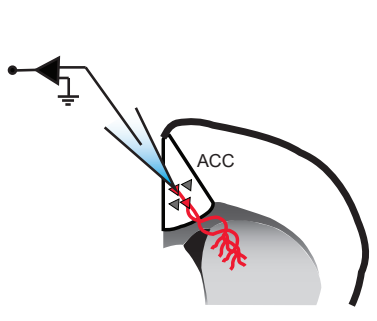

E

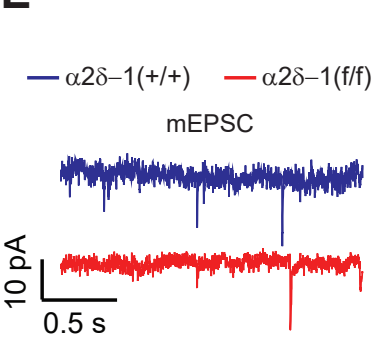

B

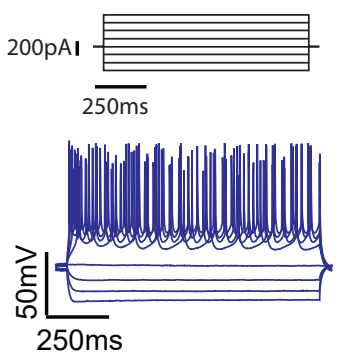

$\mathbf{F}$

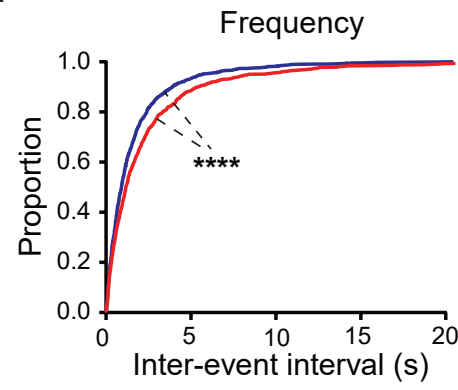

$-\alpha 2 \delta 1(+/+)$

$-\alpha 2 \delta 1(\mathrm{f} / \mathrm{f})$

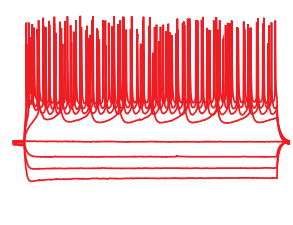

C

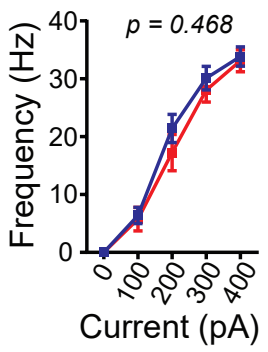

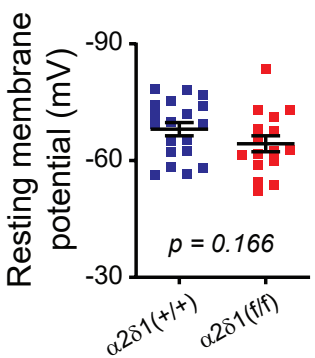

G

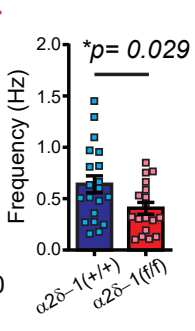

Amplitude
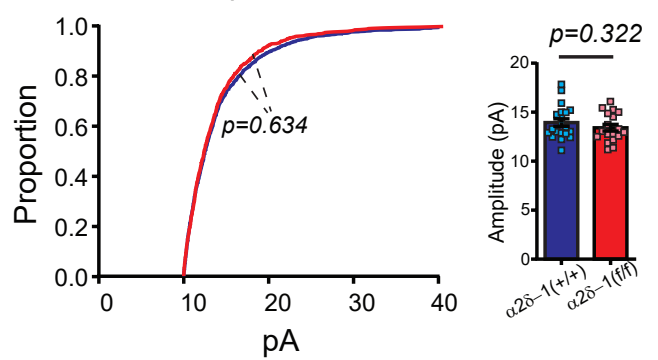

- Untrained 口 Trained
H

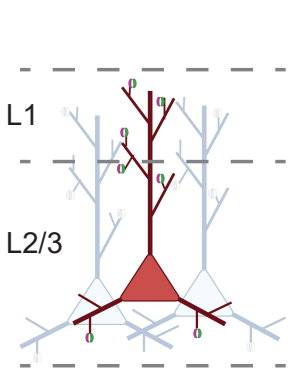

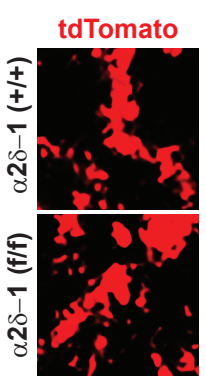

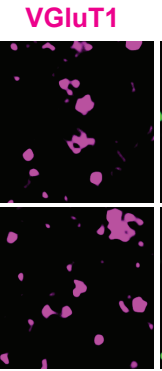

PSD95

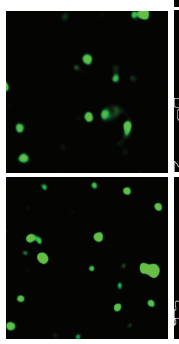

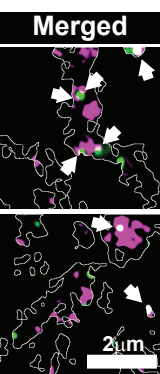

$\stackrel{* * * *}{*} p=0.003$

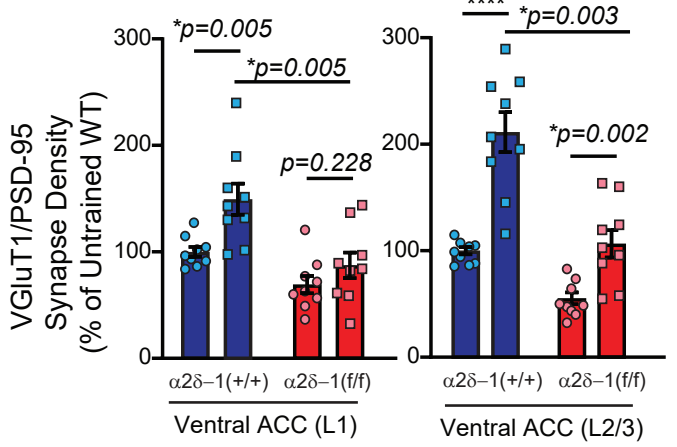


Figure 7 Ulloa Severino et al.

bioRxiv preprint doi: https://doi.org/10.1101/2021.04.20.440613; this version posted April 21, 2021. The copyright holder for this preprint (which was not certified by peer review) is the author/funder, who has granted bioRxiv a license to display the preprint in perpetuity. It is made

A availab Bunder aCC-BY-NC-ND 4.0 International license.
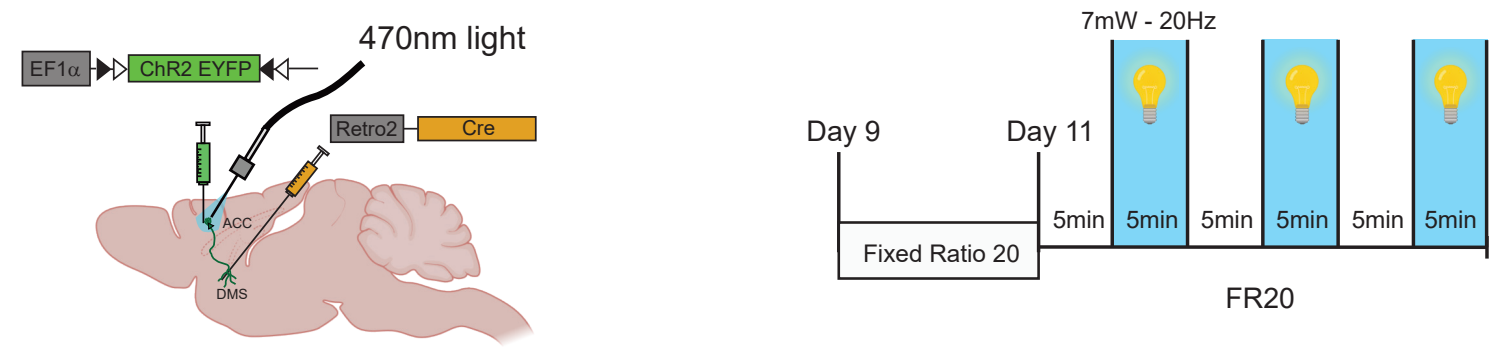

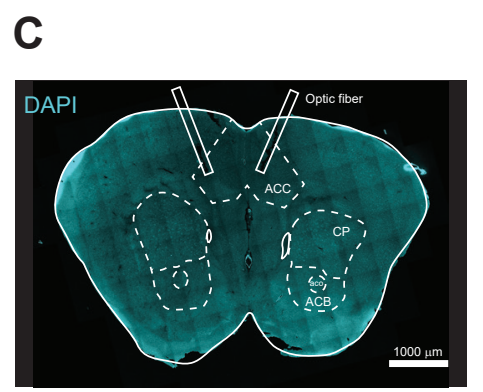

D

CTRL
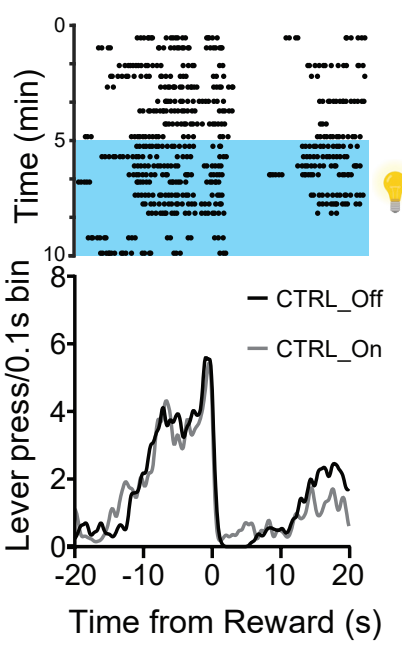

G

$\mathbf{F}$

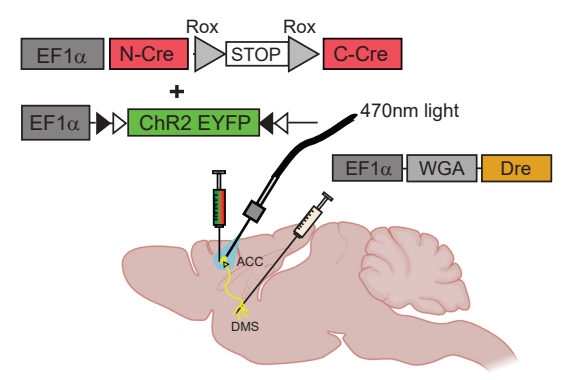

$\alpha 2 \delta-1(+/+)::$ Rosa(STOP)loxP-tdTomato

$\alpha 2 \delta-1(f / f):: R o s a(S T O P) l o x P-t d T o m a t o$
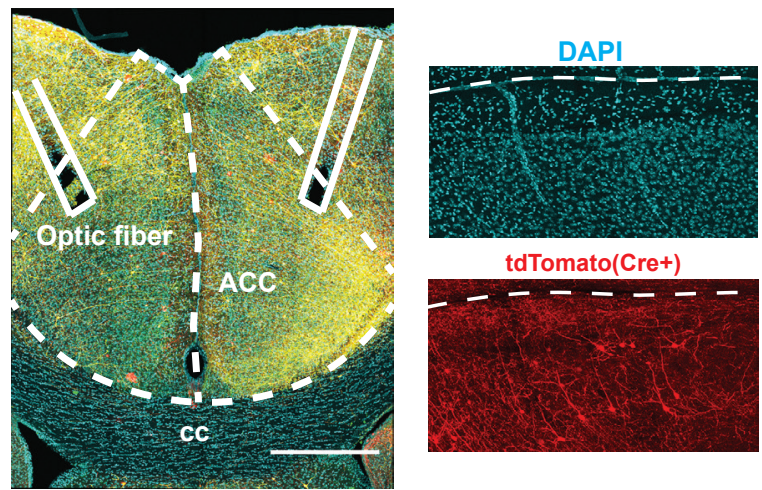

tdTomato(Cre+)
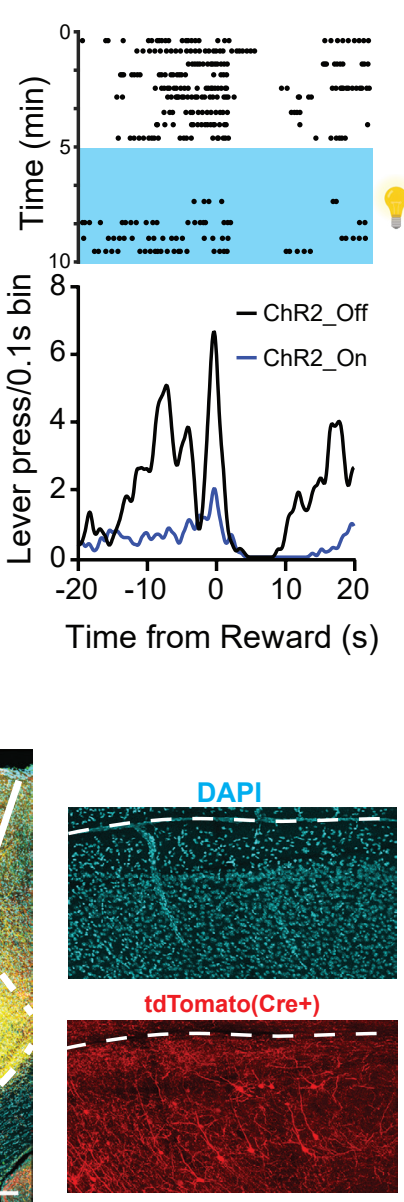

$E$

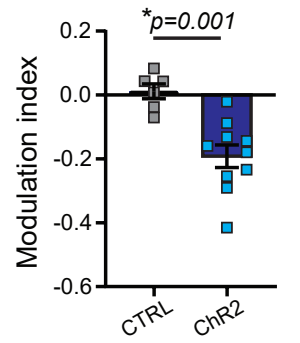

H
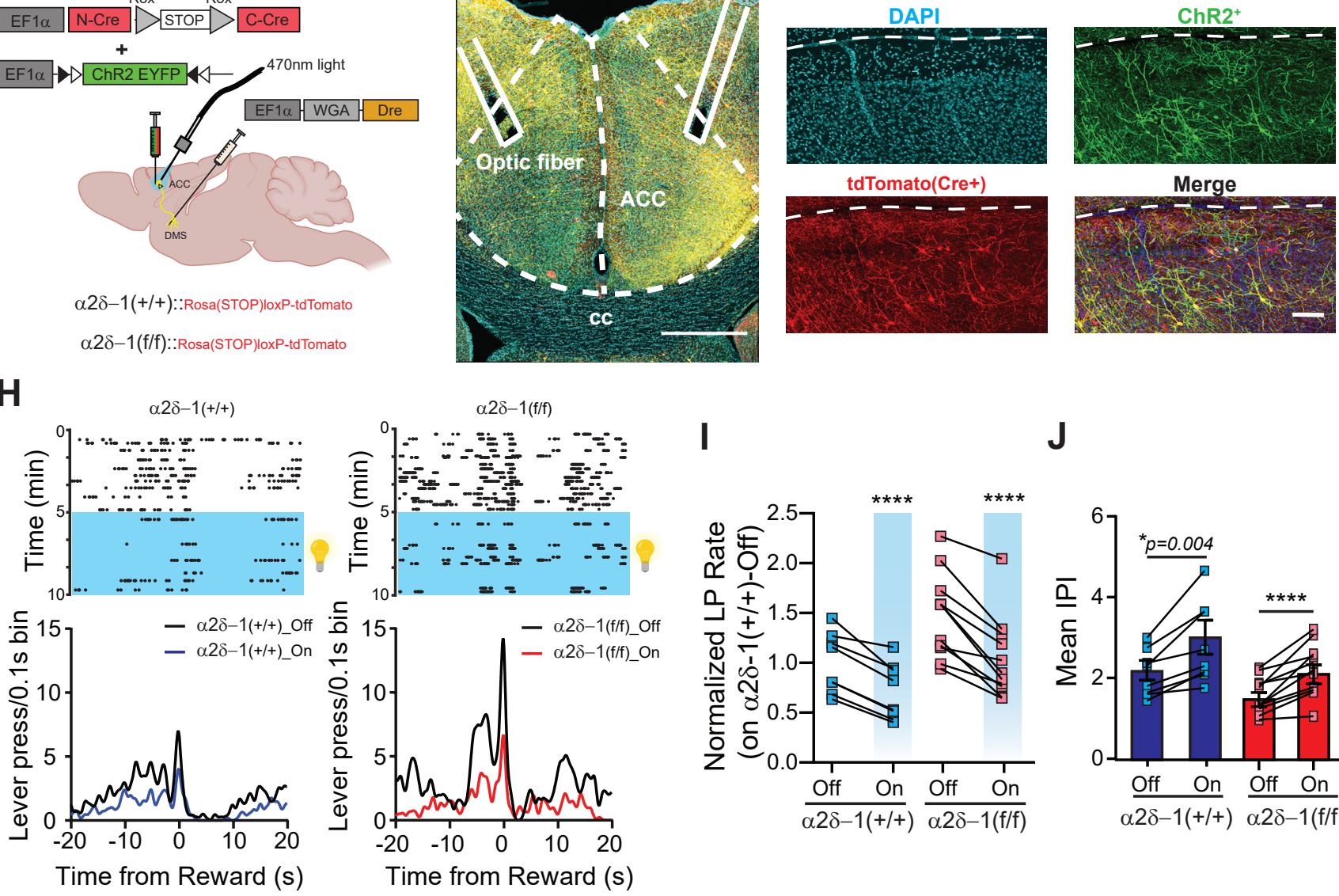

J

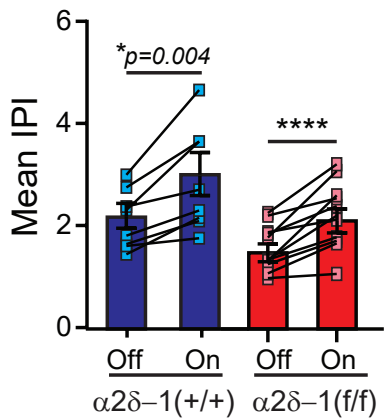


bioRxiv preprint doi: https://doi.org/10.1101/2021.04.20.440613; this version posted April 21, 2021. The copyright holder for this preprint (which was not certified by peer review) is the author/funder, who has granted bioRxiv a license to display the preprint in perpetuity. It is made available under aCC-BY-NC-ND 4.0 International license.

Supplementary Fig 1 (related to Figure 1), Ulloa Severino et al.

A

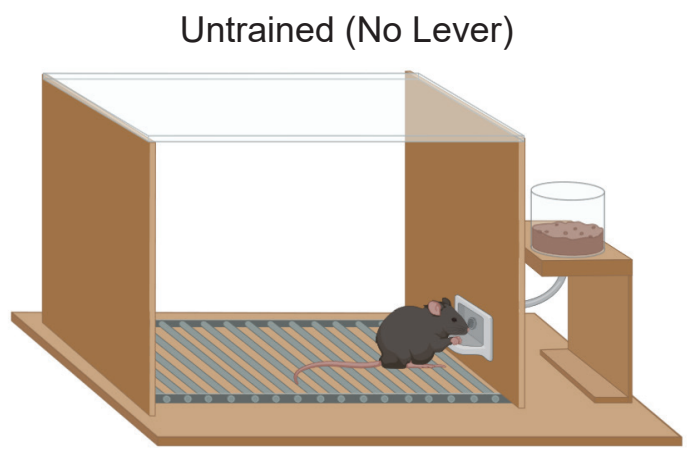

B

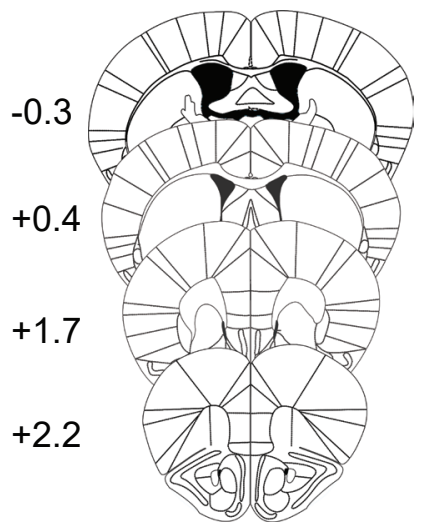

C

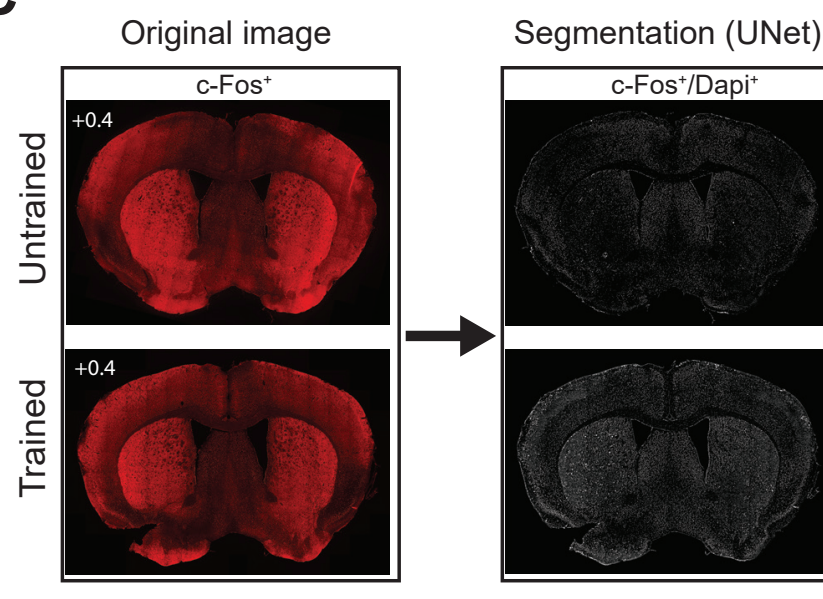

WholeBrain atlas registration

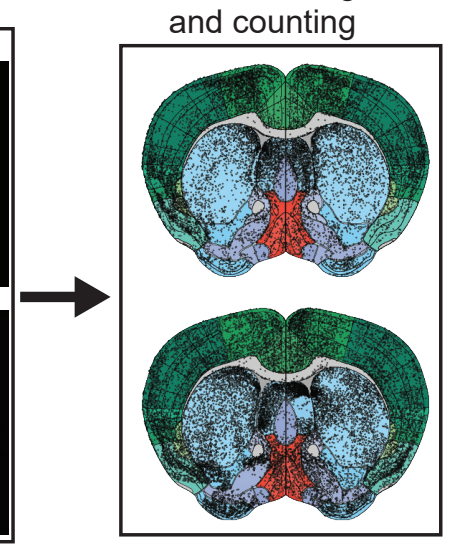

E

D
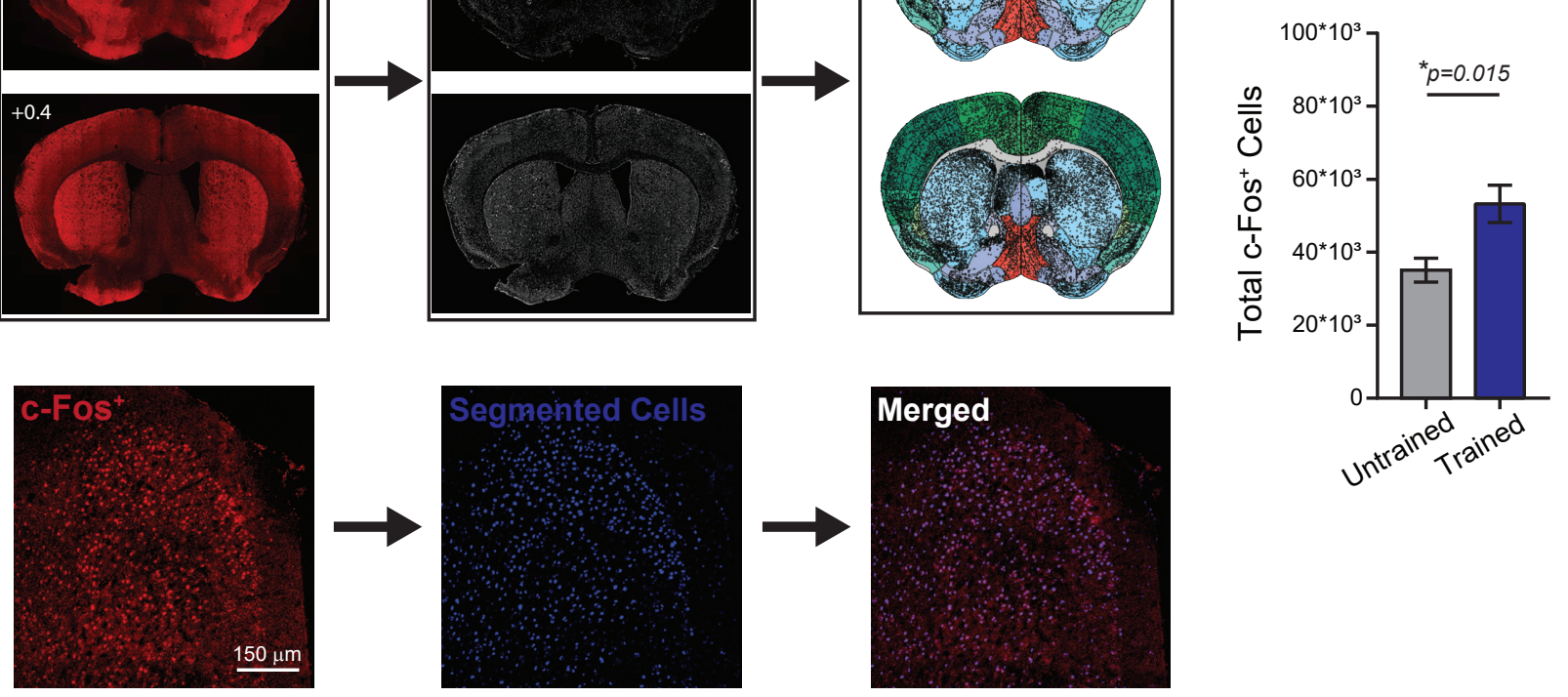

$\mathbf{F}$

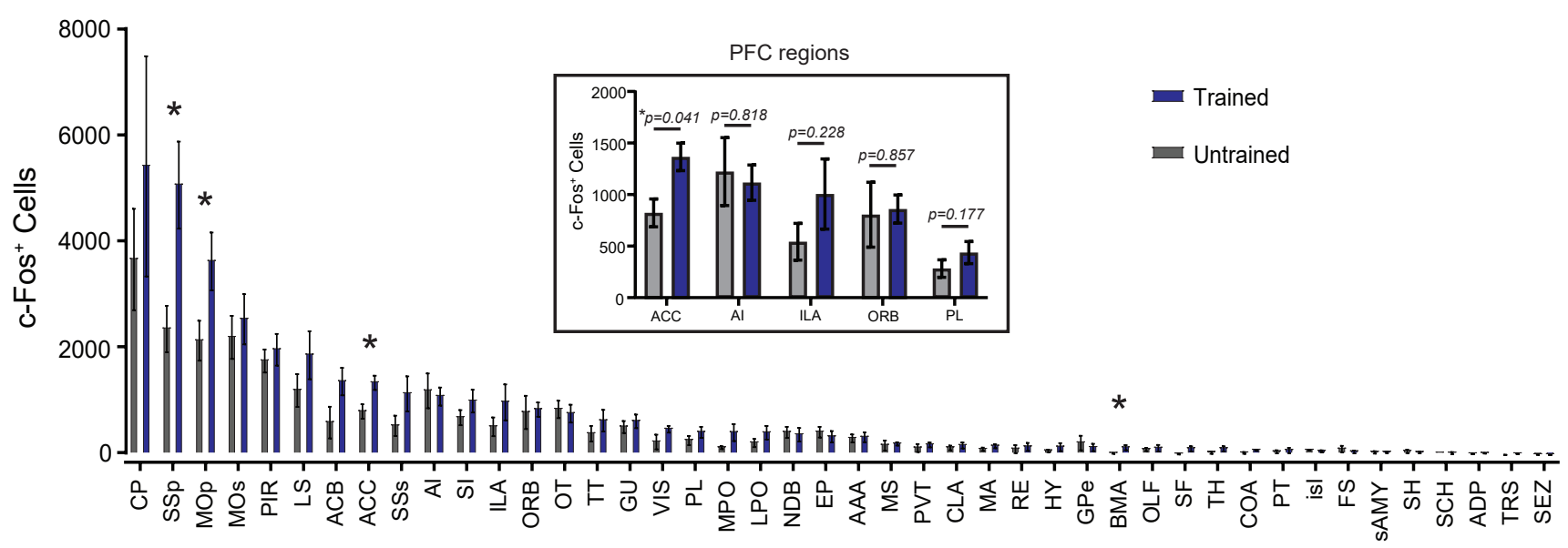


bioRxiv preprint doi: https://doi.org/10.1101/2021.04.20.440613; this version posted April 21, 2021. The copyright holder for this preprint (which was not certified by peer review) is the author/funder, who has granted bioRxiv a license to display the preprint in perpetuity. It is made available under aCC-BY-NC-ND 4.0 International license.

Supplementary Fig 2 (related to Figure 2), Ulloa Severino et al.

A

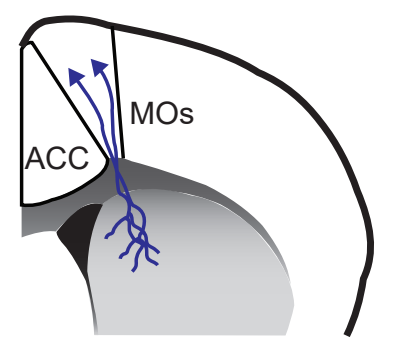

B

Secondary Motor Cortex (MOs)

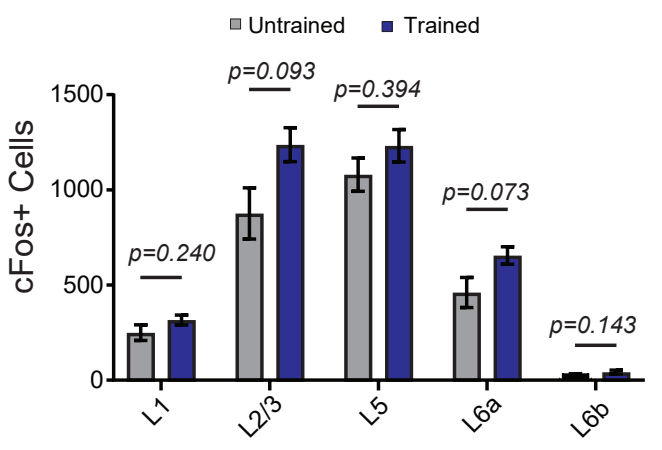

C

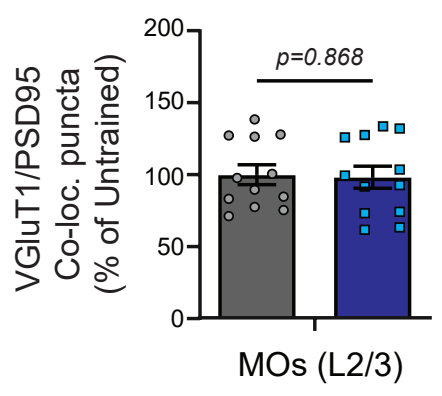

D

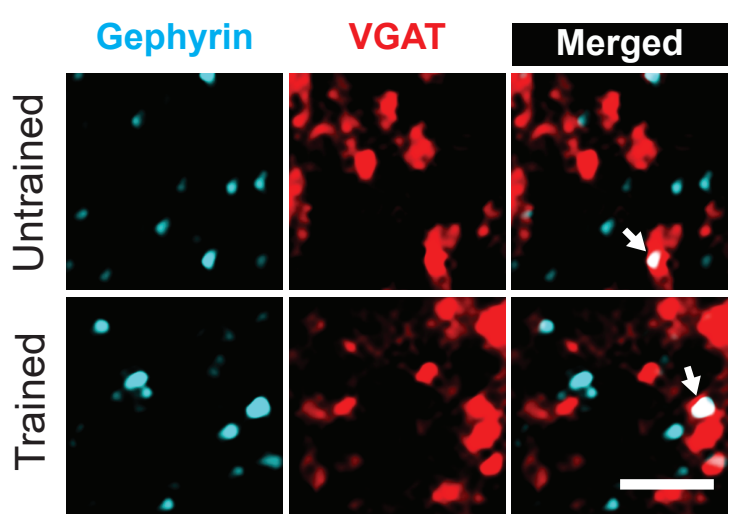

E

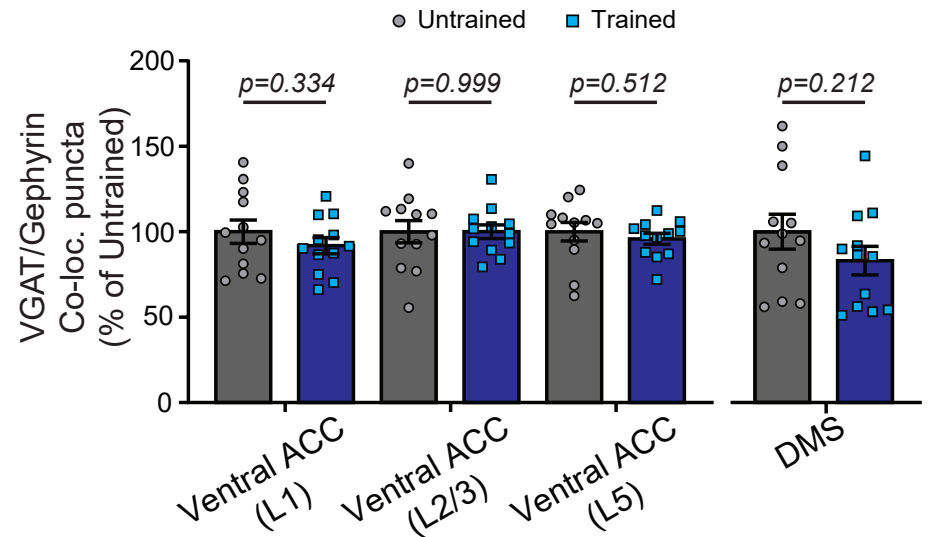


bioRxiv preprint doi: https://doi.org/10.1101/2021.04.20.440613; this version posted April 21, 2021. The copyright holder for this preprint (which was not certified by peer review) is the author/funder, who has granted bioRxiv a license to display the preprint in perpetuity. It is made available under aCC-BY-NC-ND 4.0 International license.

Supplementary Fig 3 (related to Figure 3), Ulloa Severino et al.

A

$\frac{\text { Untrained }}{\circ \alpha 2 \delta-1(\mathrm{WT}) \quad 0 \alpha 2 \delta-1(\mathrm{Het}) \quad 0 \alpha 2 \delta-1(\mathrm{KO})}$

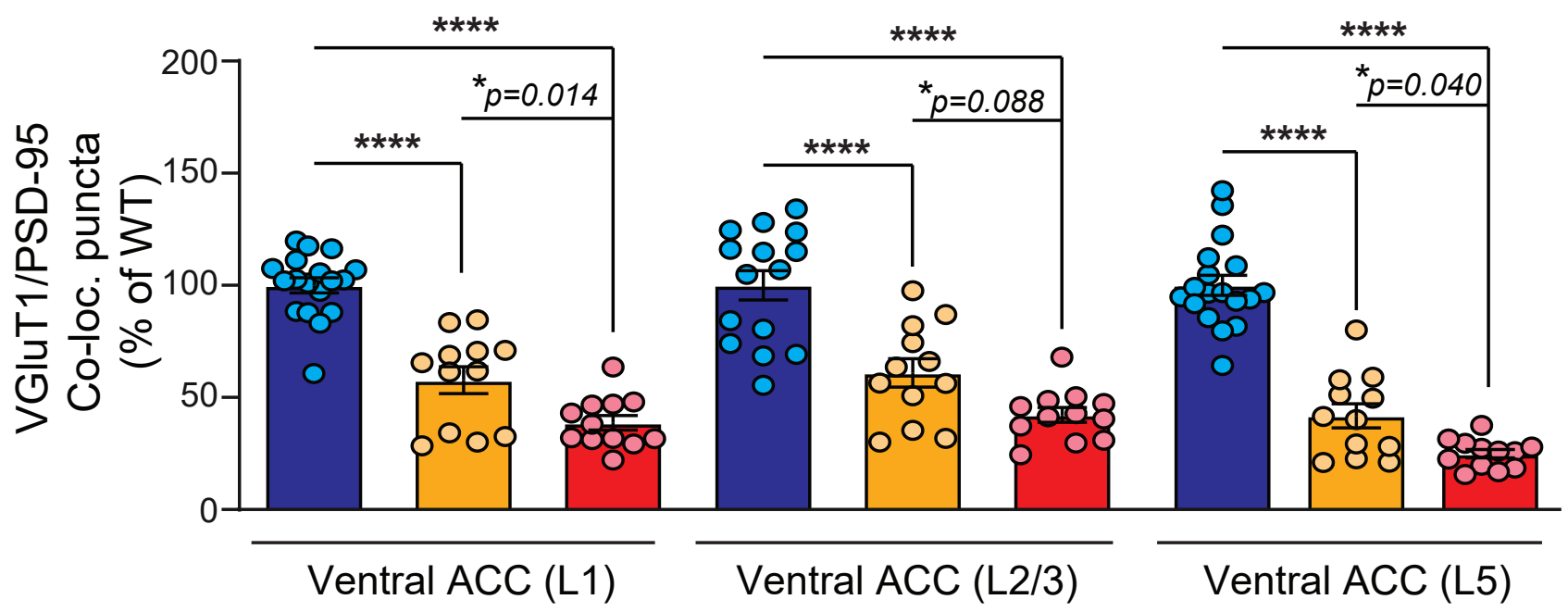

B

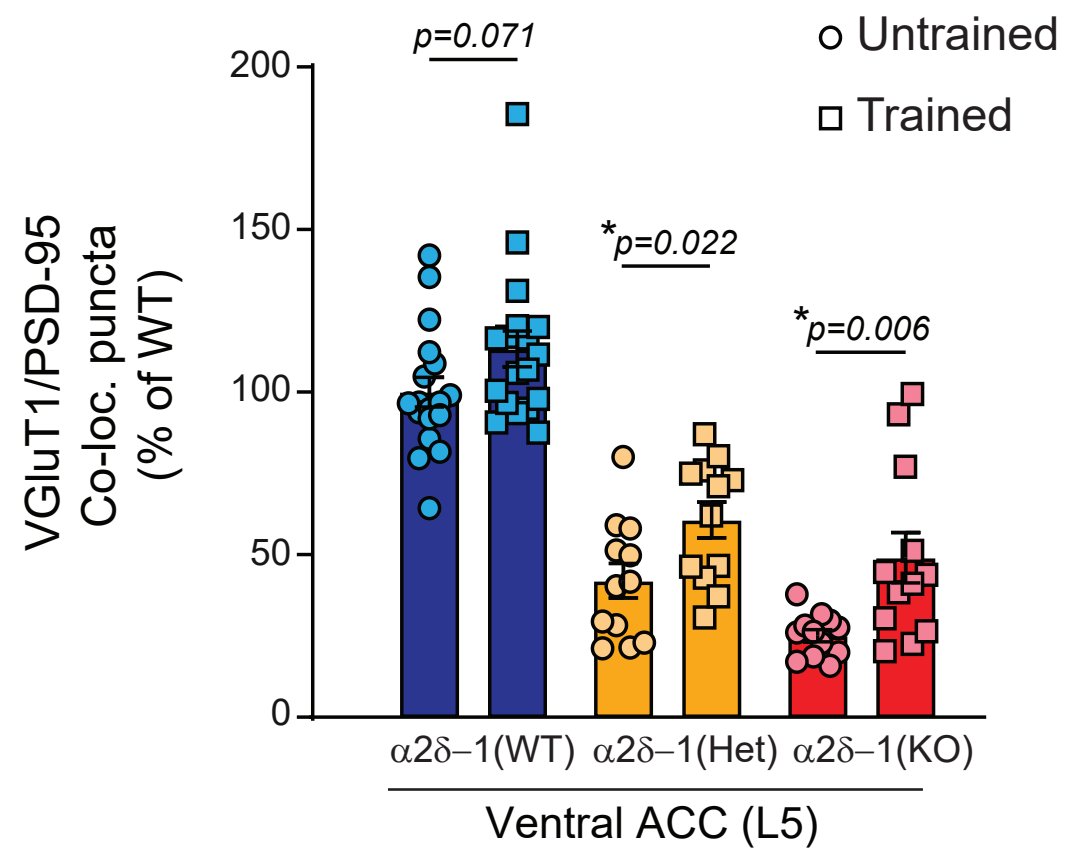


bioRxiv preprint doi: https://doi.org/10.1101/2021.04.20.440613; this version posted April 21, 2021. The copyright holder for this preprint (which

was not certified by peer review) is the author/funder, who has granted bioRxiv a license to display the preprint in perpetuity. It is made available under aCC-BY-NC-ND 4.0 International license.

\section{Supplementary Fig 4 (related to Figure 4), Ulloa Severino et al.}

A

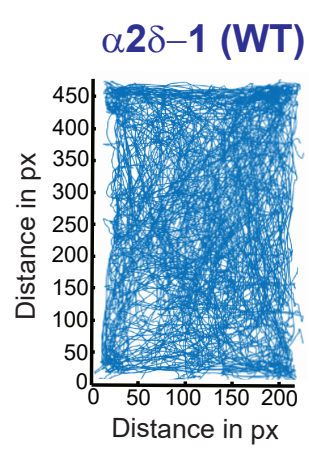

B
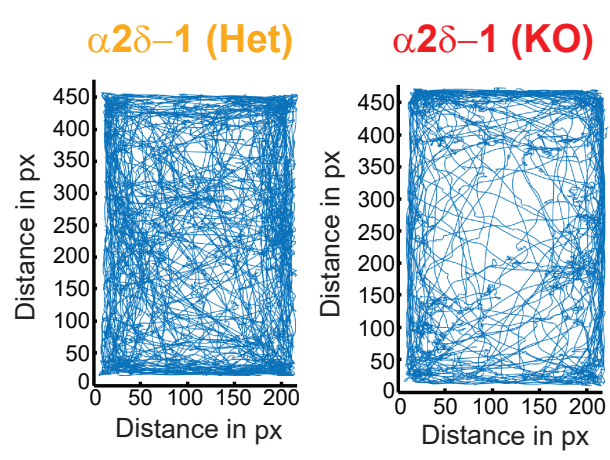

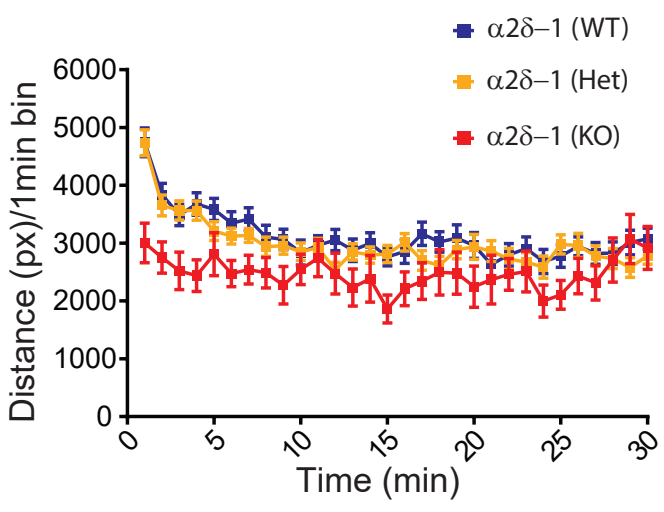


bioRxiv preprint doi: https://doi.org/10.1101/2021.04.20.440613; this version posted April 21, 2021. The copyright holder for this preprint (which

was not certified by peer review) is the author/funder, who has granted bioRxiv a license to display the preprint in perpetuity. It is made available under aCC-BY-NC-ND 4.0 International license.

\section{Supplementary Fig 5 (related to Figure 5), Ulloa Severino et al.}

A

B
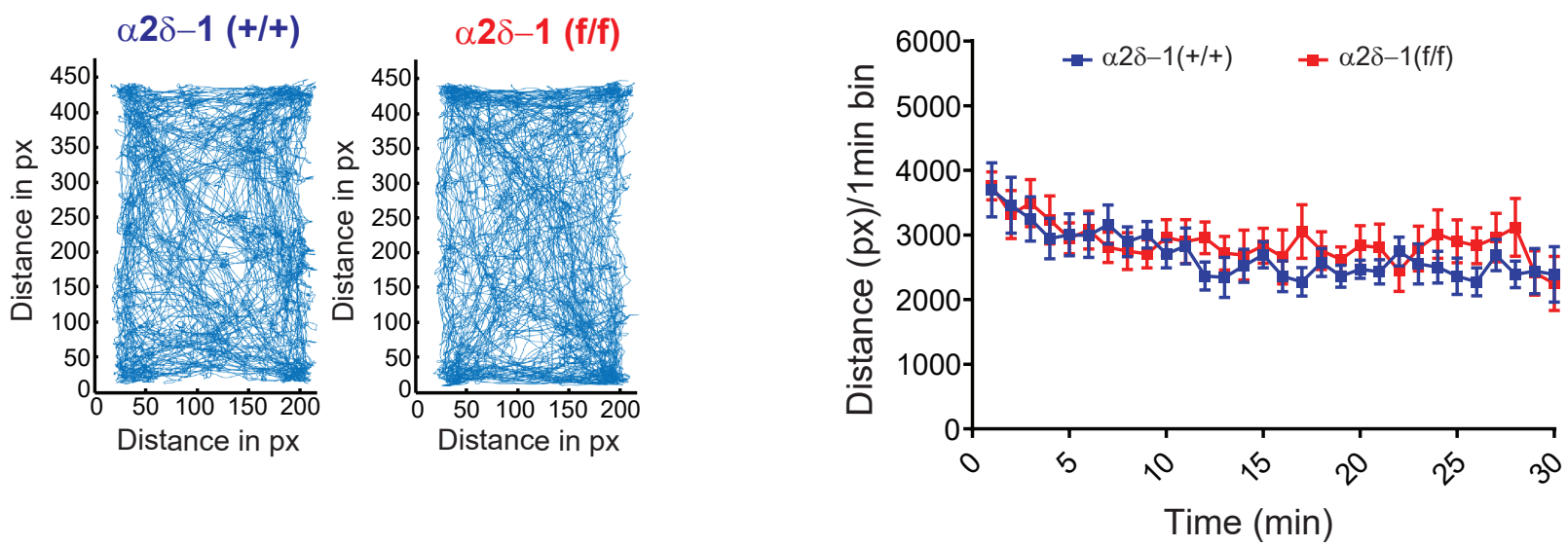
bioRxiv preprint doi: https://doi.org/10.1101/2021.04.20.440613; this version posted April 21, 2021. The copyright holder for this preprint (which

was not certified by peer review) is the author/funder, who has granted bioRxiv a license to display the preprint in perpetuity. It is made available under aCC-BY-NC-ND 4.0 International license.

Supplementary Fig 6 (related to Figure 7), Ulloa Severino et al.

A

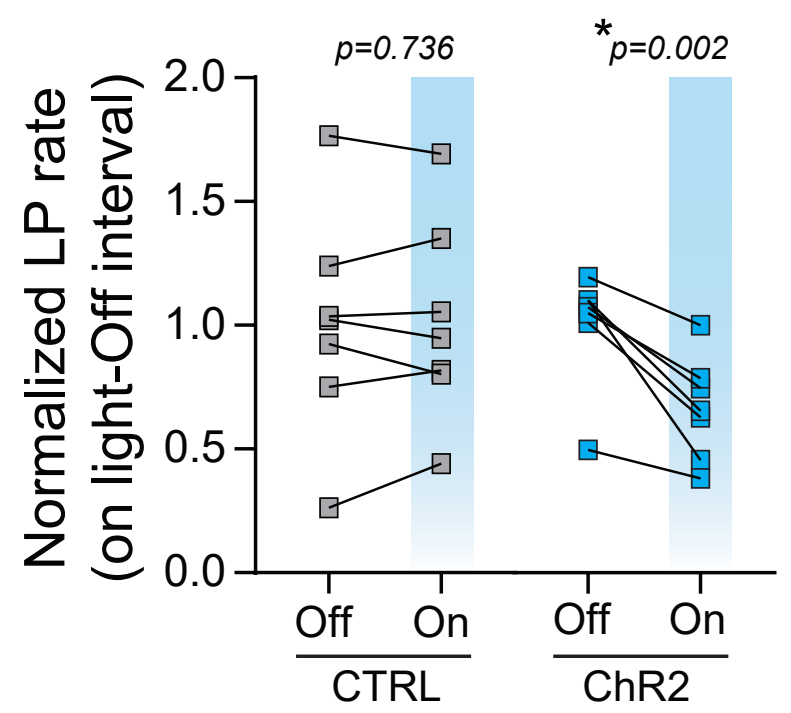

C
B

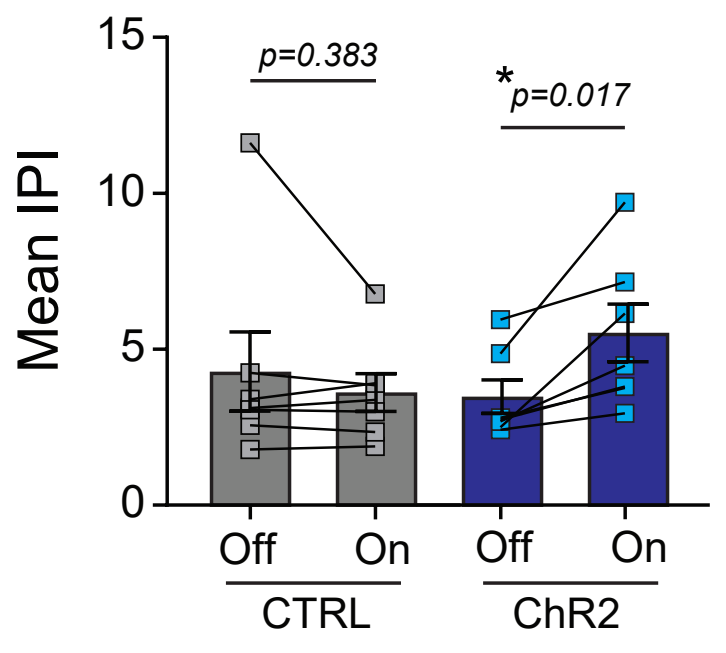

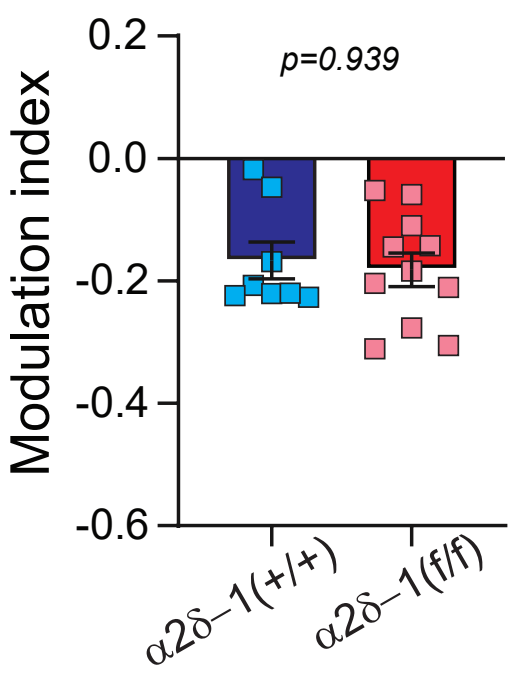

